\title{
WestVirginiaUniversity
}

THE RESEARCH REPOSITORY @ WVU

Graduate Theses, Dissertations, and Problem Reports

2011

\section{Examination of Genotypic Variation in Aluminum Tolerance of Populus}

\author{
Ernest Smith \\ West Virginia University
}

Follow this and additional works at: https://researchrepository.wvu.edu/etd

\section{Recommended Citation}

Smith, Ernest, "Examination of Genotypic Variation in Aluminum Tolerance of Populus" (2011). Graduate Theses, Dissertations, and Problem Reports. 3295.

https://researchrepository.wvu.edu/etd/3295

This Thesis is protected by copyright and/or related rights. It has been brought to you by the The Research Repository @ WVU with permission from the rights-holder(s). You are free to use this Thesis in any way that is permitted by the copyright and related rights legislation that applies to your use. For other uses you must obtain permission from the rights-holder(s) directly, unless additional rights are indicated by a Creative Commons license in the record and/ or on the work itself. This Thesis has been accepted for inclusion in WVU Graduate Theses, Dissertations, and Problem Reports collection by an authorized administrator of The Research Repository @ WVU. For more information, please contact researchrepository@mail.wvu.edu. 


\title{
Examination of Genotypic Variation in Aluminum Tolerance of Populus
}

\author{
Ernest Smith
}

\author{
Thesis submitted to the \\ Eberly College of Arts and Sciences \\ at West Virginia University \\ in partial fulfillment of the requirements \\ for the degree of
}

Master of Science

in

Biology

Dr. Jonathan Cumming, Ph.D., Chair

Dr. Richard Thomas, Ph.D.

Dr. Steven DiFazio, Ph.D.

Department of Biology

Morgantown, West Virginia

2011

Keywords: Aluminum tolerance, Populus, Callose, Organic Acids

Copyright 2011 Ernie Smith 


\section{ABSTRACT \\ Examination of Genotypic Variation in Aluminum Tolerance of Populus \\ Ernest Smith}

Soil acidity and aluminum (Al) toxicity are major factors limiting crop yield and forest productivity worldwide. Hybrid poplar (Populus spp.) was used as a model woody tree species to assess genotypic variation in $\mathrm{Al}$ resistance and physiological stress responses to $\mathrm{Al}$. In the first study eight hybrid crosses of $P$. trichocarpa, $P$. deltoides and $P$. nigra were exposed to $\mathrm{Al}$ in solution culture. Resistance to Al varied by genotype and hybrid cross, with $P$. trichocarpa $\times P$. deltoides crosses being most resistant, $P$. trichocarpa $\times P$. nigra being intermediate and $P$. deltoides $\times P$. nigra being most sensitive to Al. Total root Al accumulation was not a good indicator of $\mathrm{Al}$ resistance/sensitivity. However, the partitioning of $\mathrm{Al}$ into apoplastic and symplastic fractions indicated that differences in sensitivity among genotypes were associated with Al uptake into the symplasm. Aluminum treatment increased callose and pectin concentrations of root tips in all genotypes, but more prominently in Al sensitive genotypes/hybrids. In $\mathrm{Al}$ sensitive genotypes, higher levels of symplastic $\mathrm{Al}$ accumulation correlated with elevated concentrations of citrate, malate, succinate or formate in root tips, whereas organic acid accumulation was not as pronounced in $\mathrm{Al}$ resistant genotypes.

These findings suggest that exclusion of $\mathrm{Al}$ from the symplast is associated with $\mathrm{Al}$ resistance. In the second study exudation was examined as a strategy for $\mathrm{Al}$ resistance in two poplar genotypes varying in $\mathrm{Al}$ tolerance. Increased citrate exudation in the $\mathrm{Al}$ tolerant genotype DTAC-7 was found to be related to increases in organically bound $\mathrm{Al}$ in solution as well as lower callose accumulation in root tips. A decrease in organic acid (OA) exudation over time was also observed in both genotypes. These findings suggest that, under short term $\mathrm{Al}$ exposure, citrate exudation is a viable mechanism to promote $\mathrm{Al}$ resistance in poplar genotypes, but also suggests that other strategies may exist in longer term $\mathrm{Al}$ exposure. Further screening of $\mathrm{Al}$ tolerant poplar genotypes could yield successful candidates to be utilized for sustainable reforestation/reclamation and carbon sequestration projects where soil acidity may limit tree growth. 


\section{Acknowledgements}

"If you torture the data long enough nature will reveal herself." These words were instilled in me by my advisor Dr. Jonathan Cumming. If it were not for him I never would have had an interest in science. Without Jonathan's countless hours of help and encouragement I believe I would never have made it to this point. I would also like to thank Dr. Richard Thomas who gave me interesting perspectives on how to be productive yet enjoy life at the same time. Also I give thanks to Dr. Stephen DiFazio, without whom none of my experiments could've occurred. I cannot thank Pat Lutsie and Wendy Sites enough for all their support throughout my journey, in terms of supplies and camaraderie.

Many thanks go to my lab mates who were there by my side many late nights in the lab. Dhiraj Naik who made me understand what hard work and dedication really mean. Shalaka Desai, thank you for just being an overall good person and all the stimulation conversation on those long days and nights. Christina Huffman, thank you for helping me with all the bound Al methods and data collection. The help of all my undergraduate workers really made the wheels turn; Nathaniel Chapman, Chara Lemley, Joshua Ang and Sherline Montoute.

Credit must be given to my family who are the pillar of my strength. I would like to thank my mom and dad, Brenda and Tim, for instilling the values and motivation in me to accomplish so much in my life. Also to my brothers Allan and Josh who despite having their own lives would come help me in the lab late at night just because I needed help. Finally I would like to thank my grandparents Ron and Ada Eagle who have given me unconditional love and support, without them I would be a shadow of the person I am today. 


\section{Table of Contents}

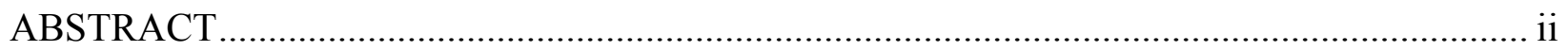

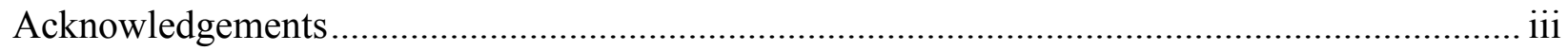

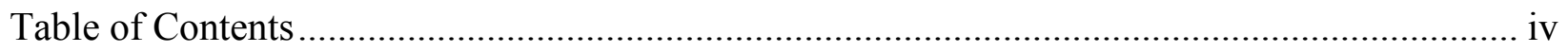

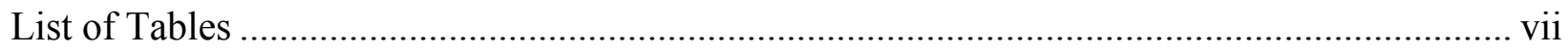

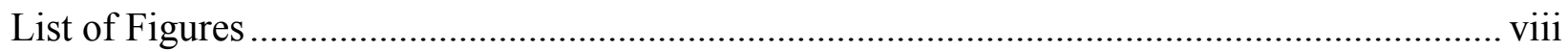

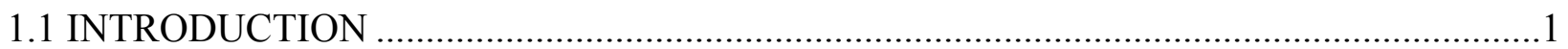

2.1 Genotypic Variation in Aluminum Resistance, Cellular Aluminum Fractions, Callose and Pectin Formation and Organic Acid Accumulation in Roots of Populus Hybrids ..........................4

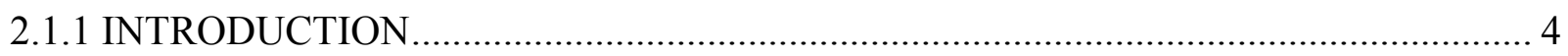

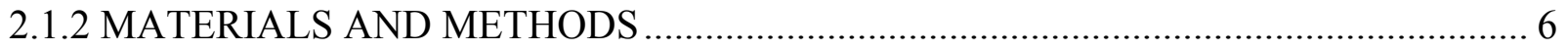

2.1.2.1 Plant materials, hydroponic culture and $\mathrm{Al}$ treatment ............................................... 6

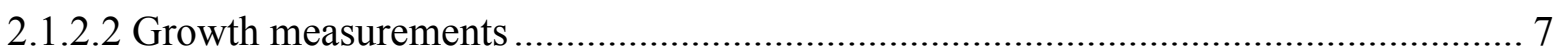

2.1.2.3 Determination of apoplastic and symplastic $\mathrm{Al}$ in root tips ..................................... 7

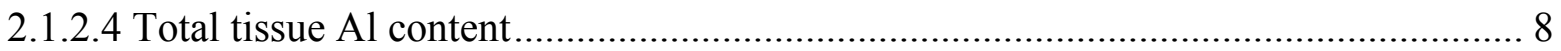

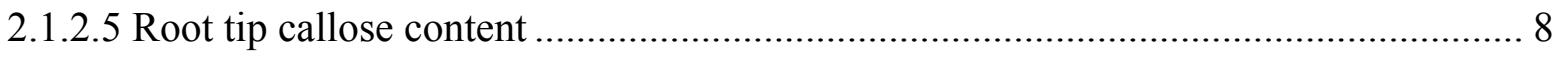

2.1.2.6 Determination of organic acids from root apices ..................................................... 9

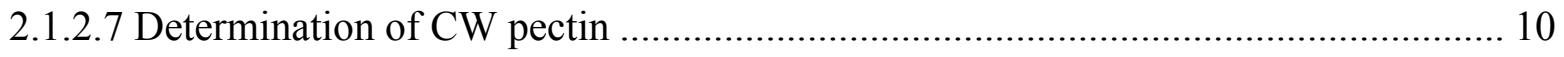

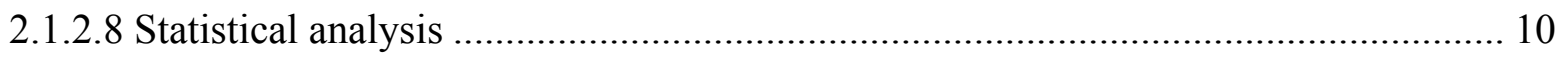

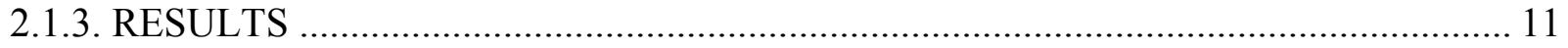

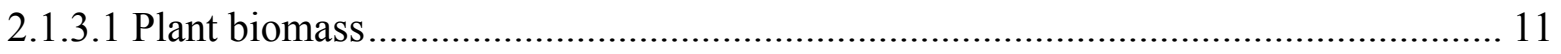

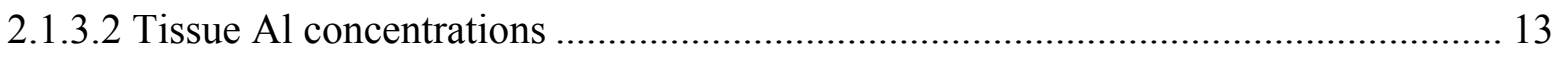

2.1.3.3 Apoplastic and symplastic Al concentrations..................................................... 14

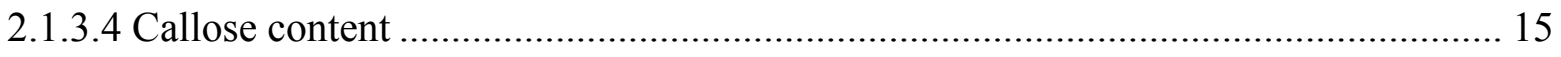

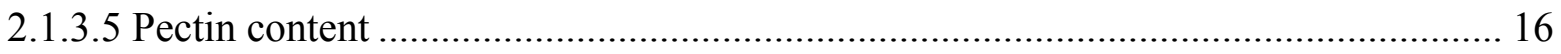

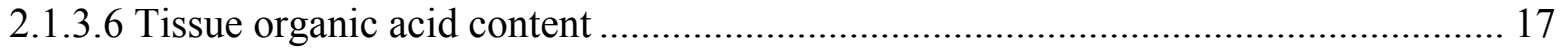

2.1.3.7 Relationships between root tolerance index, callose, pectin and $\mathrm{Al}$ fractions .......... 19

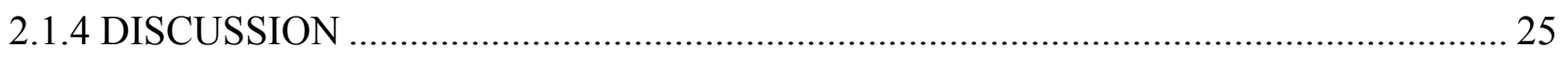

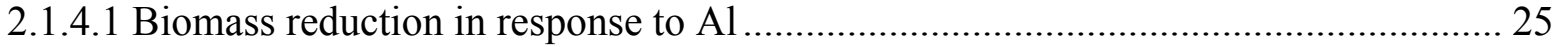

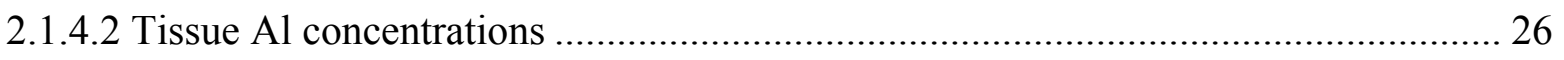

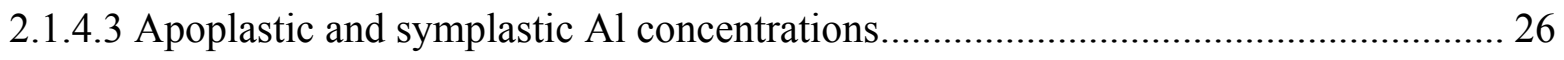

2.1.4.4 Callose accumulation in root tips ....................................................................... 27 


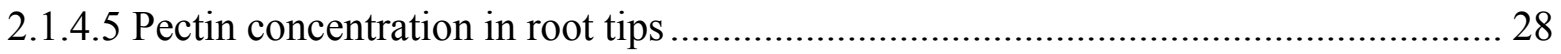

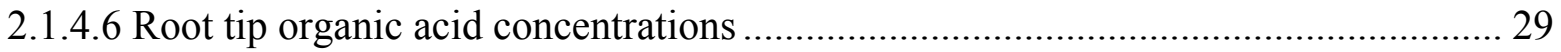

2.1.4.7 Physiology of $\mathrm{Al}$ tolerance in Populus genotypes............................................... 30

3.1 Examining the Role of Root Exudation in Aluminum Tolerance of Populus Genotypes ........32

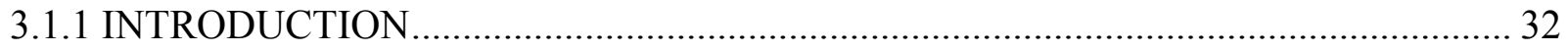

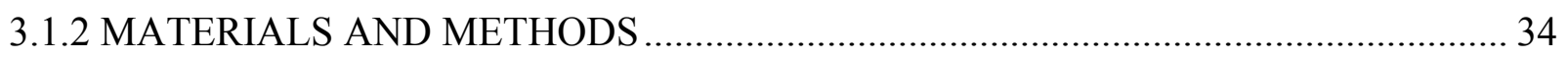

3.1.2.1 Plant materials, hydroponic culture and Al treatment .......................................... 34

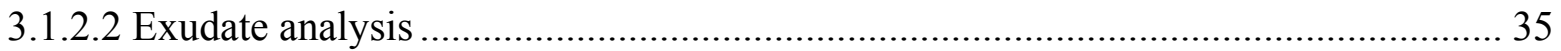

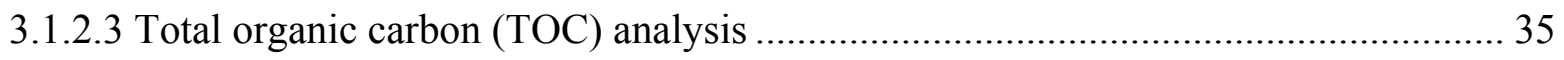

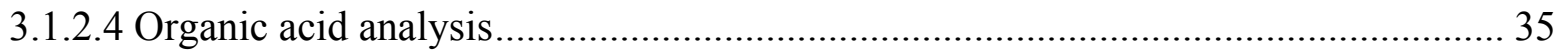

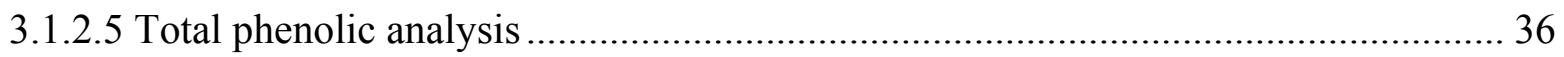

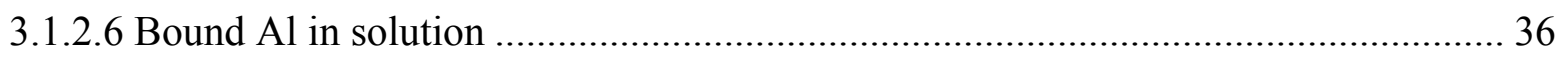

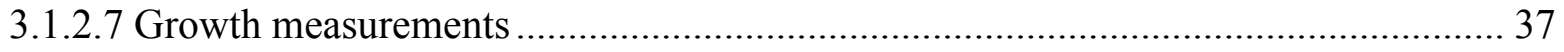

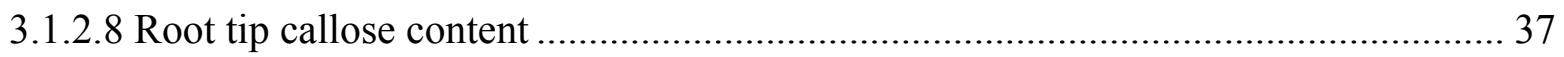

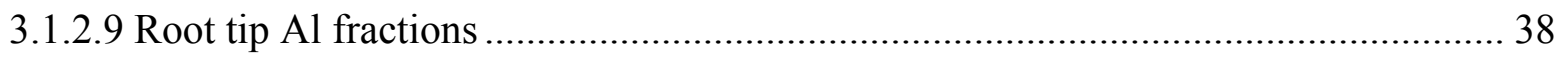

3.1.2.10 Root tip organic acid and total phenol content ................................................ 38

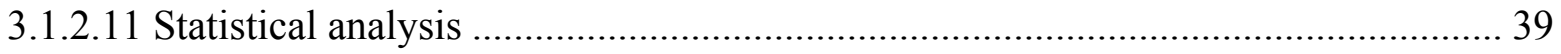

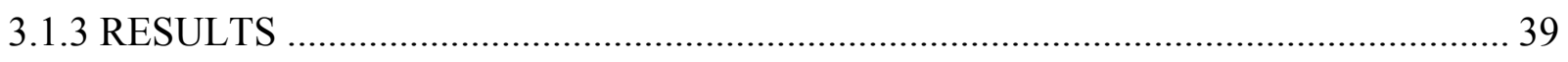

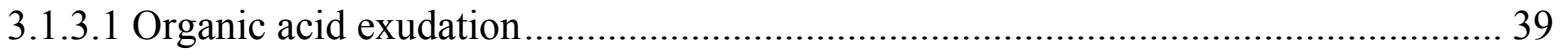

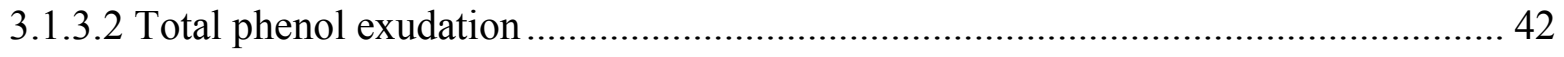

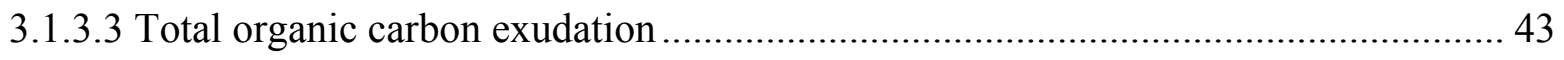

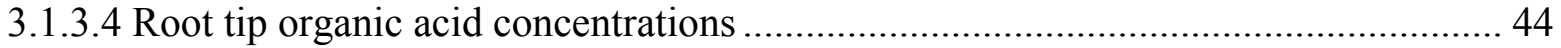

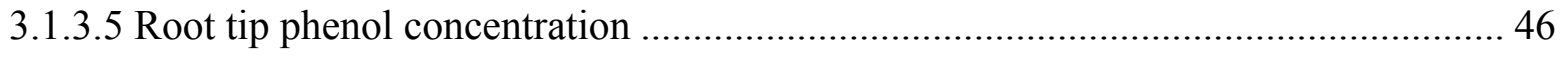

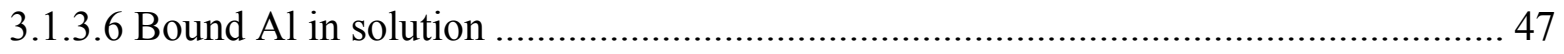

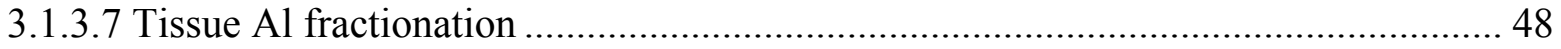

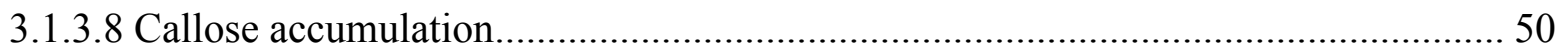

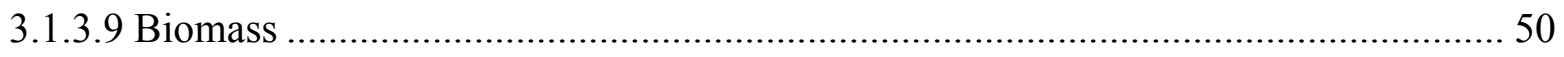

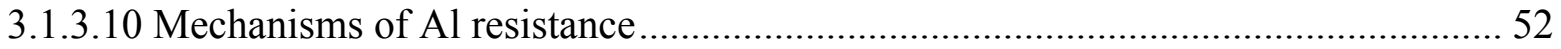

3.1.3.11 Aluminum induced changes in exudation .................................................. 53

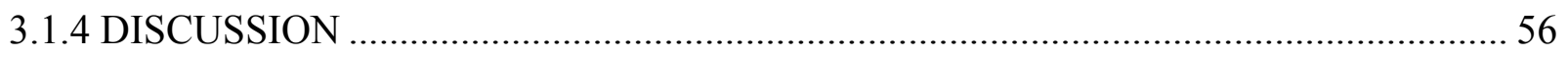

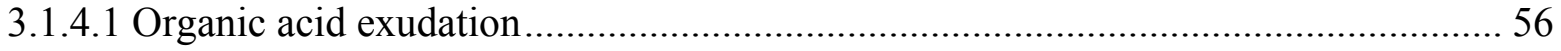

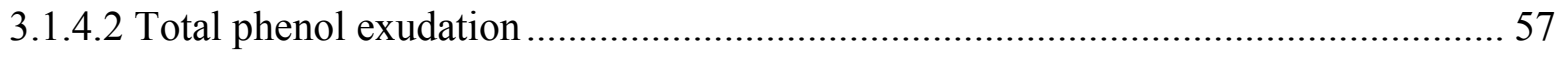




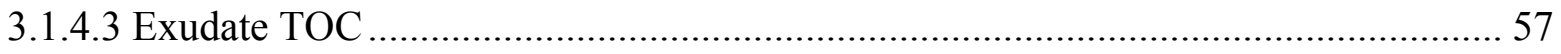

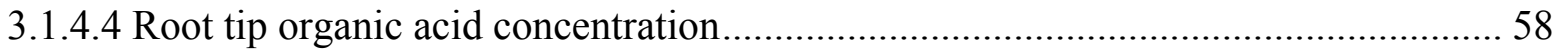

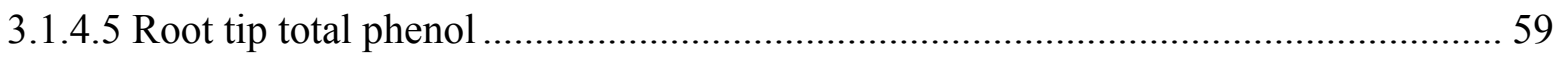

3.1.4.6 Apoplastic, symplastic and total Al in root tips .............................................. 59

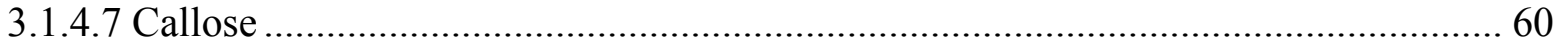

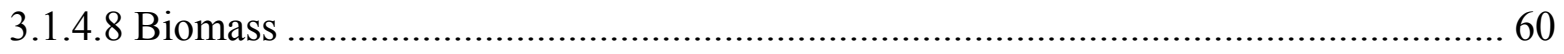

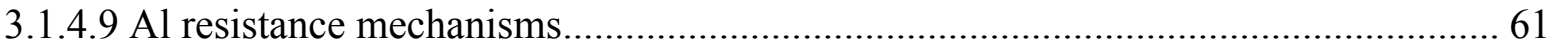

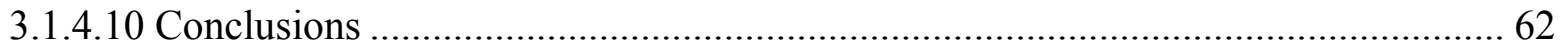

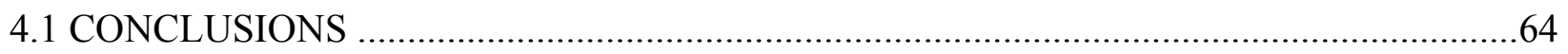

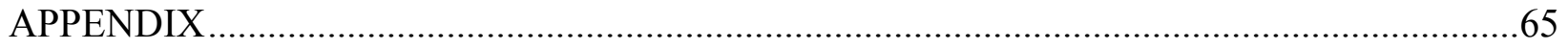

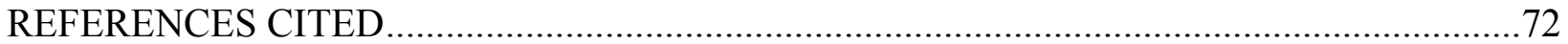




\section{List of Tables}

A.1 Two-way analysis of variance (ANOVA) examining the effect of genotype and Al treatment of eight Populus genotypes exposed to $\mathrm{Al}$ for 30 days...............................................................65

A.2 Two-way ANOVA examining the effect of hybrid cross and Al treatment of eight Populus

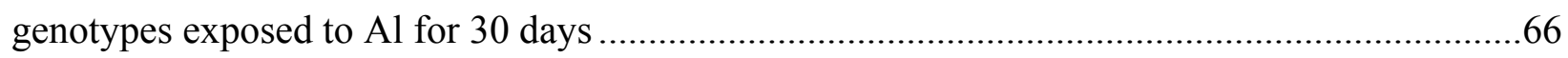

A.3 Table of $\mathrm{R}^{2}$ values between $\mathrm{Al}$ fractions and tolerance index..............................................67

A.4 Three-way ANOVA on two Populus genotypes differing in length of Al exposure...............68

A.5 Two-way ANOVA table for time periods of Al exposure in two Populus genotypes ...........69 


\section{List of Figures}

1-1 Shoot and root biomass of eight Populus genotypes exposed to Al....................................12

1-2 Tissue Al concentrations of eight Populus genotypes exposed to Al................................14

1-3 Apoplastic and symplastic Al in root tips of Populus genotypes exposed to Al..................15

1-4 Callose and pectin accumulation in root tips of Populus genotypes exposed to Al..............17

1-5 Tissue organic acid concentrations in root tips of Populus genotypes exposed to Al............18

1-6 Relationships between root tolerance index and root tip callose and pectin concentrations of eight Populus genotypes exposed to $200 \mu \mathrm{M} \mathrm{Al}$.....................................................................20

1-7 Relationships between root tolerance index and apoplastic, symplastic and total Al concentrations in root tissue of eight poplar genotypes exposed to $200 \mu \mathrm{M} \mathrm{Al}$.........................21

1-8 Relationships between callose and apoplastic, symplastic and total Al concentrations in root tissue of eight poplar genotypes exposed to $200 \mu \mathrm{M}$ Al ........................................................22

1-9 Relationships between pectin and apoplastic, symplastic and total $\mathrm{Al}$ concentrations in root tissue of eight poplar genotypes exposed to $200 \mu \mathrm{M}$ Al ....................................................23

1-10 Relationships citrate and apoplastic, symplastic and total Al concentrations in root tissue of eight poplar genotypes exposed to $200 \mu \mathrm{M} \mathrm{Al}$

1-11 Differences in cell physiology between Al tolerant and sensitve Populus genotypes exposed to $\mathrm{Al}$

1-12 Diagram of citrate exudation as an Al tolerance mechanism in Populus genotypes.............31

2-1 Organic acid exudation of two Populus genotypes post 1 day Al exposure ........................40

2-2 Organic acid exudation of two Populus genotypes post 7 days Al exposure.......................41

2-3 Phenol exudate concentration of two Populus genotypes post 7 days Al exposure...............42

2-4 Total organic carbon of exudates from two Populus genotypes exposed to Al ...................43

2-5 Root tip organic acid concentration of two Populus genotypes post 1 day Al exposure ........44

2-6 Root tip organic acid concentration of two Populus genotypes post 7 days Al exposure.......45

2-7 Total phenol in root tips of two Populus genotypes exposed to Al...................................46

2-8 Bound $\mathrm{Al}$ in solution from two Populus genotypes exposed to $\mathrm{Al}$....................................47

2-9 Fractionation of $\mathrm{Al}$ in Populus genotype root tissue after $\mathrm{Al}$ exposure ..............................48

2-10 Callose accumulation in two Populus genotypes exposed to Al ......................................49

2-11 Biomass accumulation in two Populus genotypes exposed to Al ...................................50 
2-12 Regression of citrate exudation and bound $\mathrm{Al}$ in solution...........................................51

2-13 Regression of citrate exudation and callose accumulation ...........................................52

2-14 Exudation profile of two Populus genotypes exposed to Al for one day ...........................53

2-15 Exudation profile of two Populus genotypes exposed to Al for seven days ......................54

A.1 Relationship between organic acids and growth in eight Populus genotypes .....................68 


\subsection{INTRODUCTION}

Aluminum (Al) is earth's third most abundant element after oxygen and silicon, accounting for almost seven percent of the earth's crust (Ma et al., 2001). While most of this Al in bound in unavailable forms in rocks and minerals, chemical weathering processes lead to the release of $\mathrm{Al}$ into the edaphic environment. The mineral solublization and release of $\mathrm{Al}$ into solution are accelerated by acidity and, once in solution, the cationic $\mathrm{Al}^{+3}$ species is toxic to many plants (Marschner, 1991). Indeed soil acidification and Al toxicity are major factors limiting plant growth and ecosystem productivity worldwide (Baringnaga, 1997). Elevated soil Al may result from natural soil weathering processes and may increase with anthropogenic inputs of nitrogen into ecosystems (Aber et al., 1998; Halvin et al., 1999). Surface mining may also increase soil acidity and $\mathrm{Al}$ availability due to the exposure of acidic overburdens to weathering processes (Karathanasis et al., 1998). In agriculture, a common practice used to alleviate soil Al toxicity is the application of lime and phosphorous to acidic soils. However, this practice is impractical as a long-term strategy for forest tree plantation management. The identification of $\mathrm{Al}$ resistant tree genotypes and the underlying mechanisms of adaptation to $\mathrm{Al}$ in the environment is a more practical strategy for wood production on acidic, Al-rich soils.

The primary target of $\mathrm{Al}$ toxicity is the root tip, and plants experiencing Al toxicity typically exhibit decreased root growth (Steiner et al., 1984; Kochian et al., 2005). The toxicity of Al to plants results from its strong affinity for biological ligands within roots. The binding of Al to cell walls, plasma membranes and symplastic metabolites detrimentally affects root physiology and, ultimately, growth (Cumming et al., 1992; Lux and Cumming, 2001; Kochian et al., 2005; Tahara et al., 2005). Negatively charged polysaccharides, such as pectin, in cell walls may attract Al to the root apoplast and increase Al concentration within the root surface and lead to toxicity and alterations in nutrient acquisition (Yamamoto et al., 1997; Taylor et al., 2000).

However, plants possess a number of mechanisms that can limit Al toxicity. Plants may chelate $\mathrm{Al}$ in the rhizosphere through the exudation of organic acids (OAs), such as citrate and malate (Silva et al., 2004; Qin et al., 2007). Aluminum may similarly be detoxified internally by the accumulation of OA-Al complexes (Watanbe and Osaki, 2002; Nguyen et al., 2003). In depth studies on Al tolerance have been conducted on a number of agricultural species (Delhaize and Ryan, 1995; Matsumoto, 2000; Kochian et al., 2005). Studies on forest tree resistance to Al have explored pathways such as organic acid exudation (Watannabe and Osaki, 2002; Silva et 
al., 2004; Qin et al., 2007), callose accumulation (Hirano et al., 2004; Hirano et al., 2006), and Al fractionation within the root (Heim et al., 2001; Nowak and Friend, 2005). A limited number of studies focus on interspecific and intraspecific differences in Al tolerance of tree species (Cuenca et al., 1990; Nguyen et al., 2003; Silva et al., 2004; Naik et al., 2009). Therefore, there is a further need to explore genotypic variation in mechanisms of Al tolerance of a tree species.

Forested ecosystems cover almost one-third of the earth's surface area, making trees, as a group, keystone ecological organisms. Trees are vital to human populations by providing resources, such as fuel, fiber, and timber, and ecological services, such as carbon and water storage (Tuskan and Walsh, 2001). Due to their extended life span and habitat, forest trees must possess the ability to overcome a variety of abiotic and biotic stresses that may detrimentally affect their growth (Brunner and Godbold, 2007). Poplar (Populus spp.) has become the model genus for the investigation of forest tree responses to environmental factors. Genotypes within the genus Populus exhibit rapid growth, ease of vegetative propagation, a high degree of genetic variation and a sequenced genome (Strauss and Martin, 2004), providing the phenotypic and genetic resources for in-depth investigation of tree response to the environment. Poplars are also used extensively in plantation production (Hansen et al., 1994), and understanding genotypic variation in response to soil factors will play an important role in supporting sustainable, lowinput wood and fiber production for the future.

Large genotypic differences in Al resistance exist within the genus Populus (Steiner et al., 1984; Naik et al., 2009). Since genotypic variation in Al resistance in many agricultural and non-woody species has been related to root exudation of OAs and phenols in response to Al (Delhaize and Ryan, 1995; Jones., 1998; Miyasaka and Hawes, 2001; Barcelo and Poschenrieder, 2002; Silva et al., 2004), investigating the function of such systems in Populus, a woody species with a sequenced genome and extensive genetic resources, would provide a unique opportunity to probe the genetic basis of $\mathrm{Al}$ resistance in a significant forest tree species. Identification of resistant genotypes and elucidating the physiological mechanisms of $\mathrm{Al}$ toxicity/resistance in a forest tree species may lead to the identification of Al resistant tree genotypes for production on acidic soils.

The first study of this thesis examines a broad range of poplar genotypes varying in lineage to see if and how these genotypes differentially respond to Al. The goal of this study was to see if differences in biomass due to $\mathrm{Al}$ stress could be reflected in physiological processes in Populus hybrid genotypes. In the second study, patterns of root exudation were assessed in 
Al-resistant and Al-sensitive Populus hybrid crosses and related exudation to Al speciation in the rhizosphere, Al fractionation within root tips, callose accumulation and growth of these genotypes when exposed to Al. From these studies a better understanding of physiological mechanisms of Al tolerance in poplar genotypes can be conveyed and lays foundation for further genetic research in poplar.

It is hypothesized that $\mathrm{Al}$ tolerant genotypes can be distinguished by greater biomass accumulation in response to Al treatment. Also these changes in biomass can be reflected by physiological responses such as callose accumulation in root tips and changes in organic acid production. Finally it is hypothesized that organic acid exudation plays a role in Al tolerance of Populus, with more tolerant genotypes exuding more organic acids. 


\subsection{Genotypic Variation in Aluminum Resistance, Cellular Aluminum Fractions, Callose and Pectin Formation and Organic Acid Accumulation in Roots of Populus Hybrids}

\subsubsection{INTRODUCTION}

Soil acidity is a major impediment to agriculture and forestry worldwide. Approximately $40 \%$ of arable land has naturally acidic soil, and soil acidification is accelerated by certain farming practices and by atmospheric acid and nitrogen deposition (Marschner, 1991; von Uexküll and Mutert, 1995). Surface mining may also exacerbate soil acidity due to the exposure of acidic overburdens to weathering processes (Karathanasis et al., 1988). The solubilization and bioavailability of aluminum (Al) is one of the major chemical constraints limiting crop yield and forest productivity on acidic soils (Kochian et al., 2005; Brunner and Godbold, 2007). In highinput agricultural systems, combating Al toxicity is accomplished through the application of lime and fertilizer. However, such practices are not feasible for much of the world's agriculture or for forested ecosystems (Halvin et al., 1999). An understanding of plant response to Al is critical to the selection of species and genotypes for long-term agricultural and managed forest productivity.

The toxicity of $\mathrm{Al}$ to plants is a result of the high affinity of cationic Al for plant cell walls, membranes and metabolites (Kochian et al., 2005; Hiradate et al., 2007). The binding of $\mathrm{Al}^{3+}$ with cell walls impairs root elongation (Ma et al., 1999; Rangel et al., 2009) and Almembrane interactions alter nutrient acquisition processes (Purcino et al., 2003; Klugh and Cumming, 2007). Aluminum also alters cell homeostasis through the alteration of membrane channel activity and ion fluxes and by binding to enzymes and other cellular components in the symplasm (Huang et al., 1992; Purcino et al., 2003).

Aluminum sensitivity and resistance mechanisms of crop plants have been well documented, particularly with emphasis on physiological and genetic basis of resistance (Delhaize and Ryan 1995; Kochian et al., 2005; Godbold and Brunner, 2007). Quantitative data on the physiological responses of tree roots to Al are less numerous (Ruf and Brunner, 2003; Hirano and Brunner, 2006; Vanguelova et al., 2007). As with crop species, tree species and genotypes within species differ widely in their responses to Al. Rankings of Al resistance among tree species have been compiled based primarily on growth responses (McCormick and Steiner, 1978; Steiner et al., 1984; Schaedle et al., 1989; Cuenca et al., 1990), whereas the physiological 
traits underlying variation among genotypes within tree species have received less attention (Geburek and Scholz, 1992; Nowak and Friend, 2005; Godbold and Brunner, 2007).

One potential physiological parameter for measuring Al resistance/sensitivity is Alinduced callose synthesis in root apices, which has been related to reductions in root growth and root elongation (Zhang et al., 1994; Horst et al., 1997; Wissemeir et al., 1998). Callose (1, 3- $\beta$ glucan) is a plant polysaccharide that is synthesized in response to various biotic and abiotic stresses. In roots of temperate forest trees, callose formation has been positively related to $\mathrm{Al}$ concentrations in solution under both laboratory and field conditions. For example, callose concentrations in root apices of European chestnut (Hirano et al., 2006) and Norway spruce (Hirano et al., 2004) were strongly correlated with Al exposure. This physiological marker of Al stress is more robust than other indicators, such as root elongation rates and hematoxylin staining (Zhang et al., 1994; Horst et al., 1997; de Macêdo et al. 2009), suggesting that callose is a reliable biochemical marker of Al sensitivity in plants. Information on callose as a marker for genotypic variation in response to $\mathrm{Al}$ exposure within tree species is scarce.

The polyvalent $\mathrm{Al}^{3+}$ ion rapidly and strongly binds to negatively charged biomolecules in the root (Zhang and Taylor, 1989; Blamey et al., 1990). Several studies indicate that Al accumulates mainly in the cell wall (CW), specifically binding to the pectin matrix (Chang et al., 1999; Wang et al., 2004). Pectin is a complex polysaccharide that is mainly composed of galacturonic acid chains and a strong, positive relationship between $\mathrm{CW}$ pectin content and $\mathrm{Al}$ accumulation has been recognized (Schmohl and Horst, 2000). Although patterns of CW pectin content and Al resistance have been observed in several crop species (Eticha et al., 2005; Rangel et al., 2009), no such studies have been reported in forest trees in relation to Al stress.

One of the well-established physiological mechanisms of Al stress resistance in plants involves the extracellular detoxification and exclusion of Al via root organic acid (OA) exudation and the intracellular chelation and detoxification of Al by OA accumulation. Recent studies on forest tree species, including Populus, Melaleuca, Melastoma and Eucalyptus, indicate that $\mathrm{Al}$-induced root $\mathrm{OA}$ exudation and accumulation may be involved in tree resistance to $\mathrm{Al}$ (Watanabe and Osaki, 2002; Nguyen et al., 2003; Silva et al., 2004; Naik et al., 2009). The exudation (Nguyen et al., 2003) or accumulation (Yang et al., 1994; Jones, 1998; Silva et al., 2004) of OAs lead to the extracellular and intracellular chelation and detoxification of the phytotoxic $\mathrm{Al}^{3+}$ ion, reducing its binding with cell components and subsequent impacts on root cell division and elongation, thus facilitating tree growth on acidic soils. While the role of 
exudation of $\mathrm{OA}$ anions in reducing $\mathrm{Al}$ uptake/binding in the root apoplast has been widely accepted, the role of symplastic OA accumulation and the intracellular detoxification of $\mathrm{Al}$ by OAs as a mechanism of $\mathrm{Al}$ resistance is still an issue of debate.

The objective of the current study was to investigate differences in $\mathrm{Al}$ resistance/sensitivity among eight hybrid poplar (Populus spp.) genotypes. To assess these differences, we measured growth and callose production as indicators of $\mathrm{Al}$ resistance as well as potential mechanisms of $\mathrm{Al}$ resistance, including $\mathrm{CW}$ pectin content and root tissue $\mathrm{OA}$ accumulation. Finally, we assessed the relationships between tolerance indices and resistance mechanisms and the concentrations of symplastic, apoplastic and total $\mathrm{Al}$ in the root, assessing the efficacy of these mechanisms in conferring $\mathrm{Al}$ resistance to poplar genotypes. Our overarching hypothesis was that $\mathrm{Al}$ resistance in poplar is associated with the exclusion of $\mathrm{Al}$ from the symplast or the intracellular chelation of $\mathrm{Al}$ by accumulated organic acids within root tips. The exclusion or chelation of Al would limit the metabolic perturbations induced by intracellular ionic $\mathrm{Al}$, thus conferring resistance to poplar genotypes exhibiting these traits.

\subsubsection{MATERIALS AND METHODS}

\subsubsection{Plant materials, hydroponic culture and Al treatment}

An experiment assessing genotypic variation among poplar hybrids was conducted using dormant hybrid poplar sapling stem cuttings from one-year-old plants originally started from cuttings obtained from Segal Ranch Hybrid Poplars (Grandview, WA, USA). Healthy cuttings of uniform size were taken from eight hybrid poplar clones representing specific crosses of Populus trichocarpa (hereafter designated as T), P. nigra (hereafter designated as $\mathrm{N}$ ) and $P$. deltoides (hereafter designated as D). The genotypes used were 199-586 $(\mathrm{T} \times \mathrm{D})$, DTAC-7 $(\mathrm{T} \times \mathrm{D})$, 50-194 $(\mathrm{T} \times \mathrm{D})$, 306-45 $(\mathrm{T} \times \mathrm{N}), 309-74(\mathrm{~T} \times \mathrm{N}), 311-93(\mathrm{~T} \times \mathrm{N})$, OP-367 $(\mathrm{D} \times \mathrm{N})$ and PE-01 $(\mathrm{D} \times \mathrm{N})$. Cuttings were approximately $15 \mathrm{~cm}$ in length and $3 \mathrm{~mm}$ in diameter with 2-4 dormant buds. These cuttings were chilled for $14 \mathrm{~d}$ at $4{ }^{\circ} \mathrm{C}$ to promote uniform bud sprouting.

The propagation system was based on $10 \mathrm{~L}$ hydroponic tanks that were aerated vigorously by two air stones and aquarium pumps. Each tank contained eight cuttings assigned such that all eight genotypes occurred together in each of seven tanks in each Al treatment. To initiate rooting, cuttings were treated with liquid-based rooting hormone $(0.2 \%$ indole-3-butyric acid, 0.1\% 1-naphthaleneacetic acid)(Dip'n Grow, Inc., Clackamas, OR, USA) and were initially 
rooted in tanks containing aerated solutions of $0.5 \mathrm{mM} \mathrm{Ca}\left(\mathrm{NO}_{3}\right)_{2}$ at $\mathrm{pH} 5.8$ for $14 \mathrm{~d}$. Following root initiation and bud break, excess shoots were removed to promote uniform growth of a single shoot for each rooted cutting. Clones were then supplied with a nutrient solution containing 1.0 $\mathrm{mM} \mathrm{NO}_{3}, 0.4 \mathrm{mM} \mathrm{NH}_{4}, 0.5 \mathrm{mM} \mathrm{K}, 0.2 \mathrm{mM} \mathrm{Ca}, 0.05 \mathrm{mM} \mathrm{H}_{2} \mathrm{PO}_{4}, 0.1 \mathrm{mM} \mathrm{Mg}$ and SO$_{4}, 50.5 \mu \mathrm{M}$ $\mathrm{Cl}, 20 \mu \mathrm{M} \mathrm{Fe}, 20 \mu \mathrm{M} \mathrm{B}, 2 \mu \mathrm{M} \mathrm{Mn}$ and $\mathrm{Zn}$ and $0.5 \mu \mathrm{M} \mathrm{Cu}, \mathrm{Na}$, Co and Mo adjusted to $\mathrm{pH}$ 4.0. Plants were grown on this solution for $11 \mathrm{~d}$ with changes twice weekly. After this $25 \mathrm{~d}$ pretreatment period, cuttings were transferred to nutrient solutions containing $0,50,100,200$ or $500 \mu \mathrm{M}$ Al. To prepare treatment solutions, $\mathrm{Al}$ was added with vigorous stirring from a $1 \mathrm{M}$ $\mathrm{AlCl}_{3}$ stock, freshly prepared on the day of use. All solutions were adjusted to $\mathrm{pH} 4.0$ with $1 \mathrm{M}$ $\mathrm{NaOH}$ or $1 \mathrm{M} \mathrm{HCl}$. Both were added slowly with continuous stirring of the solutions to avoid $\mathrm{Al}$ precipitation. Treatment solutions were changed twice weekly.

Plants were maintained in a climate-controlled greenhouse with supplemental lighting providing a 14-h photoperiod (mixed metal halide sources) and day/night temperatures of $24 / 19 \pm 3{ }^{\circ} \mathrm{C}$. Relative humidity fluctuated with temperature and day. Cuttings were harvested following 30 days of $\mathrm{Al}$ exposure.

\subsubsection{Growth measurements}

After $30 \mathrm{~d}$ of $\mathrm{Al}$ treatment, root tips were removed for measurement of tissue $\mathrm{Al}$ and root tip biochemistry (see below), with subsets being used to calculate fresh:dry weight ratios. Shoots and remaining roots from each cutting were separated, dried in an oven at $60{ }^{\circ} \mathrm{C}$ for $72 \mathrm{~h}$ and reweighed. For each genotype, the root tolerance index (TI) was calculated as: (Root dry weight of $\mathrm{Al}$ treated plants/mean root dry weight of control plants)*100.

\subsubsection{Determination of apoplastic and symplastic $\mathrm{Al}$ in root tips}

Apoplastic and symplastic Al contents were determined after (Tice et al., 1992; Nowak and Friend, 2005) with minor modifications. At harvest, roots of the eight hybrid poplar genotypes were blotted on tissue paper. Root apices $(\sim 2 \mathrm{~cm})$ of 8-10 roots were collected, rinsed in $1.5 \mathrm{mM} \mathrm{CaCl}_{2}$ solution and kept in this solution at $4{ }^{\circ} \mathrm{C}$ until initiation of the $\mathrm{Al}$ fractionation procedure.

The fractionation of $\mathrm{Al}$ for apoplastic and symplastic $\mathrm{Al}$ was performed as follows. Step 
1 (apoplastic $\mathrm{Al}$ ): roots were washed with $10 \mathrm{~mL}$ of desorption solution containing ice-cold 0.25 $\mathrm{mM}$ citric acid and $0.25 \mathrm{mM} \mathrm{CaCl}_{2}$ with gentle agitation for $2 \mathrm{~min}$. Step 2 (symplastic $\mathrm{Al}$ ): root samples were transferred to $10 \mathrm{~mL}$ of the same desorption solution and cell membranes of the root samples were ruptured using combined methods of freezing $\left(-20{ }^{\circ} \mathrm{C}\right)$ and sonication $(2 \mathrm{~min}$ sonication in ice-cold water bath). This process was repeated three times and solutions were pooled and used for symplastic Al determinations. Apoplastic and symplastic Al content were quantified as $\mu \mathrm{mol} \mathrm{g}^{-1}$ dry weight of root tissue.

\subsubsection{Total tissue Al content}

Dried leaf and root tissues of each genotype were ground to pass a 20-mesh sieve in a Wiley Mill. Samples of $0.1 \mathrm{~g}$ of leaves and roots were digested in $5 \mathrm{~mL} \mathrm{HNO}_{3}$ and $2 \mathrm{~mL}$ of $35 \%$ $\mathrm{H}_{2} \mathrm{O}_{2}$ (Jones and Case, 1990). Samples were digested in a $75 \mathrm{ml}$ closed vessel microwave digestion system (MARS Express, MARS, Inc., Cary, NC, USA) for $2 \mathrm{~h}$ at $200^{\circ} \mathrm{C}$. After digestion, digests were brought to final volume of $75 \mathrm{~mL}$ and filtered though No. 44 Whatman filter paper. Aluminum concentrations were measured with a GTA 110 graphite tube furnace atomic absorption spectrometer (Varian, Inc., Mulgrave, Victoria, Australia).

\subsubsection{Root tip callose content}

Callose in root tips was assayed by a modification of the methods described by Hirano and Brunner (2006). Root tips ( $2 \mathrm{~cm}$ in length) were excised and fixed in $1 \mathrm{ml}$ of $96 \% \mathrm{v} / \mathrm{v}$ ethanol. Samples ( $\sim 200 \mathrm{mg}$ fresh weight) were homogenized using pre-cooled mortars and pestles for $3 \mathrm{~min}$, sonicated for $2 \mathrm{~min}$ in ice water and the resulting slurries transferred to $2 \mathrm{~mL}$ Eppendorf tubes. Homogenized root tip samples were then washed three-times with $1 \mathrm{~mL}$ of $20 \% \mathrm{v} / \mathrm{v}$ ethanol containing $5 \% \mathrm{w} / \mathrm{v}$ PVPP. One $\mathrm{mL}$ of $1 \mathrm{M} \mathrm{NaOH}$ was added to the washed samples and the tubes were heated at $85^{\circ} \mathrm{C}$ for $20 \mathrm{~min}$ to solubilize callose. The extract was centrifuged at $11,000 \times g$ for $20 \min 4{ }^{\circ} \mathrm{C}$ and the clean supernatant assayed for callose. The callose assay mixture contained $0.2 \mathrm{~mL}$ of supernatant, $0.4 \mathrm{~mL}$ of $0.1 \% \mathrm{w} / \mathrm{v}$ aniline blue, 0.21 $\mathrm{mL}$ of $1 \mathrm{M} \mathrm{HCl}$ and $0.59 \mathrm{~mL}$ of $1 \mathrm{M}$ glycine- $\mathrm{NaOH}$ buffer $(\mathrm{pH} \mathrm{9.0).} \mathrm{Blanks} \mathrm{contained} \mathrm{assay}$ mixture lacking aniline blue and reaction controls lacked supernatant. The reaction mixture was 
incubated for $20 \mathrm{~min}$ at $50{ }^{\circ} \mathrm{C}$ and then $30 \mathrm{~min}$ at room temperature. Callose was quantified with a Quantech FM109515 fluorometer (Barnstead/Turner, Dubuque, IA, USA) at excitation and emission wavelengths of 393 and $484 \mathrm{~nm}$, respectively. Slitwidths were set to $3 \mathrm{~nm}$. Curdlan (Sigma, St. Louis, MO, USA) was used as a standard. For each root sample, fluorescence intensities in the absence of aniline blue stain were subtracted from the intensities in the presence of aniline blue stain (Wissemeier et al., 1998). Callose concentration was expressed as $\mu \mathrm{g}$ curdlan equivalent $(\mathrm{CE}) \mathrm{g}^{-1} \mathrm{FW}$ root mass.

\subsubsection{Determination of organic acids from root apices}

Preparation of organic acids from root apices was carried out according to (Cumming et al., 2001; Qiu and Jin, 2002), with minor modifications. Root tips ( $\sim 2 \mathrm{~cm}$ in length) were excised, rinsed with distilled water, blotted with paper towels, weighed and immediately frozen in liquid nitrogen and stored at $-80{ }^{\circ} \mathrm{C}$ for organic acid determination. The frozen roots were ground in a cold mortar with $2 \mathrm{~mL}$ of cold $80 \% \mathrm{v} / \mathrm{v}$ ethanol to form slurries and samples were sonicated for $2 \mathrm{~min}$ in an ice bath. The mixture was centrifuged at $8,000 \times g$ for 15 min at $4{ }^{\circ} \mathrm{C}$ and the pellet was extracted twice with $2 \mathrm{~mL}$ ice-cold water. The supernatants from each of these extractions were pooled and concentrated in a Speed Vac SC110 rotoevapopator (ThermoSavant, Holbrook, NY, USA). The dried residues were dissolved in de-ionized water and filtered through a membrane filter $(0.45 \mu \mathrm{m}$, Fisher Scientific, USA). Concentrations of citrate, malate, succinate and formate were measured using a Dionex ICS-1500 ion chromatograph with an ion suppressor and a conductivity detector (Dionex, Sunnyvale, CA, USA). For separation of organic acids, a Bio-Rad Aminex HPX-87H column (300 mm $\times 7.8 \mathrm{~mm}$ ID)(Bio-Rad Laboratories, Hercules, CA, USA) at $40{ }^{\circ} \mathrm{C}$ was employed with minor modification (Cumming et al. 2001). For the separation of organic acids, the eluent was $2.3 \mathrm{mM}$ heptafluorobutyric acid at a flow rate of $0.6 \mathrm{~mL} \mathrm{~min}{ }^{-1}$, the reagent solution was $5 \mathrm{mM}$ tetrabutylammonium hydroxide at a flow rate of $0.6 \mathrm{~mL} \mathrm{~min}^{-1}$ and the analysis time was $20 \mathrm{~min}$. Calibration equations were determined based on peak area for each organic acid obtained for standard organic acids. Peak areas were determined using Chromeleon software (Dionex, Sunnyvale, CA, USA). Tissue organic acid contents were quantified as $\mu \mathrm{mol} \mathrm{g}{ }^{-1} \mathrm{FW}$ of root tissue. 


\subsubsection{Determination of $\mathrm{CW}$ pectin}

The terminal 5-cm sections of one primary and two seminal roots were harvested per plant. Root samples were collected in $90 \% \mathrm{v} / \mathrm{v}$ ethanol in $2 \mathrm{~mL}$ Eppendorf tubes and extracted following methods modified after Schmohl and Horst (2000). Root samples were thoroughly homogenized in $2 \mathrm{~mL}$ of ethanol using pre-cooled mortar and pestle for $3 \mathrm{~min}$. The homogenization was repeated three times. After each ethanol addition, the samples were centrifuged at $11000 \times g$ for $5 \mathrm{~min}$ and the supernatant was discarded. The remaining cell wall material was dried using a Speed Vac SC110 rotoevapopator (Thermo-Savant, Holbrook, NY, USA), weighed and hydrolyzed in $1 \mathrm{~mL}$ of concentrated $\mathrm{H}_{2} \mathrm{SO}_{4}$. The pectin assay mixture contained $0.4 \mathrm{~mL}$ of hydrolysate and $2.5 \mathrm{~mL}$ of $1.25 \mathrm{mM}$ solution of sodium tetraborate in concentrated $\mathrm{H}_{2} \mathrm{SO}_{4}$. The reaction mixture was incubated for $5 \mathrm{~min}$ in boiling water bath, cooled at room temperature for $5 \mathrm{~min}$ and then mixed with $100 \mu \mathrm{L}$ of $0.15 \% \mathrm{w} / \mathrm{v} m$-hydroxydiphenyl reagent. Blanks contained assay mixture lacking $m$-hydroxydiphenyl reagent. Pectin content was measured using a Genysis 20 spectrophotometer (Thermo Spectronic, Madison, WI, USA) at $520 \mathrm{~nm}$ (Blumenkrantz and Asboe-Hansen, 1973). Galacturonic acid was used as a calibration standard and the root pectin content was expressed as galacturonic acid equivalents (GaE). Tissue pectin contents were quantified as $\mu \mathrm{g} \mathrm{GaE} \mathrm{g}^{-1} \mathrm{FW}$ of root tissue.

\subsubsection{Statistical analysis}

The experiment was established as nested factorial design ( 8 genotypes within $5 \mathrm{Al}$ treatments) with 7 replicated tanks per Al treatment. Replication ranged ( $\mathrm{n}=4$ to 7$)$ depending on measured variable. Data were log-transformed wherever necessary in order to achieve homogeneity of variance. Biomass, tissue $\mathrm{Al}$ concentrations, apoplastic and symplastic $\mathrm{Al}$ concentrations, callose and pectin concentrations and root tip organic acid concentrations were analyzed using nested analyses of variance followed by Tukey-Kramer's LSD to identify significant differences among genotypes or hybrids within Al treatments. Data comparing genotype responses to $\mathrm{Al}$ were analyzed by nested ANOVA (genotype within $\mathrm{Al}$ )(reported in Table A.1). Since there were multiple genotypes per hybrid cross, data were also analyzed as a doubly nested design (genotype within hybrid within Al) allowing assessment of broad hybrid 
responses to $\mathrm{Al}$ (reported in Table A.2). Coefficients of determination $\left(\mathrm{R}^{2}\right)$ were evaluated to assess relationships between measured variables (Table A.3). All statistical analyses were carried out using SAS JMP v.7 software (SAS Institute, Cary, NC, USA).

\subsubsection{RESULTS}

\subsubsection{Plant biomass}

In all hybrid poplar genotypes, significant reductions in growth occurred at Al concentrations as low as $50 \mu \mathrm{M}$, with growth inhibition becoming increasingly pronounced as $\mathrm{Al}$ concentration increased (Fig. 1-1). Across all genotypes, shoot biomass was reduced by $47 \%$ at $50 \mu \mathrm{M} \mathrm{Al}$ and up to $85 \%$ at $500 \mu \mathrm{M} \mathrm{Al}$ (Fig. 1-1a). However, significant variation in $\mathrm{Al}$ resistance among the eight genotypes was evident (Fig. 1-1, Table A.1). Reductions in shoot growth at $50 \mu \mathrm{M}$ Al ranged between $27 \%$ for the $\mathrm{T} \times \mathrm{D}$ genotype DTAC- 1 and $72 \%$ for the $\mathrm{D} \times \mathrm{N}$ genotype PC-01. At $500 \mu \mathrm{M} \mathrm{Al}$, reductions varied from 49\% DTAC-1 to $97 \%$ in PC-01, reflecting the high degree of variation in Al resistance among genotypes. In addition, shoot growth of genotypes within hybrid crosses in response to Al were consistent, with $\mathrm{T} \times \mathrm{D}$ hybrids being the most $\mathrm{Al}$ resistant, the $\mathrm{T} \times \mathrm{N}$ being intermediate and the $\mathrm{D} \times \mathrm{N}$ hybrids being the most $\mathrm{Al}$ sensitive (Fig. 1-1a, Table A.2).

Roots in the 200 and $500 \mu \mathrm{M}$ Al treatments exhibited classic Al toxicity symptoms and were brown and stunted with numerous thick and short lateral roots. However, significant growth reductions occurred at $\mathrm{Al}$ concentrations as low as $50 \mu \mathrm{M}$, at which concentration root biomass was reduced by $41 \%$ across all genotypes. Reductions in root growth increased with increasing Al up to $78 \%$ at $500 \mu \mathrm{M} \mathrm{Al}$ (Fig. 1-1b). Again, there was substantial variation among genotypes (Table A.1). At $50 \mu \mathrm{M}$ Al, root growth reductions ranged from $14 \%$ in the $\mathrm{T} \times \mathrm{D}$ genotype DTAC-1 to $86 \%$ in the $\mathrm{D} \times \mathrm{N}$ genotype $\mathrm{PC}-01$. At $500 \mu \mathrm{M} \mathrm{Al}$, reductions ranged from $60 \%$ in DTAC-1 to $98 \%$ in PC-01. Root growth responses to Al were also consistent within hybrid crosses, with $\mathrm{T} \times \mathrm{D}$ crosses being the least and $\mathrm{D} \times \mathrm{N}$ crosses the most affected by $\mathrm{Al}$ (Fig. 1-1b, Table A.2).

The impacts of Al were more pronounced on shoot than root growth, with the root:shoot ratio increasing from 1.6 at $0 \mu \mathrm{M} \mathrm{Al}$ to 3.4 at $500 \mu \mathrm{M} \mathrm{Al}$ across all genotypes. However, genotypes varied significantly in this growth allocation response under Al exposure (Table A.1). 
The change in root:shoot ratio was most pronounced in the $T \times N$ genotype 311-93, increasing 4fold across the $\mathrm{Al}$ treatment gradient. In contrast, the root:shoot ratio of the $\mathrm{T} \times \mathrm{D}$ genotype DTAC-1 declined slightly, but significantly, over this same Al gradient. While genotypes varied in response to $\mathrm{Al}$, there was no consistent pattern of response to $\mathrm{Al}$ for the root:shoot ratio for the poplar hybrid crosses (Table A.2).

Within all hybrid crosses used in this study, resistant and sensitive genotypes could be identified based on Al-induced changes in biomass accumulation. We used the root tolerance index (TI) as the relative root biomass at $200 \mu \mathrm{M} \mathrm{Al}$ for each genotype to compare genotype/hybrid responses for other measured variables (see later sections). At this Al concentration, the magnitude of root TI among the genotypes ranged from 5 to 54 . Genotypes of $\mathrm{T} \times \mathrm{D}$ hybrids (DTAC-1, 199-586) had root TI values above 50 . Genotypes of $\mathrm{D} \times \mathrm{N}$ hybrids were less than 13. The root TI values of the other 4 genotypes were intermediate and ranged between 28 and 32.
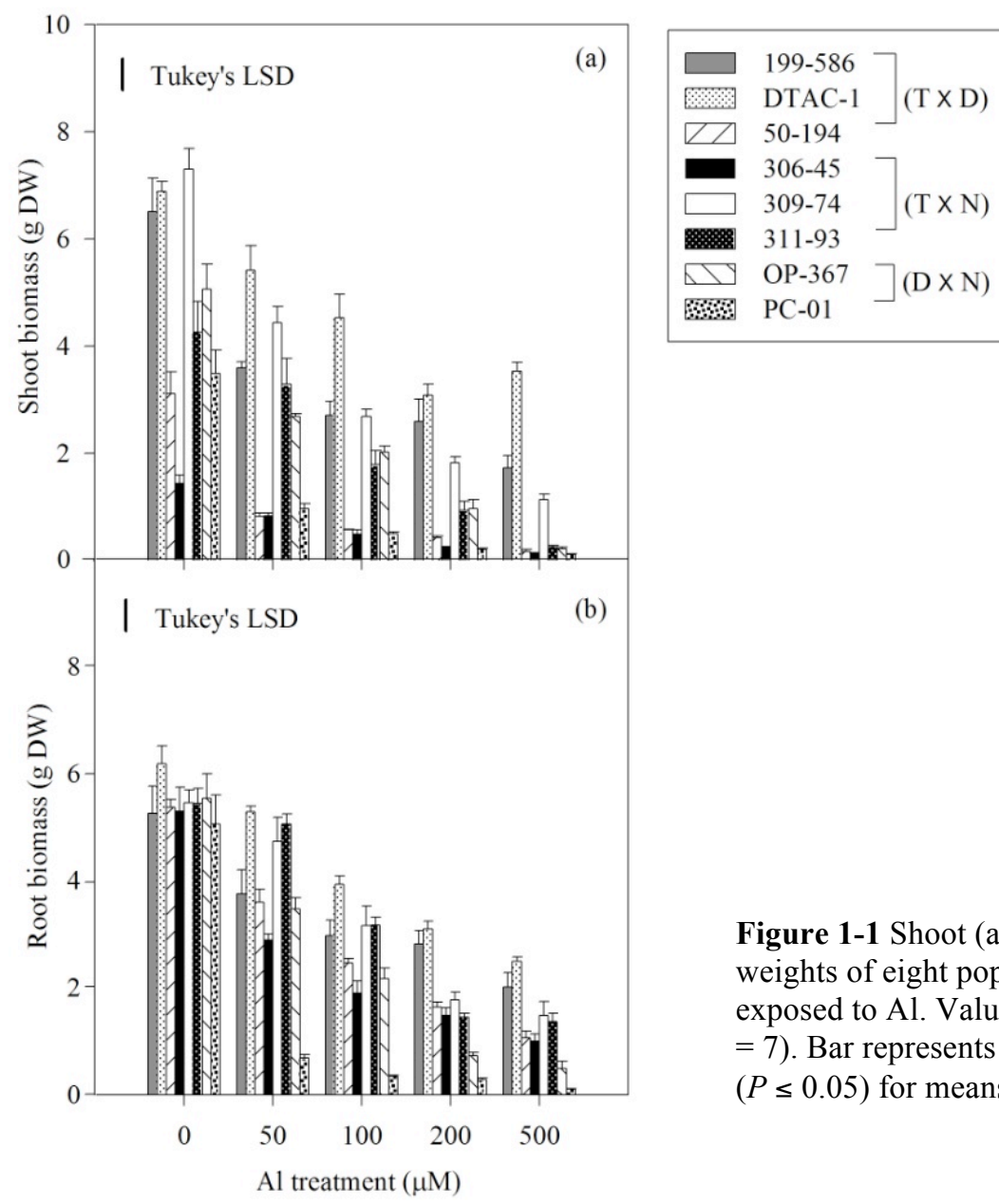

Figure 1-1 Shoot (a) and root (b) dry weights of eight poplar genotypes exposed to Al. Values are means \pm S.E. (n $=7)$. Bar represents Tukey-Kramer's LSD $(P \leq 0.05)$ for means comparisons. 


\subsubsection{Tissue Al concentrations}

Total shoot and root Al concentrations exhibited distinctly binary patterns of accumulation (Fig. 1-2). In shoots of poplar genotypes, exposure to Al led to 4- to 6-fold increases in foliar Al concentrations compared to plants grown without Al. Genotypes varied extensively, with DTAC-1 accumulating the most and PC-01 the least Al (Fig. 1-2a and Table A.1). There were no consistent differences in foliar Al accumulation among hybrids (Table A.2).

In poplar genotypes grown in control solutions, only low concentrations of total Al were detected in roots and exposure to any $\mathrm{Al}$ treatment led to high total root Al concentrations (Fig. 1-2b). Total root $\mathrm{Al}$ varied by $\sim 100 \mu \mathrm{mol} \mathrm{g}^{-1} \mathrm{DW}$ among genotypes within and among $\mathrm{Al}$ treatments. While there was significant variation in total root $\mathrm{Al}$ accumulation among genotypes in response to $\mathrm{Al}$ exposure, there were no consistent patterns of accumulation discernable for genotype or hybrid crosses to indicate that genetic background of the poplar genotypes influenced $\mathrm{Al}$ accumulation (Fig. 1-2b and Tables A.1, A.2). 


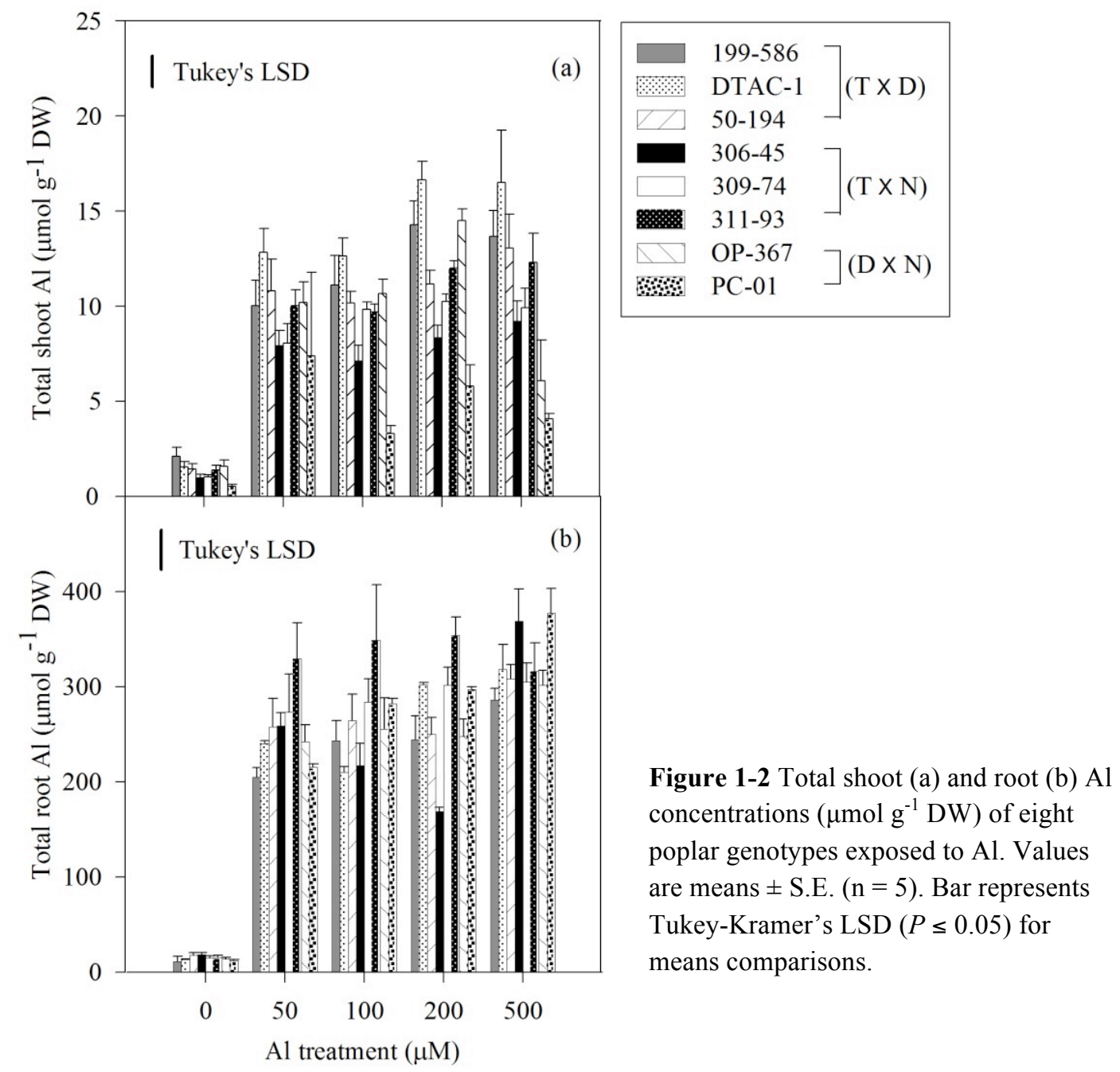

\subsubsection{Apoplastic and symplastic Al concentrations}

Aluminum resistance in poplar may be related to differences in the binding and compartmentation of $\mathrm{Al}$ within roots. To assess this, root apices were subjected to a fractionated desorption of $\mathrm{Al}$ to differentiate between apoplastically and symplastically-bound $\mathrm{Al}$ in the poplar genotypes. Fractionated desorption released between 10 and $30 \%$ of the total $\mathrm{Al}$ in the root tips, depending on the genotype and the Al exposure concentration.

The concentration of $\mathrm{Al}$ in apoplastic fractions increased with increasing $\mathrm{Al}$ exposure concentration (Fig. 1-3a). Apoplastic Al accumulation varied among genotypes and hybrid crosses and was significantly higher in the $\mathrm{T} \times \mathrm{D}$ hybrid genotypes $199-586$ and DTAC -1 than in the $\mathrm{D} \times \mathrm{N}$ hybrid genotypes OP-367 and PC-01 (Fig. 1-3a and Tables A.1, A.2). Symplastic Al concentrations also increased with exposure to $\mathrm{Al}$ (Fig. 1-3b), however, in contrast to 
apoplastic fractions, we observed significantly higher symplastic $\mathrm{Al}$ content in $\mathrm{Al}$-sensitive $\mathrm{D} \times \mathrm{N}$ hybrid genotypes OP-367 and PC-01 as compared to other genotypes (Fig. 1-3b and Tables A.1, A.2). The Al-tolerant $T \times D$ hybrid genotypes 199-586 and DTAC-1 showed the least symplastic Al compared to other genotypes. $\mathrm{T} \times \mathrm{N}$ genotypes accumulated intermediate levels of apoplastic and symplastic Al (Fig. 1-3a and 1-3b).

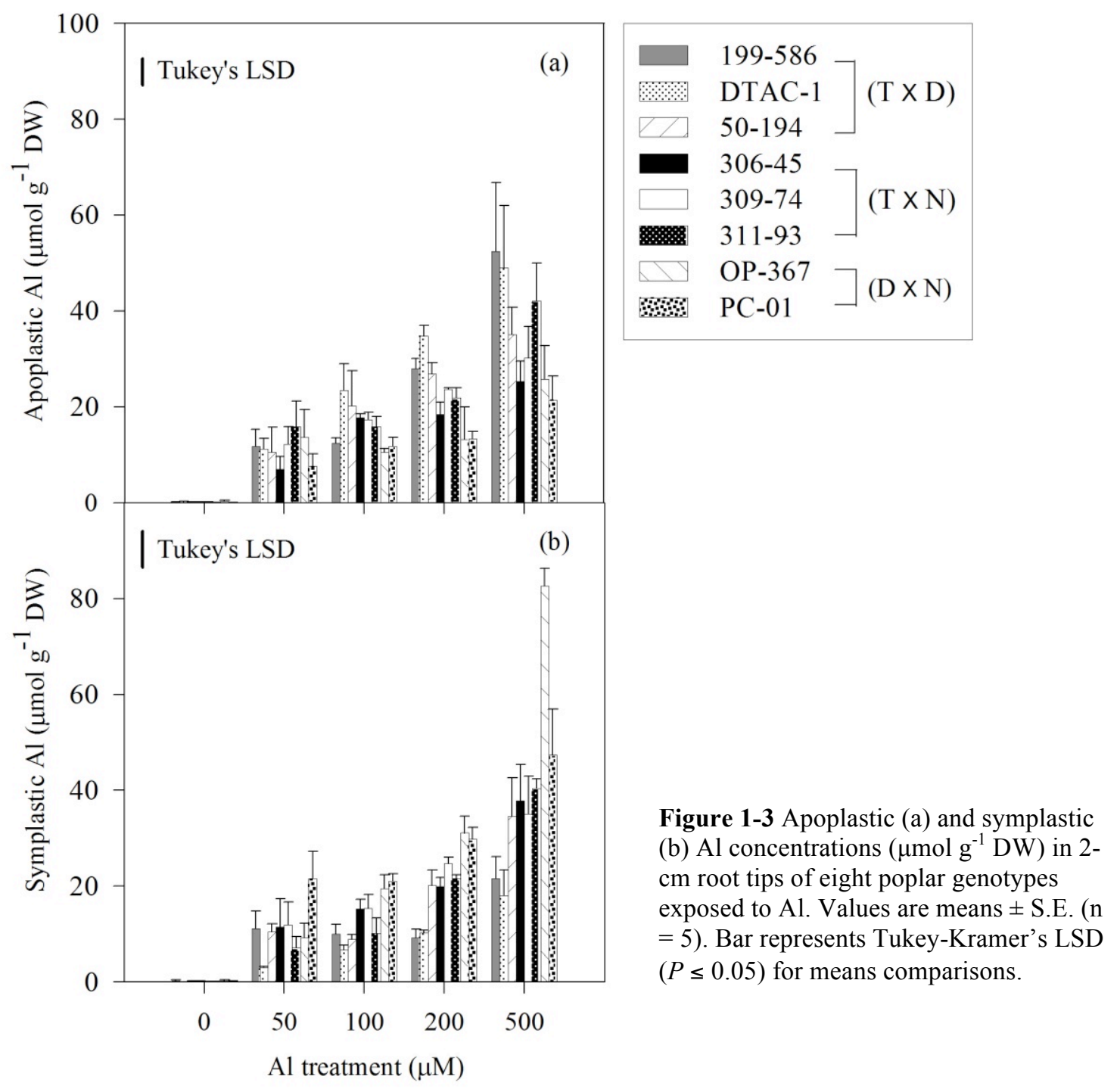

\subsubsection{Callose content}

The $\mathrm{Al}$ resistance of poplar hybrid genotypes was reflected in differential Al-induced callose accumulation (Fig. 1-4a). Callose accumulation increased with increasing Al 
concentration in the nutrient solution and $\mathrm{Al}$ exposure differentially induced callose formation up to 10-fold in comparison to controls among the genotypes (Fig. 1-4a and Table A.1). The Alresistant $\mathrm{T} \times \mathrm{D}$ hybrid genotypes 199-586 and DTAC-1 exhibited less callose accumulation than the Al-sensitive $\mathrm{D} \times \mathrm{N}$ hybrid genotypes $\mathrm{OP}-367$ and $\mathrm{PC}-01$ across the full range of $\mathrm{Al}$ exposure (Fig. 1-4a). The intermediate sensitivity of the $\mathrm{T} \times \mathrm{N}$ hybrid genotypes 306-45, 309-74 and 31193 and the $\mathrm{T} \times \mathrm{D}$ genotype 50-194 was reflected by the intermediate callose accumulation in these genotypes (Fig. 1-4a). Consistent differences in callose accumulation among hybrid crosses to Al exposure were also evident (Table A.2).

\subsubsection{Pectin content}

Pectin in the cell wall (CW) increased with exposure to $\mathrm{Al}$, especially at higher $\mathrm{Al}$ concentrations and the extent of this increase was genotype specific (Fig. 1-4b and Table A.1). The Al-resistant $\mathrm{T} \times \mathrm{D}$ hybrid genotypes 199-586 and DTAC-1 produced significantly less pectin than the Al-sensitive $\mathrm{D} \times \mathrm{N}$ hybrid genotypes OP-367 and PC-01; an intermediate response was observed in the $\mathrm{T} \times \mathrm{N}$ hybrid genotypes 306-45, 309-74 and 311-93 and the $\mathrm{T} \times \mathrm{D}$ genotype 50-194 (Fig. 1-4b). Consistent differences in root pectin concentration among hybrid crosses in response to $\mathrm{Al}$ exposure were also evident, supporting the patterns established by the genotypes (Table A.2). 


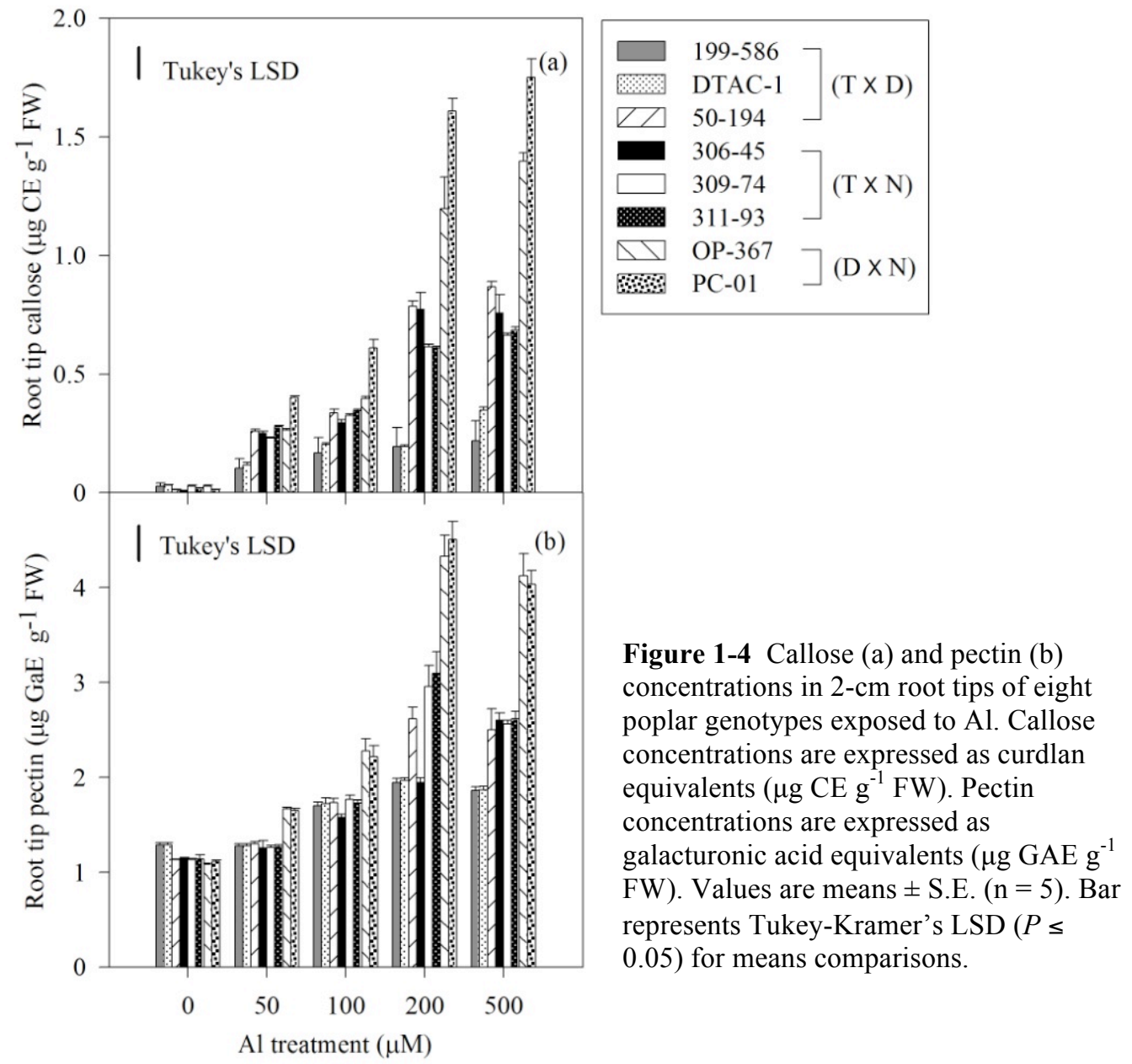

\subsubsection{Tissue organic acid content}

Exposure of the eight poplar genotypes to $\mathrm{Al}$ resulted in the increased production and accumulation of certain OAs in root tips (Fig. 1-5). Organic acid concentrations were below the level of detection in roots not exposed at Al. However, the concentrations of citrate, malate, succinate and formate significantly increased in root tips over the 50-500 $\mu \mathrm{M}$ Al treatment range (Fig. 1-5).

Citrate accumulation exhibited significant genotype- and hybrid-dependent responses to Al (Fig. 1-5 and Tables A.1, A.2). Roots of the Al-sensitive $\mathrm{D} \times \mathrm{N}$ hybrid genotypes OP-367 and PC-01 accumulated three-fold higher citrate concentrations compared to the Al-resistant $\mathrm{T} \times \mathrm{D}$ 
hybrid genotypes 199-586 and DTAC-1. The intermediately sensitive $\mathrm{T} \times \mathrm{N}$ genotypes accumulated citrate to concentrations that were intermediate between those of the $D \times N$ and $T \times D$ genotypes (Fig. 1-5). Malate accumulation in response to Al varied by genotype (Fig. 1-5 and Table A.1). Roots of the Al sensitive genotype OP-367 accumulated the highest malate concentration of all genotypes, ranging between 2- and 11-fold higher than other genotypes at $500 \mu \mathrm{M} \mathrm{Al}$ (Fig. 1-5). Consistent responses of genotypes within hybrid crosses were not evident for the malate response (Table A.2). Similarly to malate, succinate accumulation varied by genotype (Table A.1) without consistent hybrid cross responses (Table A.2). In contrast to malate, the Al-sensitive genotype PC-01 accumulated the highest succinate in root tips, ranging between 2- and 12-fold higher than other genotypes at $500 \mu \mathrm{M} \mathrm{Al}$ (Fig. 1-5). Formate was the least abundant $\mathrm{OA}$ in all the genotypes and its accumulation was the most responsive to $\mathrm{Al}$ in $\mathrm{D} \times \mathrm{N}$ genotypes (Fig.1-5 and Tables A.1, A.2).

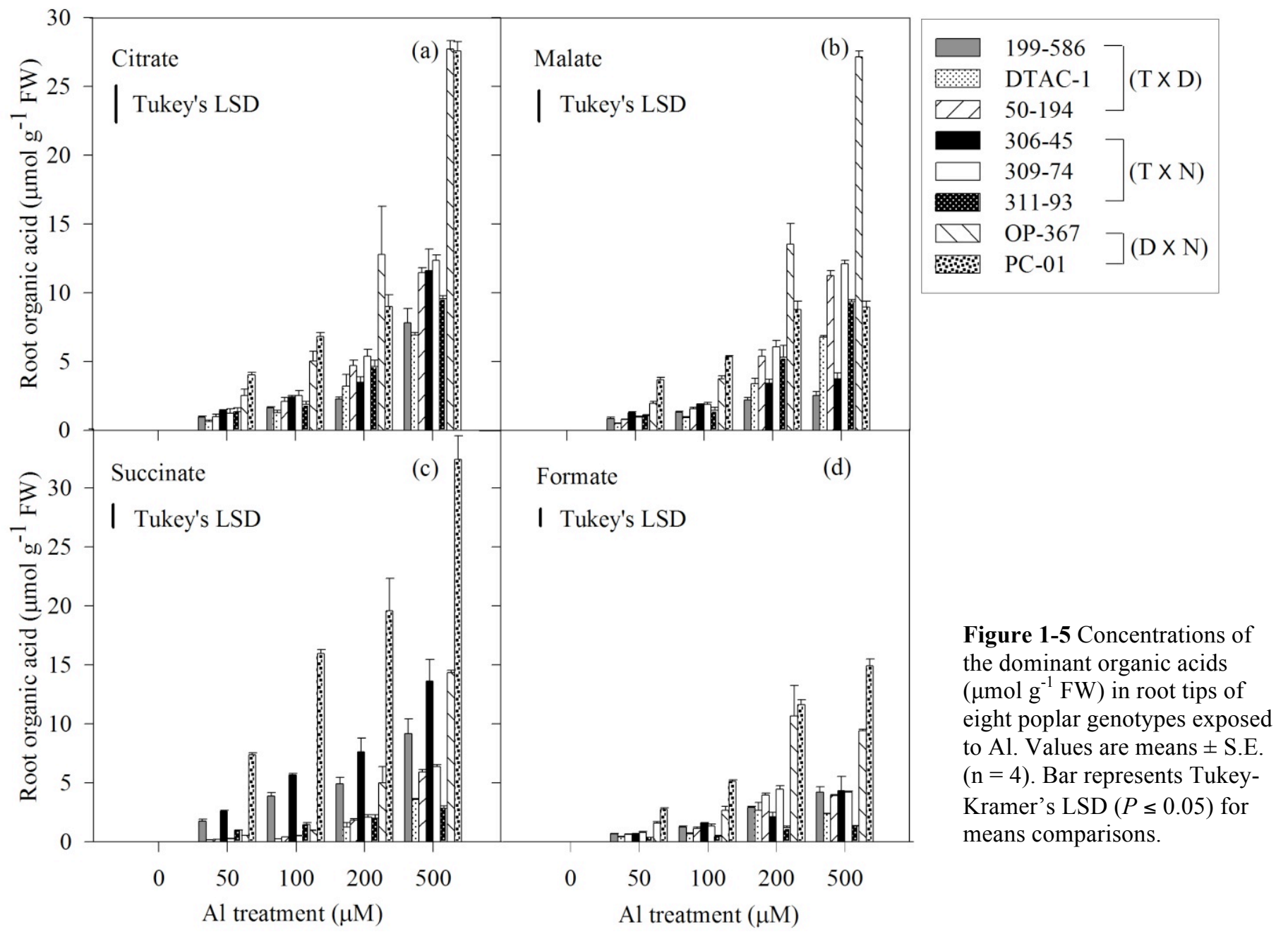




\subsubsection{Relationships between root tolerance index, callose, pectin and Al fractions}

Sensitivity to $\mathrm{Al}$ as measured by root $\mathrm{TI}$ at $200 \mu \mathrm{M}$ Al was highly correlated with root callose accumulation in poplar genotypes $\left(\mathrm{R}^{2}=0.781\right)($ Fig. 1-6a). The Al-sensitive $\mathrm{D} \times \mathrm{N}$ hybrid genotypes OP-367 and PC-01 had the lowest tolerance index and the highest level of callose accumulation. The opposite was observed in the Al-resistant $\mathrm{T} \times \mathrm{D}$ hybrid genotypes 199-586 and DTAC-1. Genotypes with intermediate root TIs exhibited intermediate root callose production (Fig. 1-6a). Root tolerance index was also negatively correlated with root pectin concentration $\left(\mathrm{R}^{2}=0.593\right)$ (Fig. 1-6b), although the $\mathrm{T} \times \mathrm{N}$ genotype 306-45 exhibited an intermediate root tolerance index and low pectin concentrations in root tips. 


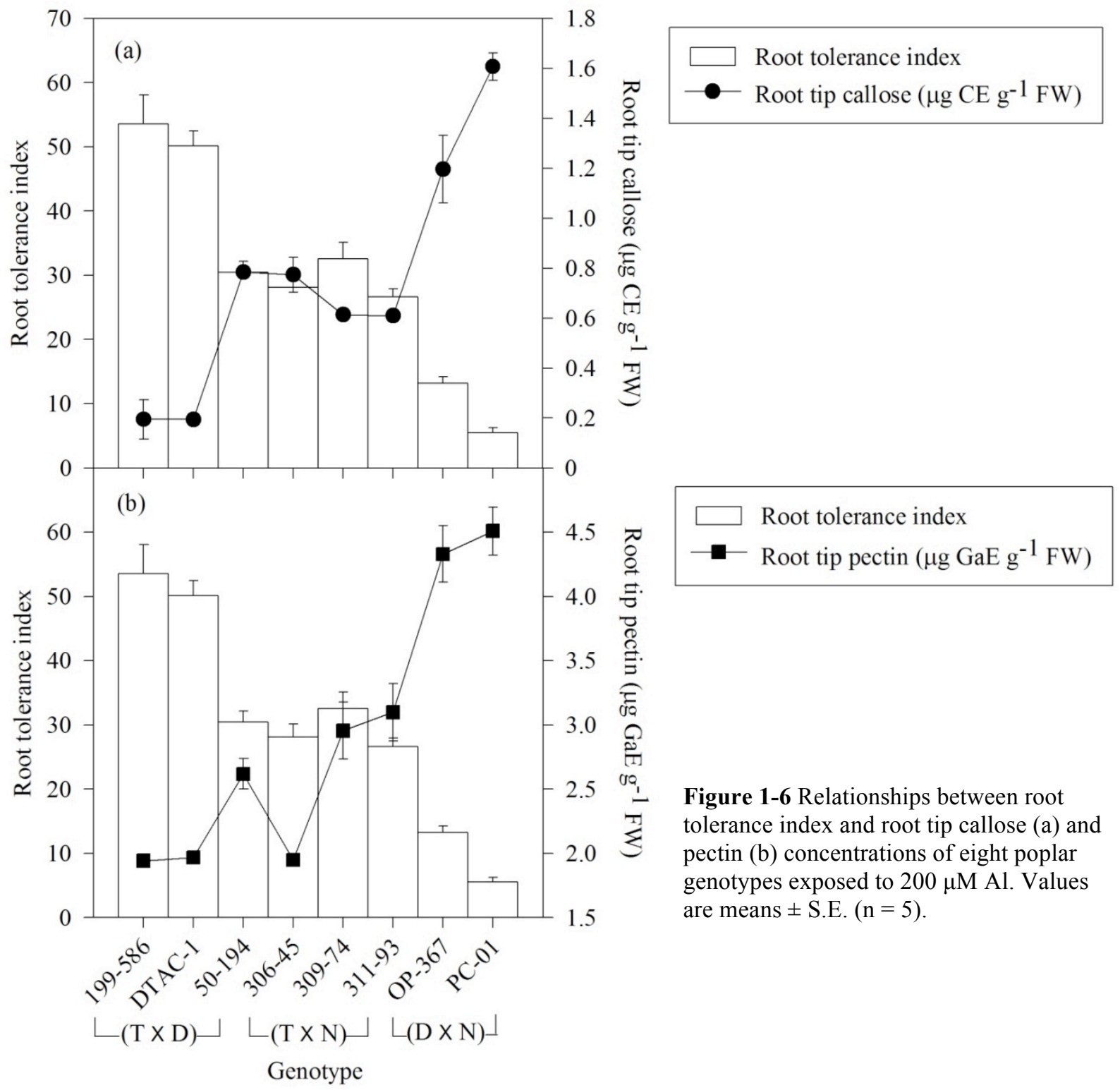

Root apoplastic and symplastic Al concentrations were highly correlated with root tolerance index (Fig. 1-7, Table A.3). These correlations were strongest at the $200 \mu \mathrm{M} \mathrm{Al}$ treatment (Table A.3). Root tolerance index was positively correlated with apoplastic root tip Al (Fig. 1-7a) and negatively correlated with symplastic Al (Fig. 7b). There was no association between total root $\mathrm{Al}$ concentration and root tolerance index (Fig. 1-7c). 

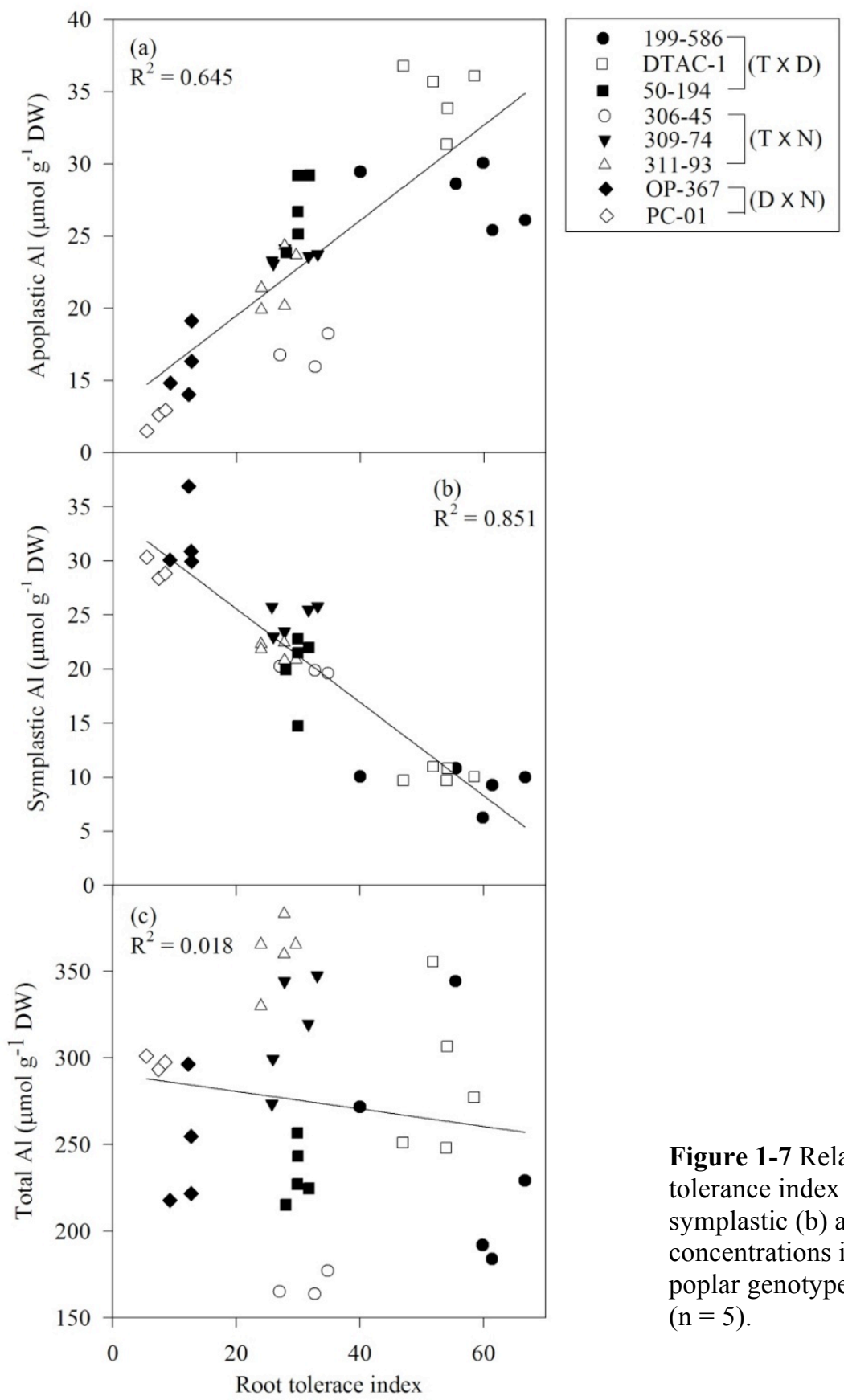

Figure 1-7 Relationships between root tolerance index and apoplastic (a), symplastic (b) and total (b) Al concentrations in root tissue of eight poplar genotypes exposed to $200 \mu \mathrm{M} \mathrm{Al}$ $(\mathrm{n}=5)$.

Root apoplastic and symplastic Al concentrations were also highly correlated with the accumulation of both callose and pectin in poplar root tips. Apoplastic Al exhibited a negative correlation with callose and pectin (Fig. 1-8a and1-9a), with the Al-resistant T $\times$ D hybrid genotypes 199-586 and DTAC-1 exhibiting the highest apoplastic Al content with the lowest callose and pectin concentrations. The Al-sensitive $\mathrm{D} \times \mathrm{N}$ hybrid genotypes OP-367 and PC-01 
had the lowest apoplastic $\mathrm{Al}$ and highest callose and pectin concentrations (Fig. 1-8a and 1-9a). The opposite was true for symplastic $\mathrm{Al}$ accumulation and callose or pectin concentrations (Fig. $1-8 \mathrm{~b}$ and 1-9b). Total root $\mathrm{Al}$ concentrations did not correlate with either callose or pectin concentrations in hybrid poplar root tips (Fig. 1-8c and 1-9c).

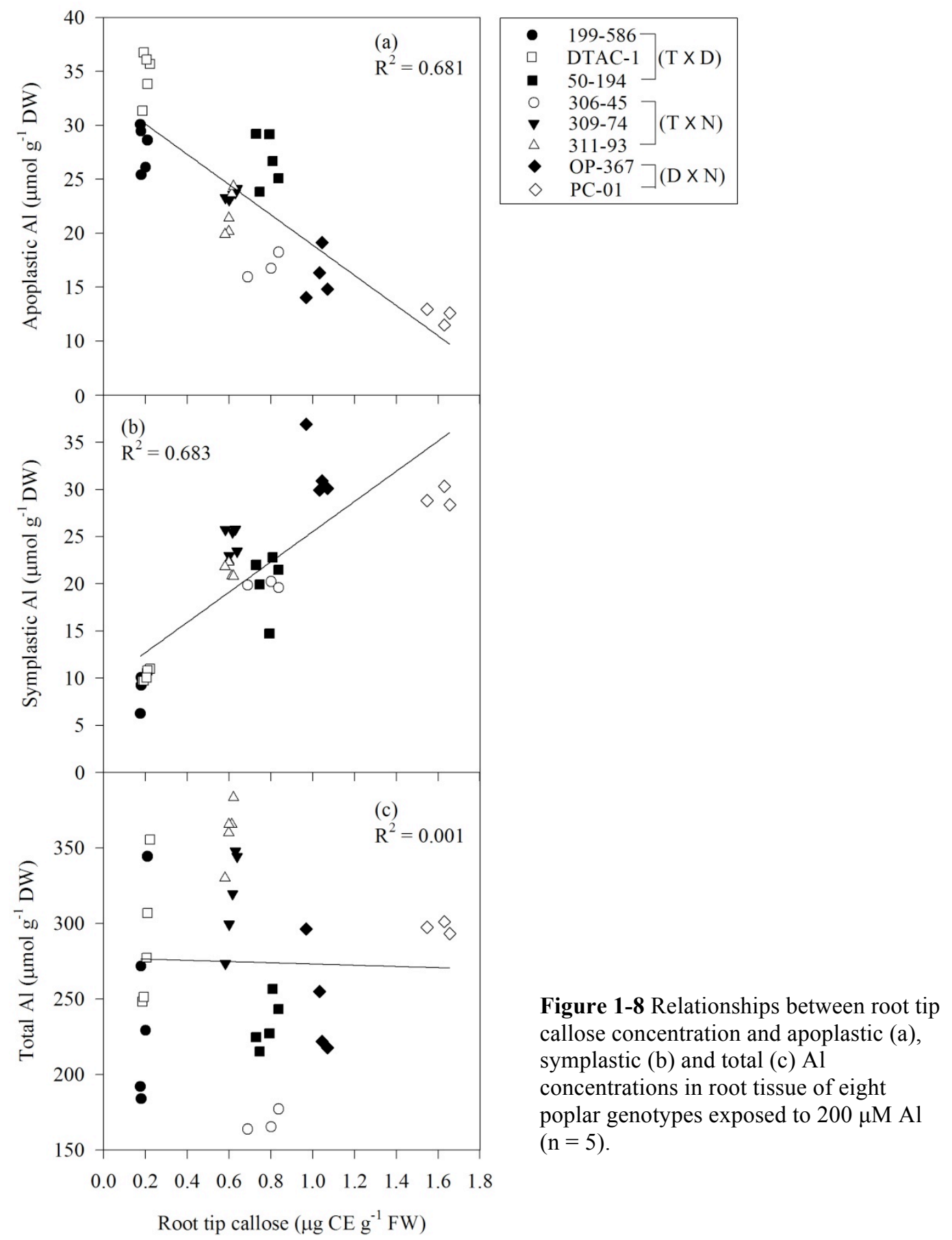




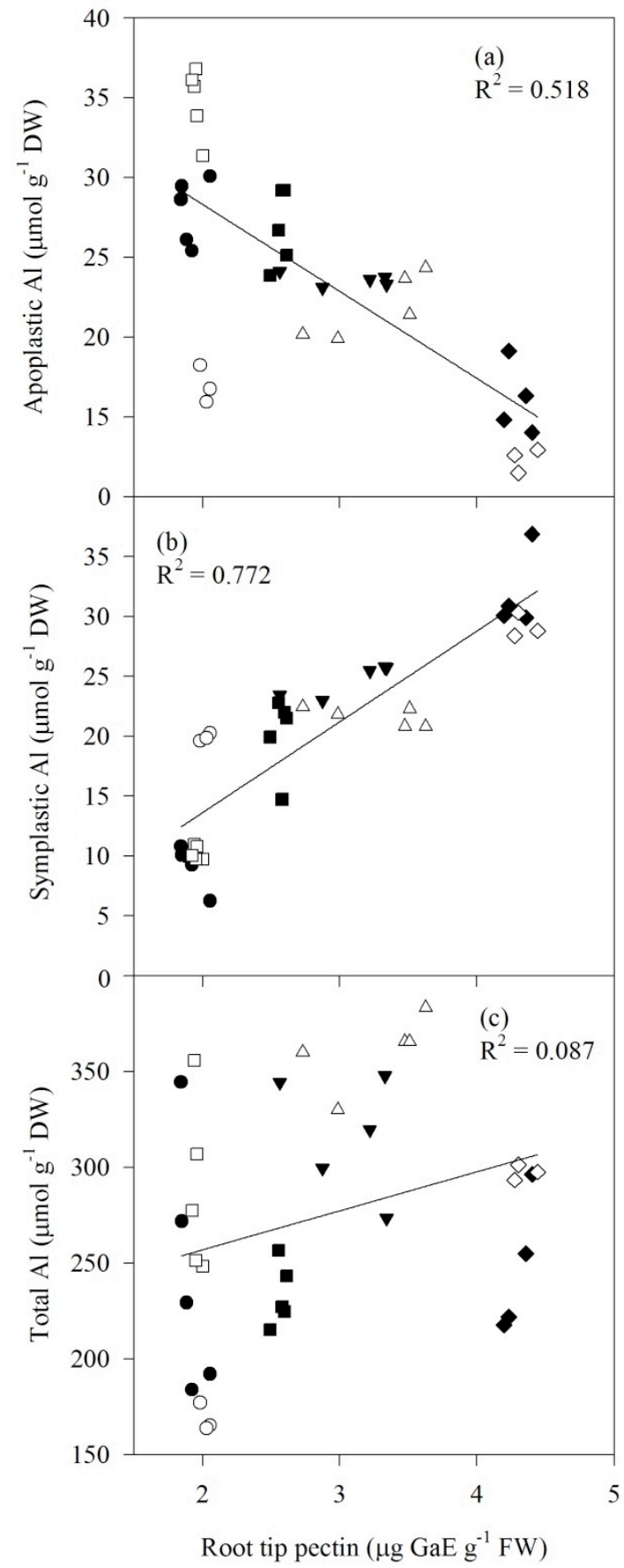

\begin{tabular}{|c|c|}
\hline & $199-586-$ \\
\hline$\square$ & DTAC-1 $(\mathrm{T} \times \mathrm{D})$ \\
\hline घ & $50-194-$ \\
\hline 0 & $306-45$ \\
\hline$\nabla$ & $309-74$ \\
\hline$\Delta$ & $311-93-$ \\
\hline$\bullet$ & OP-367 $\sqsupset(\mathrm{D} \times \mathrm{N})$ \\
\hline$\diamond$ & PC-01 \\
\hline
\end{tabular}

Figure 1-9 Relationships between root tip pectin concentration and apoplastic (a), symplastic (b) and total (c) Al concentrations in root tissue of eight poplar genotypes exposed to $200 \mu \mathrm{M} \mathrm{Al}$ $(\mathrm{n}=5)$.

Root apoplastic and symplastic Al concentrations were correlated with root tip citrate concentrations in hybrid poplar genotypes. Apoplastic Al exhibited a negative correlation with root tip citrate concentration, with the Al-resistant $\mathrm{T} \times \mathrm{D}$ hybrid genotypes 199-586 and DTAC-1 exhibiting the highest apoplastic Al content and the lowest citrate concentration and the Al-sensitive $\mathrm{D} \times \mathrm{N}$ hybrids exhibiting the highest citrate concentration coupled with lower levels of apoplastic Al (Fig. 1-10a). Conversely, high symplastic Al concentrations were associated 
with elevated root tip citrate accumulation (Fig. 1-10b). Total root Al shows no clear relationship with root tip citrate accumulation (Fig. 1-10c).

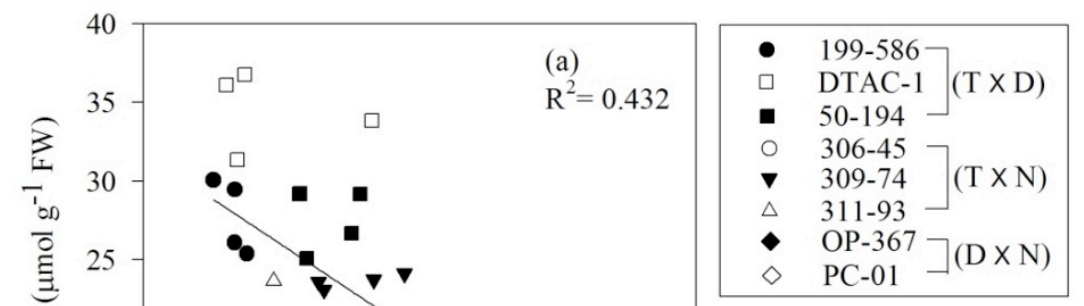

Figure 1-10 Relationships between root tip citrate concentration and apoplastic (a), symplastic (b) and total (c) Al concentrations in root tissue of eight poplar genotypes exposed to $200 \mu \mathrm{M} \mathrm{Al}(\mathrm{n}=4)$.

150

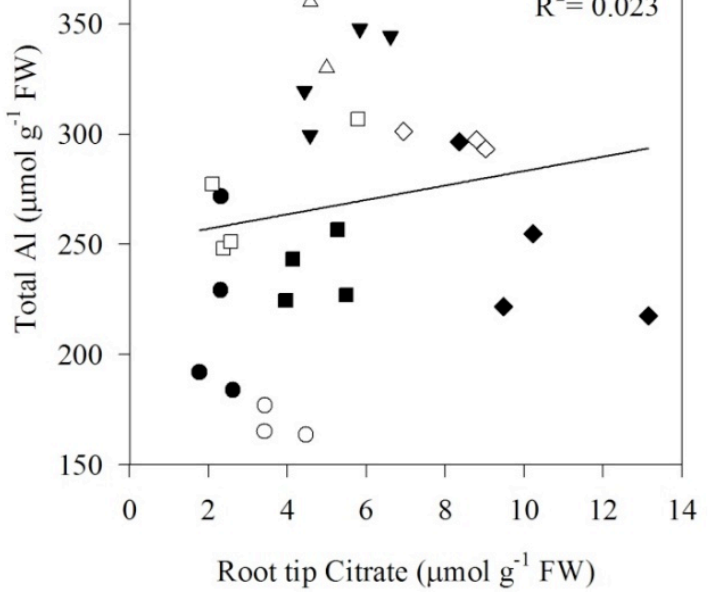

(c)

(c)
$\mathrm{R}^{2}=0.023$

In addition to the relationships with citrate, apoplastic Al concentration was also correlated with root tip succinate accumulation $\left(\mathrm{R}^{2}=0.455\right)$, but not with malate or formate concentration (data not presented). Symplastic Al concentration was correlated with malate 
accumulation in root tissue $\left(\mathrm{R}^{2}=0.626\right)$ (data not presented), whereas the associations with root tip succinate and formate concentrations were not significant (data not presented). Total root Al was not correlated with the concentrations of any of the other detected organic acids (data not presented).

\subsubsection{DISCUSSION}

\subsubsection{Biomass reduction in response to Al}

Reduction in root biomass is often the best indicator of Al sensitivity, reflecting Alrelated disruptions of root cell physiological processes and subsequent growth (Larsen et al. 1997; Ma et al., 1999; Kochian et al., 2005; Hiradate et al., 2007; Klugh and Cumming, 2007; Rangel et al., 2009). In the current study, poplar genotypes and hybrid crosses exhibited distinct differences in $\mathrm{Al}$ sensitivity based on root growth (Fig. $1 \mathrm{~b}$ and Tables A.1, A.2). The T×D hybrids were, in general, most resistant, the $\mathrm{T} \times \mathrm{N}$ moderate and the $\mathrm{D} \times \mathrm{N}$ most sensitive to $\mathrm{Al}$ exposure. The exception was the $\mathrm{T} \times \mathrm{D}$ hybrid genotype 50-194, which grouped, in many respects, with the $\mathrm{T} \times \mathrm{N}$ hybrids (Fig. 6). Although the number of genotypes used in the current study was relatively limited due to the intensive focus on biochemical markers, the clear genotypic response clusterings suggest that the genetic traits underlying Al resistance/sensitivity may be associated with particular genera, particularly the $P$. trichocarpa lineage. The observed variation in $\mathrm{Al}$ resistance of poplar genotypes corroborates an earlier study carried out on 22 poplar hybrids (Steiner et al. 1984). Although there were additional species crosses in this latter study, $\mathrm{T} \times \mathrm{D}$ hybrids were the most resistant (root length) followed by $\mathrm{T} \times \mathrm{N}$ or $\mathrm{D} \times \mathrm{N}$ hybrid poplar genotypes when exposed to $111 \mu \mathrm{M} \mathrm{Al}$.

Higher external Al concentrations $(\geq 200 \mu \mathrm{M})$ elicited the most distinct partitioning of poplar hybrid crosses into tolerant and sensitive categories with respect to reductions in root biomass, although $\mathrm{Al}$ inhibited root growth in all genotypes at as little as $50 \mu \mathrm{M} \mathrm{Al}$ (Fig. 1b). This suggests that dose response studies are essential in order to explore thresholds for differentiating genotype differences in Al resistance and sensitivity (Barceló and Poschenrieder, 2002; Tahara et al., 2005). In contrast to many previous studies, our results also suggest the importance of shoot growth in Al sensitivity (Fig. 1a). Root:shoot ratios increased significantly across the Al exposure gradient and genotypes varied significantly in these responses (Table 
A.1). However, hybrid crosses as groups did not vary consistently with respect to root:shoot ratio (Table A.2). A possible explanation for reduced shoot growth in Al sensitive genotypes is Al-induced reduction of nutrient uptake by roots ( $\mathrm{Lu}$ and Sucoff, 2003; Naik et al., 2009) or the possible hyper-accumulation of $\mathrm{Al}$ in shoots of $\mathrm{Al}$ sensitive species (Nguyen et al., 2003; Klugh and Cumming, 2007).

\subsubsection{Tissue Al concentrations}

In poplar, $\mathrm{Al}$ resistant $\mathrm{T} \times \mathrm{D}$ hybrids exhibited the highest leaf total $\mathrm{Al}$ concentrations (Fig. 2a). Furthermore, shoot growth was positively correlated with leaf Al concentration across all genotypes within each $\mathrm{Al}$ treatment (data not presented), suggesting that the hyper-accumulation of $\mathrm{Al}$ is not the basis for $\mathrm{Al}$ sensitivity and reductions in shoot growth in this genus. The concentrations of $\mathrm{Al}$ in poplar leaves (as high as $16.6 \mu \mathrm{mol} \mathrm{g}{ }^{-1}$ or $448 \mu \mathrm{g} \mathrm{g}^{-1}$, Fig. 2a) are comparable to that of other species within this genus (Lu and Sucoff, 2003; Naik et al. 2009) and other woody species (Nguyen, et al. 2003; Klugh and Cumming, 2007).

Although root total Al varied among genotypes (Fig. 2b and Table A.1), there were no significant differences among hybrids (Table A.2) and no significant association between Al resistance/sensitivity and total root $\mathrm{Al}$ concentration (Fig. 7c). Concentrations of $\mathrm{Al}$ in roots were consistent with other reports for woody species (Lux and Cumming, 2001; Lu and Sucoff, 2003). While total root tissue Al concentrations are considered an indicator of Al uptake and stress (Delihaze and Ryan,1995; Kochian et al., 2005), other studies have shown that total tissue Al content may not be reflective of total biological Al exposure (Naidoo et al., 1978; Kinraide and Parker, 1989). The lack of a consistent relationship between Al accumulation in roots and Al resistance/sensitivity in the current study may be because the root is acting as a simple cation exchanger and levels measured after tissue digestion do not reflect the biological activity of $\mathrm{Al}$ within the root.

\subsubsection{Apoplastic and symplastic Al concentrations}

The $\mathrm{Al}$ extraction procedure allowed the separation of operationally defined apoplastic and symplastic $\mathrm{Al}$ fractions in roots of poplar genotypes after $\mathrm{Al}$ treatment (Nowak and 
Friend 2005). Among all the poplar genotypes, apoplastic Al was highest (48-52 $\mu \mathrm{mol} \mathrm{Al} \mathrm{g}{ }^{-1}$ DW) for Al resistant genotypes exposed to $500 \mu \mathrm{M} \mathrm{Al} \mathrm{(Fig.} \mathrm{3a)} \mathrm{and} \mathrm{apoplastic} \mathrm{Al} \mathrm{was} \mathrm{positively}$ correlated with root TI (Fig. 7a). This suggests that apoplastic Al binding may be responsible for $\mathrm{Al}$ resistance in poplar genotypes. The strong binding of $\mathrm{Al}$ in the apoplastic region of the root has been suggested to represent a detoxification system in wheat, pine and bean genotypes (Tice et al., 1992; Nowak and Friend, 2005; Rangel et al., 2009).

Across all Al treatments, approximately $40 \%$ of the fractionated $\mathrm{Al}$ in root tips of poplar remained following the $0.25 \mathrm{mM}$ citrate wash, suggesting that this fraction was retained in a compartment inaccessible to the citrate rinse, ascribed to be the root symplast by Nowak and Friend (2005). Symplastic Al was greatest (47-82 $\left.\mu \mathrm{mol} \mathrm{Al} \mathrm{g}{ }^{-1} \mathrm{DW}\right)$ for Al sensitive poplar genotypes exposed to $500 \mu \mathrm{M} \mathrm{Al}$ (Fig. 3b). Across all genotypes, root growth was negatively correlated with root symplastic Al accumulation (Fig. 7b), which suggests that the uptake of Al into the symplasm may underlie Al induced stress leading to toxicity in poplar genotypes. The accumulation of $\mathrm{Al}$ in the symplast will lead to distinct perturbations of cell metabolism, including cell membrane potentials and accompanying transport activity, calcium homeostasis, and oxidative stress (Miyasaka et al., 1989; Huang et al., 1992; Olivetti et al., 1995; Osawa and Kojima, 2006; Vanguelova et al., 2007; Naik et al. 2009). This pattern supports our first hypothesis that excluding Al from the symplast underlies Al resistance in poplar. In comparison to other species, apoplastic and symplastic Al were similar to values reported for wheat roots (Tice et al., 1992) and pine roots (Nowak and Friend 2005). In loblolly and slash pine roots, Nowak and Friend (2005) noted essentially equal distribution between apoplastic and symplastic pools within the ranges noted here for poplar. Total Al concentrations reported in Fig. 2 and Fig. 7-10 represent values derived from total root system digests, which likely vary in binding properties compared to $1-\mathrm{cm}$ root tips used for apoplastic and symplastic Al determinations.

\subsubsection{Callose accumulation in root tips}

In the poplar hybrid genotypes investigated in this study, increasing external $\mathrm{Al}$ concentrations induced the accumulation of callose in root tips (Fig. 4a). Although the number of the genotypes studied was limited, Al-induced callose accumulation was strongly correlated with Al sensitivity based on root biomass reduction (Fig. 6a). Callose accumulation was greater 
in $\mathrm{Al}$ sensitive $\mathrm{D} \times \mathrm{N}$ hybrid genotypes as compared to $\mathrm{Al}$ tolerant $\mathrm{T} \times \mathrm{D}$ hybrid genotypes (Fig. $4 \mathrm{a}$ and Fig. 6a). Furthermore, elevated callose production was negatively correlated with apoplastic Al accumulation (Fig. 8a) and positively correlated with symplastic Al accumulation (Fig. 8b) in poplar genotypes. These results suggest that Al-induced callose formation can be used as an indicator of Al sensitivity among the poplar hybrids and that production was stimulated by the uptake of Al into the symplast.

Similar correlations between callose formation in root tips and sensitivity to Al have been found in cowpea (Wissemeier et al., 1992), maize cultivars (Llugany et al., 1994; Horst et al., 1997) and Melaleuca and Eucalyptus species (Tahara et al., 2005). However, callose production may or may not be associated with accumulation of Al in the root. Hirano et al. (2006) noted that fine root callose was positively correlated with fine root total $\mathrm{Al}$ in chestnut seedlings exposed to Al for 28 d, a pattern supported by Schmohl and Horst (2000) in maize. However, Horst et al. (1997) found no such correlation in maize and no correlation to total Al in poplar was found in the current study (Fig. 8c). The current study is the first to document the relationship between Al-induced callose production and specific root Al fractions, specifically the uptake of $\mathrm{Al}$ into the root tip symplast.

\subsubsection{Pectin concentration in root tips}

Aluminum treatment increased the pectin content in all genotypes (Fig. 4b). This is the first report, to our knowledge, revealing the involvement of $\mathrm{CW}$ pectin in forest tree response to Al. Furthermore, this finding suggests that root pectin concentration is not simply a static physiological characteristic, but changes in response to the edaphic environment (Guglielmino et al., 1997; Nowak and Friend, 2005). Pectin concentrations were similar among poplar genotypes when not exposed to $\mathrm{Al}$ (Fig. 4b). When exposed to $\mathrm{Al}$, pectin concentration increased to a greater extent in Al-sensitive $\mathrm{D} \times \mathrm{N}$ hybrid genotypes than in Al-tolerant $\mathrm{T} \times \mathrm{D}$ hybrid genotypes (Fig. 4b and Fig. 6b). The exception was the $\mathrm{T} \times \mathrm{N}$ genotype 306-45, which did not exhibit an elevated pectin response at $200 \mu \mathrm{M} \mathrm{Al}$, but did so at $500 \mu \mathrm{M} \mathrm{Al}$ (Fig. 4b). The differences in pectin content of root apices associated with $\mathrm{Al}$ resistance and sensitivity in poplar hybrids may reflect a fundamental change in cell wall biochemistry resulting from altered cell homeostasis under $\mathrm{Al}$ exposure. Similar increases in $\mathrm{CW}$ pectin content upon exposure to $\mathrm{Al}$ have been 
reported in maize root tips (Schmol and Horst, 2000; Eticha et al., 2005), and common bean roots (Yang et al., 2010).

The differences in pectin content of root apices associated with Al resistance and sensitivity in poplar hybrids were also correlated with root tip Al fractions. Sensitive genotypes exhibiting high pectin concentrations had low apoplastic and high symplastic Al concentrations (Fig. 9a and 9b). This pattern is contrary to the concept that pectin is negatively charged and genotypes with elevated pectin should adsorb considerably more cationic Al into the $\mathrm{CW}$, which has been reported by some to be the primary site of Al toxicity (Horst et al., 2010; Yang et al., 2011). However, the degree of methylation of pectin defines the negativity of the CW (Guglielmino et al., 1997) and the Al content of the CW may be best related to CW pectin methylation. The current study did not assess the methylation of pectin in hybrid poplar genotypes. This may prove to be a useful tool to further understand the mechanisms by which pectin can affect the amount of Al bound to the cell wall (Wojciechowski and Fall, 1996; Schmohl and Horst, 2000; Eticha et al., 2005).

As an additional explanation for this negative association between $\mathrm{CW}$ pectin and apoplastic $\mathrm{Al}$ in poplar, it may be that the $\mathrm{Al}$ fractionation method used for poplar roots operationally misidentified $\mathrm{Al}$ fractions in $\mathrm{Al}$ sensitive poplar genotypes. For example, Al may bind more tightly in root cell walls with elevated pectin contents and not be removed by the extract used to measure the "apoplastic" Al fraction. This would lead to an apparent depression of apoplastic Al and an increase in the putative "symplastic" fraction, as noted for the Alsensitive $\mathrm{D} \times \mathrm{N}$ hybrid poplar genotypes in the current study. Consistent with this, Yang et al. (2010) also noted that environmental stress altered cell wall biochemistry and Al binding and toxicity in Phaseolus vulgaris. Thus, the role of apoplastic biochemical changes induced by Al and the subsequent influence on Al binding within the apoplast will require further investigation in order to ascribe Al sensitivity to specific Al fractions in poplar.

\subsubsection{Root tip organic acid concentrations}

In the current study, the accumulation of organic acids in root tips was stimulated by exposure to $\mathrm{Al}$ (Fig. 5). Concentrations of organic acids in root tips were below the level of detection in plants not exposed to $\mathrm{Al}$, but increased upon exposure to Al. Depending on 
genotype, citrate, malate, succinate and formate concentrations increased up to $\sim 30 \mu \mathrm{mol} \mathrm{g}^{-1} \mathrm{FW}$ (Fig. 5).

Of the organic acids detected, citrate and formate exhibited responses that were consistent in direction and magnitude among the clones of the same hybrid cross (Table A.1 and A.2). The $\mathrm{Al}$ sensitive $\mathrm{D} \times \mathrm{N}$ hybrid genotypes accumulated almost twice the concentrations of citrate and formate compared to other genotypes across all Al treatments (Fig. 5). Malate and succinate increased in the root tips in response to $\mathrm{Al}$ in some genotypes (Fig. 5), but these changes were not consistently related to Al resistance or sensitivity (Fig. A.1).

Many studies have shown citrate to play a major role in the chelation of Al (Tolrá et al., 2005; Osawa and Kojima, 2006; Qin et al., 2007). While other studies have suggested citrate as a possible internal detoxification mechanism (López-Bució et al., 2000; Ma et al., 2001; Kochian et al., 2005), the current study shows that higher levels of citrate and other organic acids within root tips were not associated with resistance to $\mathrm{Al}$ in poplar genotypes and, indeed, organic acid accumulation was most pronounced in Al sensitive genotypes (Fig. A.1). These findings suggest that the accumulation of organic acids in root tissues of poplar may be a response to elevated Al accumulation in the symplast (Fig. 10b), but this response is not sufficient to promote resistance to $\mathrm{Al}$ in the rhizosphere (Fig. A.1). This finding does not support our second hypothesis that internal chelation of $\mathrm{Al}$ by organic acids plays a role in $\mathrm{Al}$ resistance in poplar.

Exudation of organic acids, which was not measured in the current study, may represent a mechanism of Al resistance in poplar (Jones, 1998). Naik et al. (2009) noted that exposure to Al induced 40- to 100-fold increases in total carbon exudation by roots of $P$. tremuloides and $P$. trichocarpa, respectively, and that citrate, malate, and oxalate were significant contributors to exudation. Exposure to $\mathrm{Al}, \mathrm{Cu}$ or $\mathrm{Zn}$ also induced the exudation of organic acids by the roots of P. tremula, with Al specifically stimulating the release of oxalate and citrate (Qin et al., 2007). Other factors, such as stable membrane transport systems and inorganic anion exudation, may also function in $\mathrm{Al}$ resistance (Kochian et al., 2005).

\subsubsection{Physiology of Al tolerance in Populus genotypes}

Increased levels of symplastic Al was most closely related to Al toxicity symptoms such as increased callose accumulation and decreased biomass (Figure 1-7 and 1-8 ). The current 
study illustrates that $\mathrm{Al}$ sensitive genotypes exposed to $\mathrm{Al}$ for extended time periods experience increased accumulation of organic acids such as citrate, increased callose and pectin accumulation in root tips and decreases in biomass (Figure 1-11). Al tolerant genotypes exhibited lower tissue organic acids coupled with higher levels of apoplastic Al (Figure 1-10). These findings suggest that organic acid exudation my play a role in $\mathrm{Al}$ tolerance in Populus genotypes (Figure 1-12).

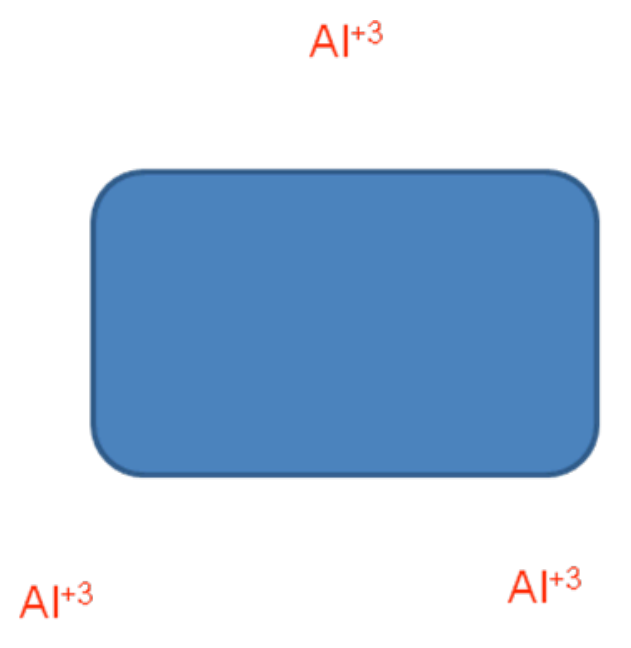

Al Tolerant

\section{$\mathrm{Al}^{+3}$}

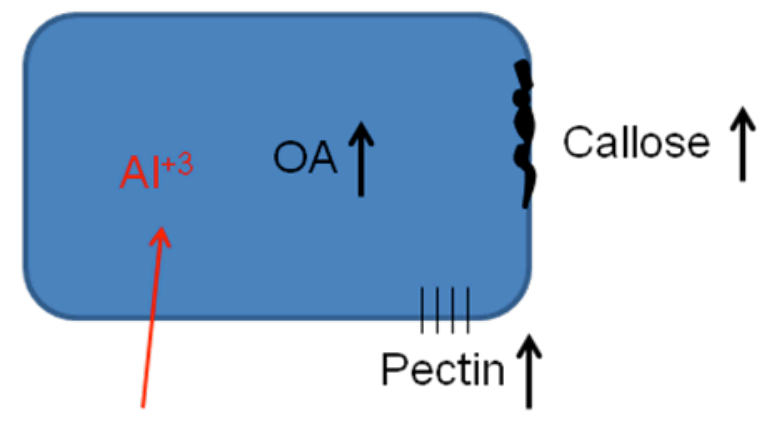

$\mathrm{Al}^{+3}$
$\mathrm{Al}^{+3}$

Al Susceptible

Figure 1-11 Differences in cell physiology between Al tolerant and sensitve Populus genotypes exposed to Al

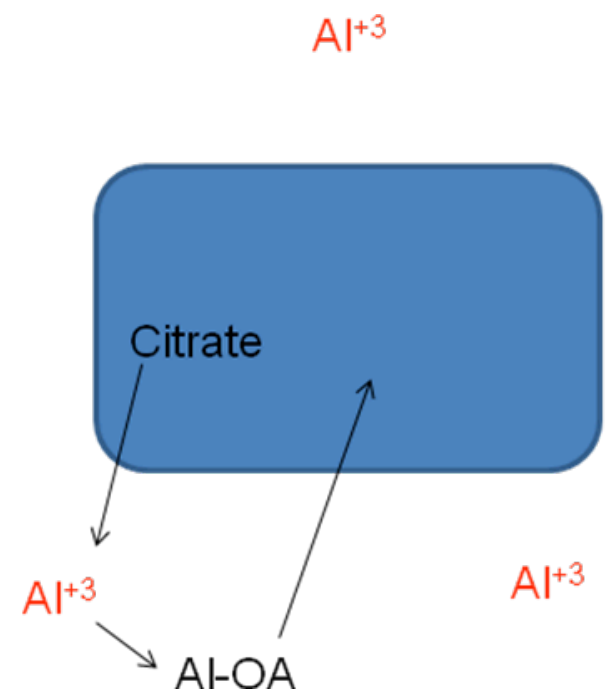

Al Tolerant

\section{$\mathrm{Al}^{+3}$}

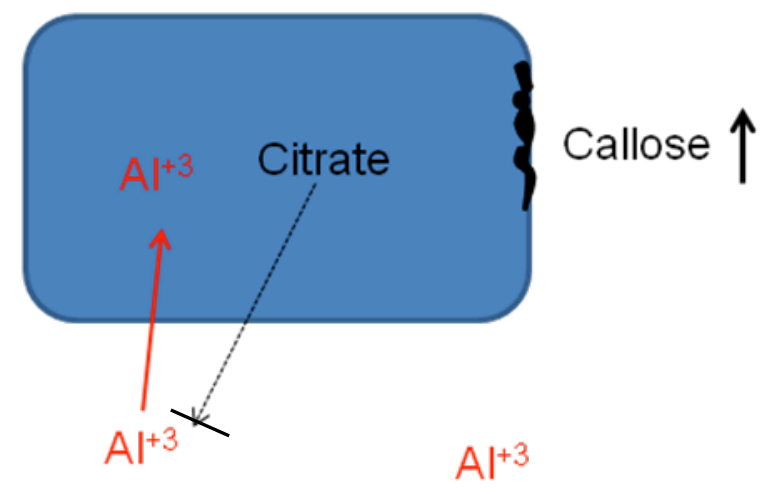

Al Susceptible

Figure 1-12 Diagram of citrate exudation as an Al tolerance mechanism in Populus genotypes 


\subsection{Examining the Role of Root Exudation in Aluminum Tolerance of Populus Genotypes}

\subsubsection{INTRODUCTION}

Soil acidification and aluminum toxicity are major factors limiting plant growth and ecosystem productivity worldwide (Baringnaga, 1997). Elevated soil Al may result from natural soil weathering processes and may increase with anthropogenic inputs of nitrogen into soil (Aber et al., 1998; Halvin et al., 1999). Surface mining may also increase soil acidity and Al availability due to the exposure of acidic overburdens to weathering processes (Karathanasis et al., 1998). In agriculture, a common practice used to alleviate soil Al toxicity is the application of lime and phosphorous to acidic soils. However, this practice is impractical as a long-term strategy for forest plantation management. The identification of Al resistant tree genotypes and the underlying mechanisms of adaptation to $\mathrm{Al}$ in the environment is a more practical strategy for the sustainable production of wood on acidic soils.

The toxicity of $\mathrm{Al}$ to plants results from the strong affinity of the $\mathrm{Al}^{3+}$ ion for biological ligands. The primary site of Al toxicity appears to be the root tip, which exhibits rapid and dramatic alterations in structure and growth cessation upon Al exposure (Delhaize et al., 1993 a, b; Ma et al., 2001; Rangel et al., 2009). These rapid changes result from changes in membrane fluidity, cell polarity, ion flux, and changes in signaling pathways that occur when Al binds to biological molecules (Kochian et al., 2005; Tahara et al., 2005). This binding of Al to cell walls, plasma membranes, and symplastic metabolites detrimentally affects root physiology and leads to long-term reductions in growth and water and nutrient uptake by plant roots (Miyasaka et al., 1989; Cumming et al., 1992; Matsumoto, 2000; Heim et al., 2001; Hiradate et al., 2007; Naik et al., 2009).

Aluminum-induced changes in cell physiology may serve as signals for the induction of adaptive responses (Cumming and Tomsett, 1992) or as Al-detoxification mechanisms (Nguyen et al., 2003; Silva et al., 2004; Kochian et al., 2005). The induction of callose, a 1,5 $\beta$-glucan, in roots is a good physiological marker for Al stress (Horst et al., 1997; Wissemeier et al., 1998; Hirano et al., 2004; Hirano and Brunner, 2006), and is robust enough to distinguish genotypic differences in Al sensitivity (Wissemeier et al., 1992; Zhang et al., 1994; Horst et al., 1997). Metabolic pathways, such as organic acid (OA) production, are altered upon exposure to $\mathrm{Al}$ and 
may promote external and internal chelation of Al (Naik et al., 2009). Plants may chelate Al in the rhizosphere through the exudation of OAs, such as citrate and malate (Silva et al., 2004; Qin et al., 2007). Although less studied, exudation of phenolic compounds has also been related to Al tolerance in trees (Heim et al., 2001; Nguyen et al., 2003). Aluminum may similarly be detoxified internally by the accumulation of OA-Al complexes (Watanbe and Osaki, 2002; Nguyen et al., 2003) as well as phenolic-Al complexes (Heim et al., 2001; Tolrá et al., 2009). These changes in metabolism may lead to differences in Al accumulation within the apoplastic and symplastic regions of the root and such changes in apoplastic and symplastic Al partitioning in roots may be related to Al tolerance (Tice et al., 1992; Nowak and Friend, 2005; Smith et al., 2011).

Due to their extended life span, forest trees must possess the ability to overcome a variety of abiotic and biotic factors that may detrimentally affect their growth (Brunner and Godbold, 2007). Forested ecosystems cover almost one-third of the earth's surface area, making trees, as a group, keystone ecological organisms. Trees are vital to human populations by providing resources, such as fuel, fiber, and timber, and ecological services, such as carbon and water storage (Tuskan and Walsh, 2001). Poplar (Populus spp.) has become the model genus for the investigation of forest tree responses to environmental factors. Genotypes within the genus Populus exhibit rapid growth, ease of vegetative propagation, a high degree of genetic variation and a sequenced genome (Strauss and Martin, 2004), providing the phenotypic and genetic resources for in-depth investigation of tree response to the environment. Poplars are also used extensively in plantation production (Hansen et al., 1994), and understanding genotypic variation in response to soil factors will play an important role in supporting sustainable, low-input wood and fiber production for the future.

Large genotypic differences in Al resistance exist within the genus Populus (Steiner et al., 1984; Naik et al., 2009). Genotypic variation in Al resistance in many agricultural and nonwoody species has been related to root exudation of OAs and phenols in response to Al exposure (Delhaize and Ryan, 1995; Miyasaka and Hawes, 2001; Barcelo and Poschenrieder, 2002; Silva et al., 2004), and investigating the function of such systems in Populus, a woody species with a sequenced genome and extensive genetic resources, would provide a unique opportunity to probe the genetic basis of Al resistance in a woody species. Identification of resistant genotypes and elucidating the physiological mechanisms of Al toxicity/resistance in a forest tree species may lead to the identification of Al resistant tree genotypes for wood production on acidic soils. 
In the current study, we assessed patterns of exudation in Al-resistant and Al-sensitive Populus hybrid crosses and related exudation to Al speciation in the rhizosphere, Al fractionation within root tips, and growth of these genotypes when exposed to Al. Building on previous study of these genotypes (Smith et al. 2011), our hypotheses were that the exudation of Al-chelating OAs or phenolic compounds by roots of the Al-resistant genotype DTAC-7 would detoxify Al in the rhizosphere and reduce the impacts of $\mathrm{Al}$ on roots, including the production of callose and the accumulation of $\mathrm{Al}$ in the apoplast and symplast of root cells.

\subsubsection{MATERIALS AND METHODS}

\subsubsection{Plant materials, hydroponic culture and Al treatment}

Stem cuttings were taken from one-year-old dormant hybrid poplar saplings originally started from cuttings obtained from Segal Ranch Hybrid Poplars (Grandview, WA, USA). Healthy cuttings of uniform size were taken from hybrid poplar clones representing specific crosses of Populus trichocarpa and P. deltoides (T $\times \mathrm{D}$, clone DTAC-7) or $P$. deltoides and $P$. nigra $(\mathrm{D} \times \mathrm{N}$, clone OP-367). Cuttings were approximately $15 \mathrm{~cm}$ in length and $3 \mathrm{~mm}$ in diameter with 2-4 dormant buds. These cuttings were chilled for $30 \mathrm{~d}$ at $4{ }^{\circ} \mathrm{C}$ to promote uniform bud sprouting.

The propagation system consisted of $10 \mathrm{~L}$ hydroponic culture tanks that were aerated vigorously by two air stones and aquarium pumps. Tanks were covered with aluminum foil to exclude light. Each tank contained two cuttings of each genotype, with six tanks for each Al treatment. To initiate rooting, cuttings were treated with liquid-based rooting hormone $(0.2 \%$ indole-3-butyric acid, 0.1\% 1-naphthaleneacetic acid)(Dip'n Grow, Inc., Clackamas, OR, USA). Following root initiation and bud break, excess shoots were removed to promote uniform growth of a single shoot for each rooted cutting. Clones were then supplied with a nutrient solution containing $1.0 \mathrm{mM} \mathrm{NO}_{3}, 0.4 \mathrm{mM} \mathrm{NH}_{4}, 0.5 \mathrm{mM} \mathrm{K}, 0.2 \mathrm{mM} \mathrm{Ca}, 0.05 \mathrm{mM} \mathrm{H}_{2} \mathrm{PO}_{4}, 0.1$ $\mathrm{mM} \mathrm{Mg}$ and $\mathrm{SO}_{4}, 50.5 \mu \mathrm{M} \mathrm{Cl}, 20 \mu \mathrm{M} \mathrm{Fe}, 20 \mu \mathrm{M} \mathrm{B}, 2 \mu \mathrm{M} \mathrm{Mn}$ and $\mathrm{Zn}$ and $0.5 \mu \mathrm{M} \mathrm{Cu}, \mathrm{Na}, \mathrm{Co}$ and Mo adjusted to $\mathrm{pH}$ 5.6. Plants were grown on this solution for $7 \mathrm{~d}$ with changes twice weekly until rooting was observed. The nutrient solution was then adjusted to $\mathrm{pH} 4$ for $14 \mathrm{~d}$. After this $21 \mathrm{~d}$ pretreatment period, cuttings were transferred to nutrient solutions containing 0,50 , or 200 $\mu \mathrm{M}$ Al. To prepare treatment solutions, $\mathrm{Al}$ was added with vigorous stirring from a $1 \mathrm{M} \mathrm{AlCl}_{3}$ 
stock, freshly prepared on the day of use. All solutions were adjusted to $\mathrm{pH} 4.0$ with $1 \mathrm{M} \mathrm{HCl}$. Treatment solutions were changed twice weekly.

Plants were maintained in a climate-controlled growth chamber with supplemental lighting ( $\left.400 \mu \mathrm{mol} \mathrm{m}^{-2} \mathrm{~s}^{-1}\right)$ providing a 14-h photoperiod (incandescent and fluorescent sources) and day/night temperatures of $24 / 19 \pm 2{ }^{\circ} \mathrm{C}$. Relative humidity was kept at $70 \pm 3 \%$. Cuttings were harvested after $24 \mathrm{~h}$ and $7 \mathrm{~d}$ of $\mathrm{Al}$ treatment. At harvest, cuttings were removed from culture tanks, roots were rinsed in respective treatment solutions and cuttings were transferred into individual exudate collection vessels containing $100 \mathrm{ml}$ of the respective treatment solution. Cuttings remained in exudate collection vessels for $24 \mathrm{~h}$.

\subsubsection{Exudate analysis}

After 24 hours in exudate collection vessels, plants were removed, volumes were brought back to $100 \mathrm{ml}$ with $\mathrm{d} \cdot \mathrm{H}_{2} \mathrm{O}$ and the exudate solutions were filtered through a $0.45 \mathrm{mM}$ PTBE syringe filters and stored at $-20^{\circ} \mathrm{C}$ (Cumming et al., 2001). Aliquots of $30 \mathrm{ml}$ from these exudate solutions were lypholyzed to dryness (FreezeOne6, Labonco Corporation, Kansas City, MO, USA) and reconstituted with $3 \mathrm{ml}$ Nanopure water. The resulting 10x concentrate was used for total organic carbon, organic acid and total phenol measurements.

\subsubsection{Total organic carbon (TOC) analysis}

Total organic carbon content of exudate samples was quantified using a TOC analyzer (Model ROC-V-CPH, Shimadzu Corp., Kyoto, Japan). Potassium hydrogen pthalate was used as a standard. Concentrations are expressed on a root dry weight (DW) basis as $\mu$ mol TOC g ${ }^{-1} \mathrm{DW}$ $\mathrm{d}^{-1}$.

\subsubsection{Organic acid analysis}

The concentrations of citrate, malate, succinate and formate in solution were measured using a Dionex ICS-1500 ion chromatograph with an ion suppressor and a conductivity detector 
(Dionex, Sunnyvale, CA, USA). For separation of organic acids, a Bio-Rad Aminex HPX-87H column (300 mm $\times 7.8 \mathrm{~mm}$ ID)(Bio-Rad Laboratories, Hercules, CA, USA) at $40{ }^{\circ} \mathrm{C}$ was employed with minor modification (Cumming et al., 2001; Qiu and Jin, 2002). For the separation of organic acids, the eluent was $2.3 \mathrm{mM}$ heptafluorobutyric acid at a flow rate of $0.6 \mathrm{~mL} \mathrm{~min}^{-1}$, the suppressant solution was $5 \mathrm{mM}$ tetrabutylammonium hydroxide at a flow rate of $0.6 \mathrm{~mL} \mathrm{~min}^{-1}$ and the analysis time was $20 \mathrm{~min}$. Calibration equations were determined based on peak area for each organic acid obtained for standard organic acids. Peak areas were determined using Chromeleon software (Dionex, Sunnyvale, CA, USA). Solution organic acid contents were quantified as $\mu \mathrm{mol} \mathrm{g} \mathrm{g}^{-1} \mathrm{DW} \mathrm{d} \mathrm{d}^{-1}$.

\subsubsection{Total phenolic analysis}

The concentration of total phenolics in the exudate samples was determined spectrophotometrically according to Heim et al., (2001). Solutions were analyzed at $725 \mathrm{~nm}$ with phenol used as a standard in same matrix as samples. Exuded total phenol concentrations were expressed as $\mu \mathrm{mol} \mathrm{g}^{-1} \mathrm{DW} \mathrm{d}{ }^{-1}$.

\subsubsection{Bound Al in solution}

At designated harvest times, 3-mL aliquots of nutrient solution were filtered through 0.45 $\mu \mathrm{m}$ PTBE syringe filters and stored at $-20^{\circ} \mathrm{C}$ until analysis. Bound $\mathrm{Al}$ in these samples was analyzed using a modified method from Tangen et al. (2002). Briefly, the comparison of samples directly from the hydroponic system to samples passed through a strong cation exchange (SCX) column allows the identification, by difference, of bound $\mathrm{Al}$ in solution, as bound $\mathrm{Al}$ does not adsorb to the SCX column. Samples were run through $50 \mathrm{mg}$ dry bed, $1 \mathrm{ml}$ sample volume HyperSep SPE-SCX columns (Thermo Scientific, Pittsburgh, PA, USA) using a vacuum manifold at a constant pressure of $-35 \mathrm{KPa}$. Columns were prepped and samples treated in the following order: $2 \mathrm{~mL} \mathrm{0.1 \% (v/v)} \mathrm{HNO}_{3} ; 4 \mathrm{~mL}$ acetate buffer $\mathrm{pH} 4.0 ; 2 \mathrm{~mL} 200 \mu \mathrm{M}$ citrate solution $\mathrm{pH} 4.0 ; 2 \mathrm{ml}$ rinse with sample; $1 \mathrm{~mL}$ of sample eluted from the column. This final 1 $\mathrm{mL}$ sample was used to measure Al concentrations usingn a GTA 110 graphite tube furnace 
atomic absorption spectrometer (Varian, Inc., Mulgrave, Victoria, Australia).

\subsubsection{Growth measurements}

Following exudate collection, root tips were removed for measurement of tissue biochemistry and $\mathrm{Al}$ concentration and subsamples were used to calculate fresh weight:dry weight ratios to adjust biomass estimates for tissue loss. Shoots and remaining roots from each cutting were separated, dried in an oven at $60{ }^{\circ} \mathrm{C}$ for $72 \mathrm{~h}$ and weighed.

\subsubsection{Root tip callose content}

Callose concentration in root tips was assayed by a modification of the methods described by Hirano and Brunner (2006). Root tips ( $\sim 2 \mathrm{~cm}$ in length) were excised and fixed in 1 $\mathrm{ml}$ of $96 \% \mathrm{v} / \mathrm{v}$ ethanol. Samples ( $\sim 20 \mathrm{mg}$ fresh weight) were weighed and placed in $2 \mathrm{~mL}$

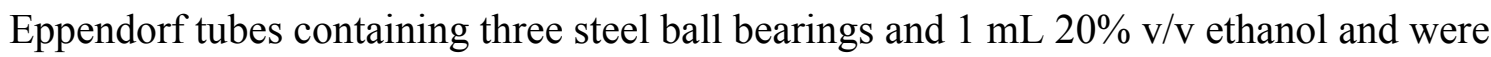
homogenized by vigorous shaking for six minutes. Homogenized root tip samples were then washed two more times with $1 \mathrm{~mL}$ of $20 \% \mathrm{v} / \mathrm{v}$ ethanol. One $\mathrm{mL}$ of $1 \mathrm{M} \mathrm{NaOH}$ was added to the washed samples and the tubes were heated at $85^{\circ} \mathrm{C}$ for $20 \mathrm{~min}$ to solubilize callose. The extract was centrifuged at $10,000 \times g$ for $15 \mathrm{~min}$ at $20^{\circ} \mathrm{C}$ and the clean supernatant assayed for callose. The callose assay mixture contained $0.4 \mathrm{~mL}$ of supernatant, $0.8 \mathrm{~mL}$ of $0.1 \% \mathrm{w} / \mathrm{v}$ aniline blue, $0.42 \mathrm{~mL}$ of $1 \mathrm{M} \mathrm{HCl}$ and $1.18 \mathrm{~mL}$ of $1 \mathrm{M}$ glycine- $\mathrm{NaOH}$ buffer ( $\mathrm{pH} 9.0$ ). Blanks contained assay mixture lacking aniline blue and reaction controls lacked supernatant. The reaction mixture was incubated for $20 \mathrm{~min}$ at $50^{\circ} \mathrm{C}$ and then $30 \mathrm{~min}$ at room temperature. Callose was quantified with a Quantech FM109515 fluorometer (Barnstead/Turner, Dubuque, IA, USA) at excitation and emission wavelengths of 393 and $484 \mathrm{~nm}$, respectively. Slitwidths were set to $3 \mathrm{~nm}$. Curdlan (Sigma, St. Louis, MO, USA) was used as a standard. For each root sample, fluorescence intensities in the absence of aniline blue stain were subtracted from the intensities in the presence of aniline blue stain (Wissemeier et al., 1998). Callose concentration was expressed as $\mu \mathrm{g}$ curdlan equivalent $(\mathrm{CE}) \mathrm{g}^{-1} \mathrm{FW}$ root mass. 


\subsubsection{Root tip Al fractions}

Apoplastic and symplastic Al contents were determined after Tice et al. (1992) and Nowak and Friend (2005) with minor modifications. At harvest, roots of the hybrid poplar genotypes were blotted on tissue paper. Root apices $(\sim 2 \mathrm{~cm})$ of 8-10 roots were collected, weighed and stored at $4{ }^{\circ} \mathrm{C}$ in $5 \mathrm{ml}$ of deionized water until initiation of the $\mathrm{Al}$ fractionation procedure.

The fractionation of $\mathrm{Al}$ for apoplastic and symplastic Al was performed as follows. Apoplastic Al: Aluminum measured in the storage water wash was considered to be $\mathrm{Al}$ in the water free space within the root. Root segments were then transferred to $5 \mathrm{ml} 1.5 \mathrm{mM} \mathrm{CaCl} 2$ at pH 4.3 and gently agitated for 5 min. This fraction was considered Donnan free space-bound Al. Roots were washed three times with $5 \mathrm{~mL}$ of desorption solution containing ice-cold $0.25 \mathrm{mM}$ citric acid and $0.25 \mathrm{mM} \mathrm{CaCl}_{2}$ with gentle agitation for $5 \mathrm{~min}$. This fraction was considered the apoplastic complexed fraction. For analysis, the sum of water free space, Donnan free space and apoplastic complexed fractions were considered the apoplastic Al fraction.

Symplastic Al: Root samples were transferred to $5 \mathrm{~mL}$ of ice-cold $0.25 \mathrm{mM}$ citric acid and $0.25 \mathrm{mM} \mathrm{CaCl}_{2}$ solution and cell membranes of the root samples were ruptured using combined methods of freezing $\left(-20{ }^{\circ} \mathrm{C}\right)$ and sonication ( 5 min sonication in ice-cold water bath). This process was repeated three times and solutions were pooled and used for symplastic Al determinations. Apoplastic and symplastic Al content were quantified as $\mu \mathrm{mol} \mathrm{g}^{-1} \mathrm{DW}$ of root tissue.

Residual Al in root tips was extracted by submerging root tips in $1 \mathrm{ml}$ of trace metal grade $\mathrm{HNO}_{3}$ for $24 \mathrm{~h}$ at $80^{\circ} \mathrm{C}$. Digests were brought to a final volume $25 \mathrm{ml}$ and filtered through $0.45 \mu \mathrm{M}$ syringe filters. Aluminum concentrations were measured with a GTA 110 graphite tube furnace atomic absorption spectrometer (Varian, Inc., Mulgrave, Victoria, Australia). Residual Al was quantified as $\mu \mathrm{mol} \mathrm{g}^{-1} \mathrm{DW}$. Total Al is presented as the summation of apoplastic, symplaastic and residual Al.

\subsubsection{Root tip organic acid and total phenol content}

At harvest, root tips were excised and stored at $-80^{\circ} \mathrm{C}$ until extraction. For tissue 
extraction of organic acids, root samples ( $20 \mathrm{mg}$ fresh weight) were weighed and placed in 2 $\mathrm{mL}$ Eppendorf tubes containing three steel ball bearings and $1 \mathrm{~mL} \mathrm{~d} \cdot \mathrm{H}_{2} \mathrm{O}$ and were homogenized by vigorous shaking for six minutes. Samples were centrifuged at $7000 \times \mathrm{g}$ at room temperature for 10 minutes and $0.7 \mathrm{ml}$ supernatant was extracted. A $0.7 \mathrm{ml}$ aliquot of $\mathrm{d} \cdot \mathrm{H}_{2} \mathrm{O}$ water was again added to the pellet and the pellet was vortexed for 20 seconds. Samples were centrifuged a second time as described above and a second $0.7 \mathrm{ml}$ aliquot of supernatant was removed for a final volume of $1.4 \mathrm{ml}$ of extract supernatant. The resulting supernatant was stored at $-20^{\circ} \mathrm{C}$ until analysis. Supernatant was analyzed for organic acid content and total phenols as described above in the exudate analysis section.

\subsubsection{Statistical analysis}

The experiment was established as a three-way factorial design ( 2 genotypes $\mathrm{x} 3 \mathrm{Al}$ treatments x 2 times), with 3-6 replicates per treatment. Data were log-transformed wherever necessary in order to achieve homogeneity of variance. Exudate concentrations, root tip organic acid and phenol concentrations, bound solution Al, root tip Al fractionation, root tip callose, and biomass were analyzed initially using three-way analyses of variance (ANOVA) followed by Tukey-Kramer's HSD to identify significant differences among genotypes and Al treatments (Table A.4). To better identify genotypic differences in response to Al at each time point, twoway ANOVAs were applied (Table A.5). Regressions analyses were performed among measured variables to assess relationships among bound $\mathrm{Al}$ in solution or callose production and organic acid exudation. All statistical analyses were carried out using SAS JMP v.7 software (SAS Institute, Cary, NC, USA).

\subsubsection{RESULTS}

\subsubsection{Organic acid exudation}

Exposure to $\mathrm{Al}$ in solution induced the exudation of citrate and malate from the roots of both hybrid genotypes and altered the contributions of other organic acids to the exudation profiles (Figure 2-1). After $24 \mathrm{~h}$ of $\mathrm{Al}$ exposure, citrate exudation was about 8-times greater in 
DTAC-7 than OP-367 and was greatest at $50 \mu \mathrm{M} \mathrm{Al}$ (Figure 2-1a). Aluminum also induced malate exudation, although production was much lower than citrate exudation and did not significantly differ between genotypes or Al treatments (Figure 1-1b, Table A.4). The exudation of lactate, formate, and acetate changed with exposure to $\mathrm{Al}$ in OP-367, but were unaffected by Al treatment in DTAC-7 (Figure 2-1c, d, e). Oxalate exudation was higher in OP-367 across Al treatments (Figure 2-1f).

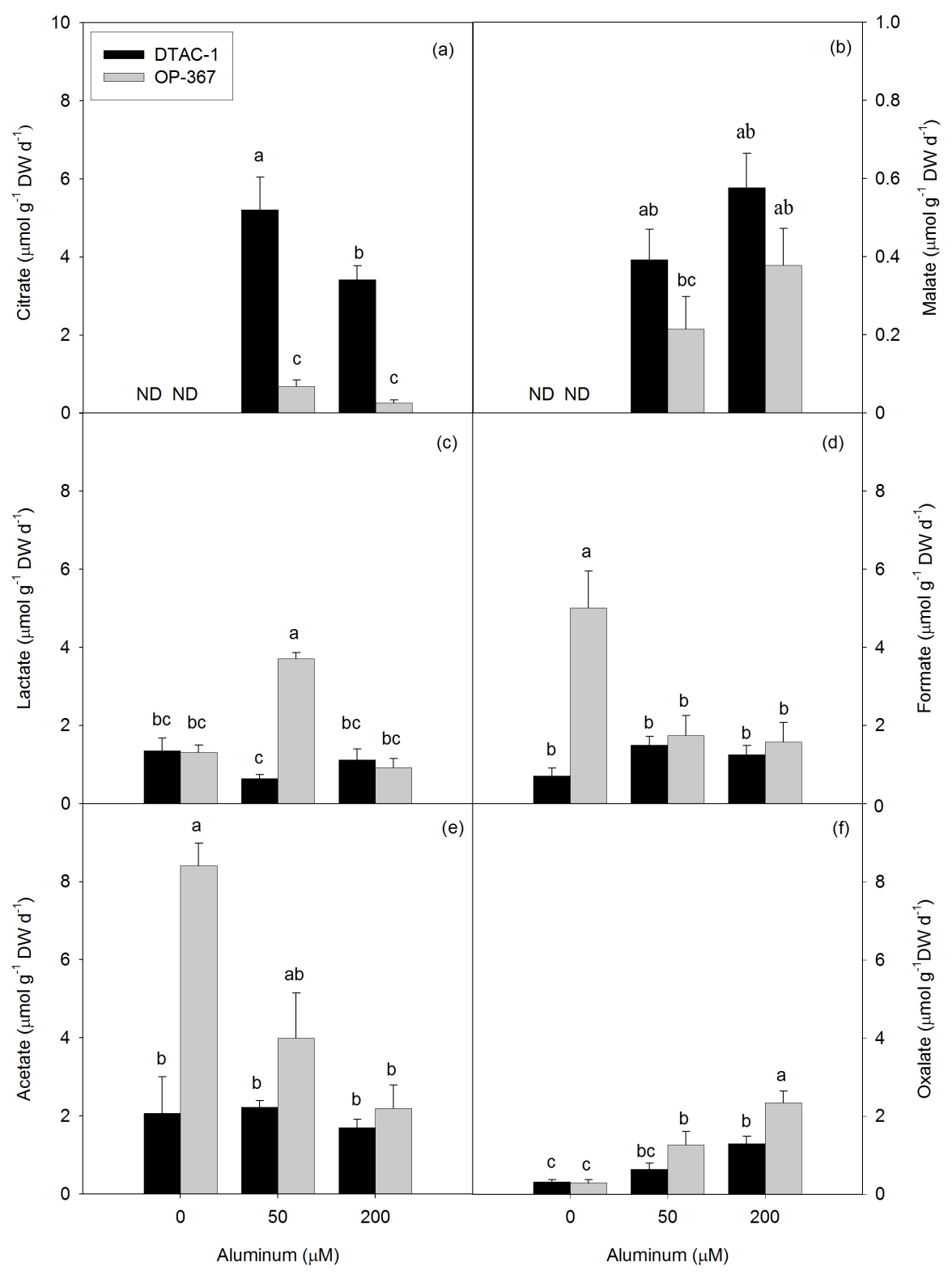

Figure 2-1 Organic acid exudate profiles in treatment containers after one day of Al exposure for (a) citrate, (b) malate, (c) lactate, (d) formate, (e) acetate and (f) oxalate. Values $(n=6)$ are means \pm SE. Means between genotypes and $\mathrm{Al}$ treatments denoted with different letters are significantly different at $\mathrm{P}<0.05$ (Tukey-Kramer's HSD Test). ND denotes organic acids not detected. Note different scale for malate. 
After seven days of Al exposure, the rates of organic acid exudation in both genotypes were lower than rates exhibited at $24 \mathrm{~h}$ (Figures 2-1 and 2-2). Exposure to Al still induced the exudation of citrate at $50 \mu \mathrm{M} \mathrm{Al}$, but this stimulation declined or was not evident at $200 \mu \mathrm{M} \mathrm{Al}$ in the two genotypes (Figure 2-2a). Malate exudation was still small relative to the production of other organic acids and DTAC-7 showed no difference in malate exudation between Al treatments, whereas OP-367 showed stimulations of malate exudation in response to Al (Figure 2-2b). Lactate, formate, and acetate exudation did not exhibit any consistent patterns between genotypes or in response to Al treatments (Figures 2-2c, d, e, Table A.4). Oxalate exudation was slightly higher in DTAC-7 at $50 \mu \mathrm{M} \mathrm{Al}$, however oxalate exudation was elevated in both genotypes at $200 \mu \mathrm{M} \mathrm{Al}$ (Figure 2-2f). 


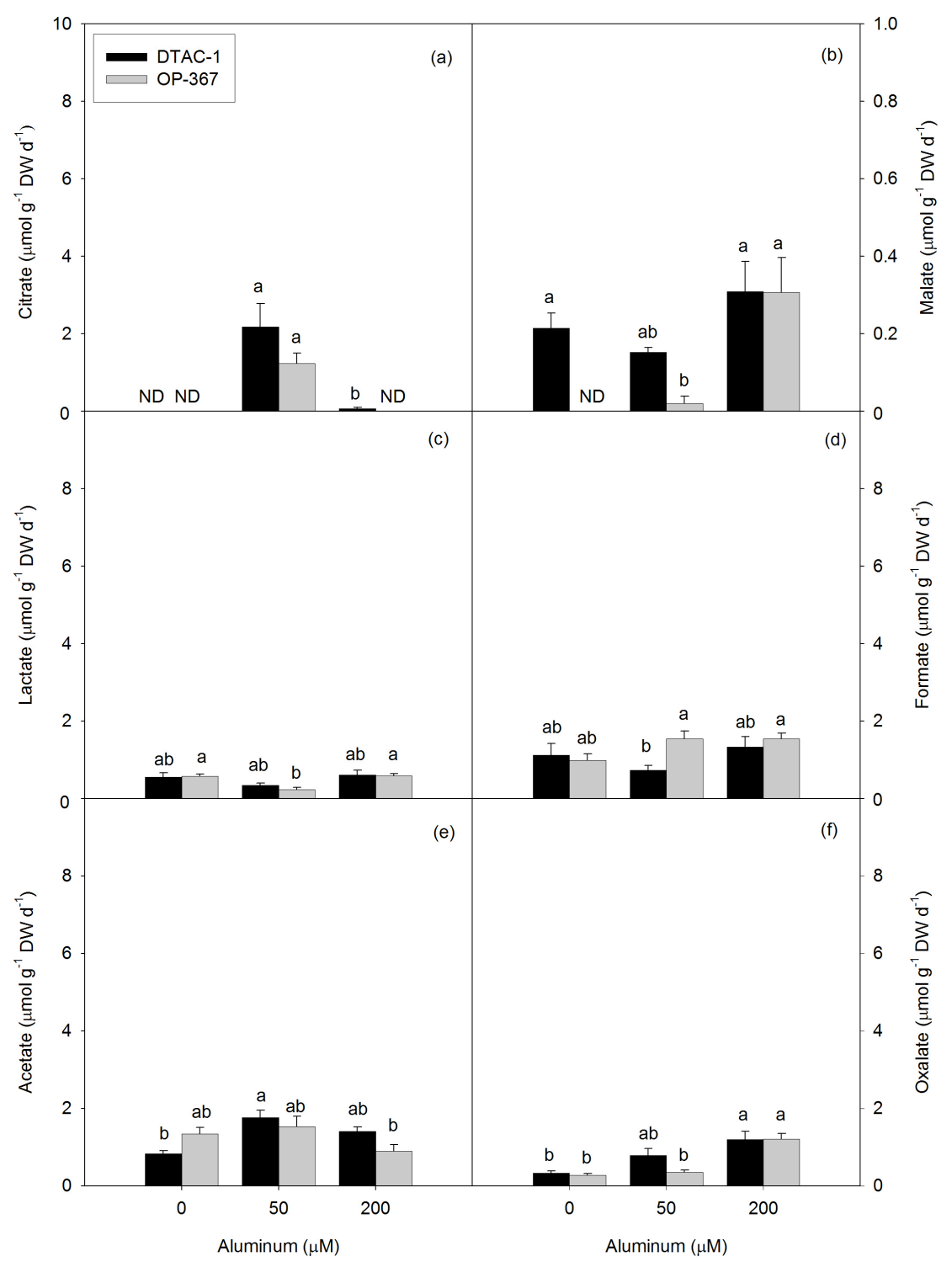

Figure 2-2 Organic acid exudate profiles in treatment containers after seven days of Al exposure for (a) citrate, (b) malate, (c) lactate, (d) formate and (e) acetate and ( $f$ ) oxalate. Values $(n=6)$ are means $\pm S E$. Means between genotypes and $\mathrm{Al}$ treatments denoted with different letters are significantly different at $\mathrm{P}<0.05$ (Tukey-Kramer's HSD Test). ND denotes organic acids not detected. Note different scale for malate.

\subsubsection{Total phenol exudation}

Exposure to $\mathrm{Al}$ at 50 or $200 \mu \mathrm{M}$ depressed the exudation of total phenols from roots of both Populus genotypes by 50 to $67 \%$ upon exposure to $\mathrm{Al}$ after $24 \mathrm{~h}$ and $7 \mathrm{~d}$ of exposure to $\mathrm{Al}$ (Figures 2-3a and 2-3b, Table A.4). 


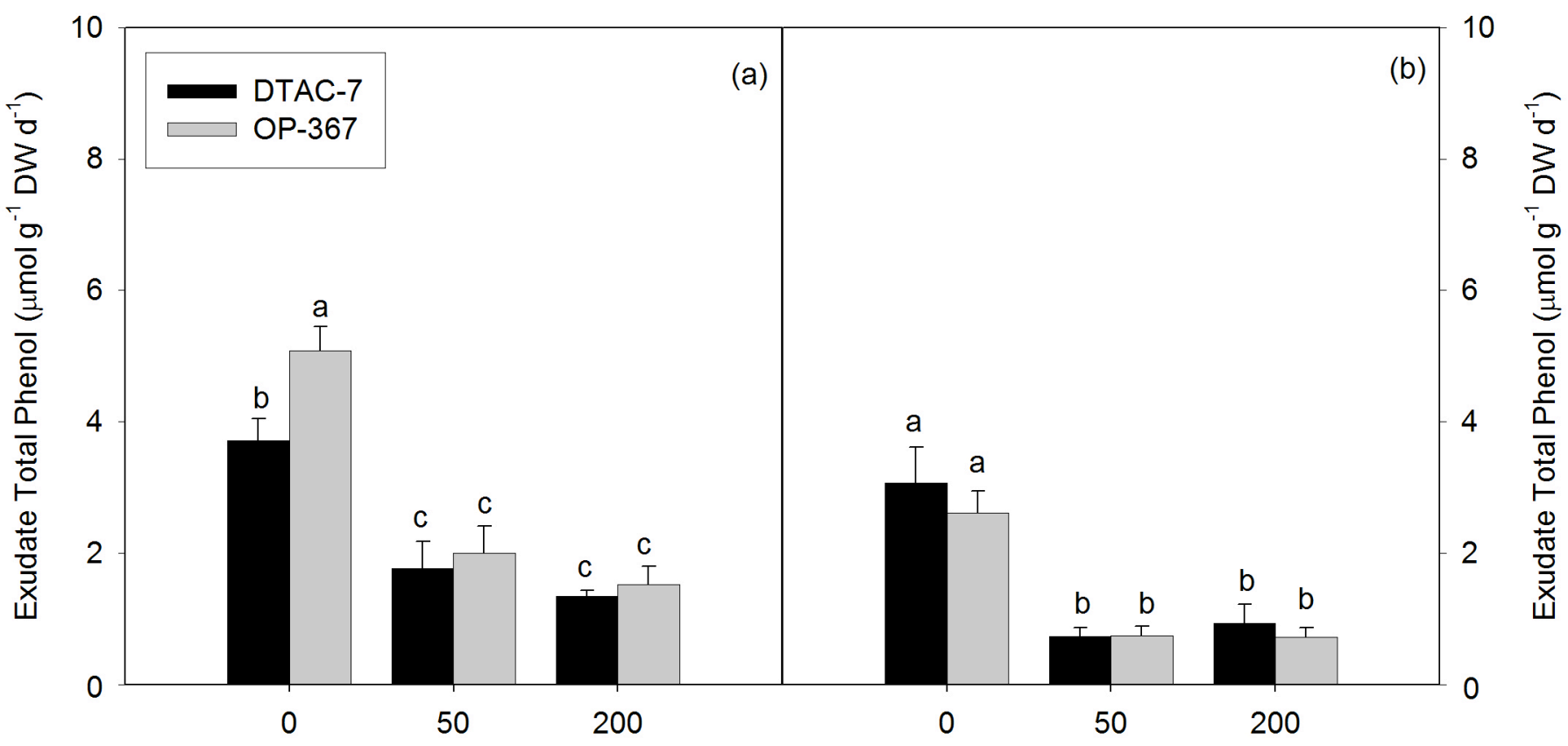

Figure 2-3 Total phenol exudation profiles after one day (a) and seven days (b) Al exposure. Values ( $\mathrm{n}=6$ ) are means \pm SE. Means between genotypes and $\mathrm{Al}$ treatments denoted with different letters are significantly different at $\mathrm{P}<0.05$ (Tukey-Kramer's HSD Test).

\subsubsection{Total organic carbon exudation}

At the $24 \mathrm{~h}$ assessment period, the flux of total $\mathrm{C}$ from roots OP-367 was $64 \%$ greater than C flux from DTAC-7 (Figure 2-4a). Exposure to Al, however, reduced the TOC content of exudates in OP-367 over all Al treatments to levels consistent with DTAC-7 (Figure 2-4a, Table A.4). In contrast, after seven days of Al exposure, TOC contents of exudates from DTAC-7 and OP-367 were elevated by $67 \%$ and $78 \%$, respectively, under exposure to $200 \mu \mathrm{M} \mathrm{Al}$ (Figure 2$4 b)$. 


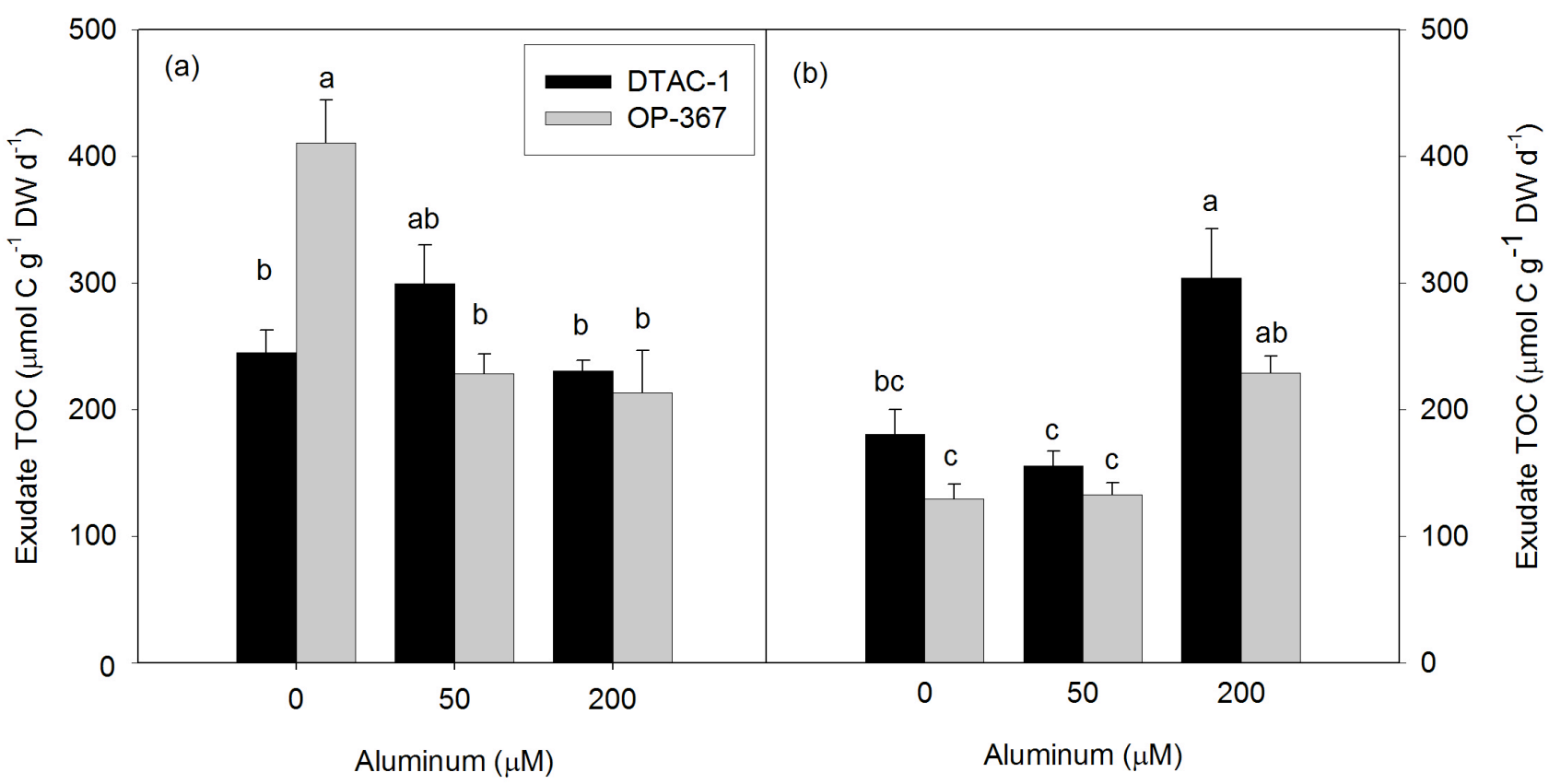

Figure 2-4 Concentration of total organic carbon (TOC) in exudates of poplar genotype roots after one day (a) and seven days (b) of Al exposure. Values $(n=6)$ are means \pm SE. Means between genotypes and Al treatments denoted with different letters are significantly different at $\mathrm{P}<0.05$ (Tukey-Kramer's HSD Test).

\subsubsection{Root tip organic acid concentrations}

Malate, lactate and citrate were the major organic acids detected in the root tips of Populus genotypes, whereas succinate was present at much lower concentrations (Figures 2-5 and 2-6) and concentrations varied by both genotype and Al exposure (Table A.4). After $24 \mathrm{~h}$ of $\mathrm{Al}$ exposure, exposure to $50 \mu \mathrm{M} \mathrm{Al}$ increased root tip citrate concentrations in DTAC-7 (Figure 2-5a). Exposure to Al reduced root tip malate concentrations in DTAC-7, but did not affect malate in OP-367 (Figure 2-5b). Succinate concentrations in root tips almost tripled at $50 \mu \mathrm{M} \mathrm{Al}$ in both genotypes. At $200 \mu \mathrm{M} \mathrm{Al}$, DTAC-7 root tip succinate concentration returned to slightly lower than that of control, whereas succinate concentrations were depleted in OP-367 root tips (Figure 2-5c). Tissue lactate concentrations increased by more than 7-fold in DTAC-7 when exposed to $200 \mu \mathrm{M} \mathrm{Al}$, whereas OP-367 exhibited no significant increases in root tip lactate concentration upon exposure to $\mathrm{Al}$ (Figure 2-5d). 


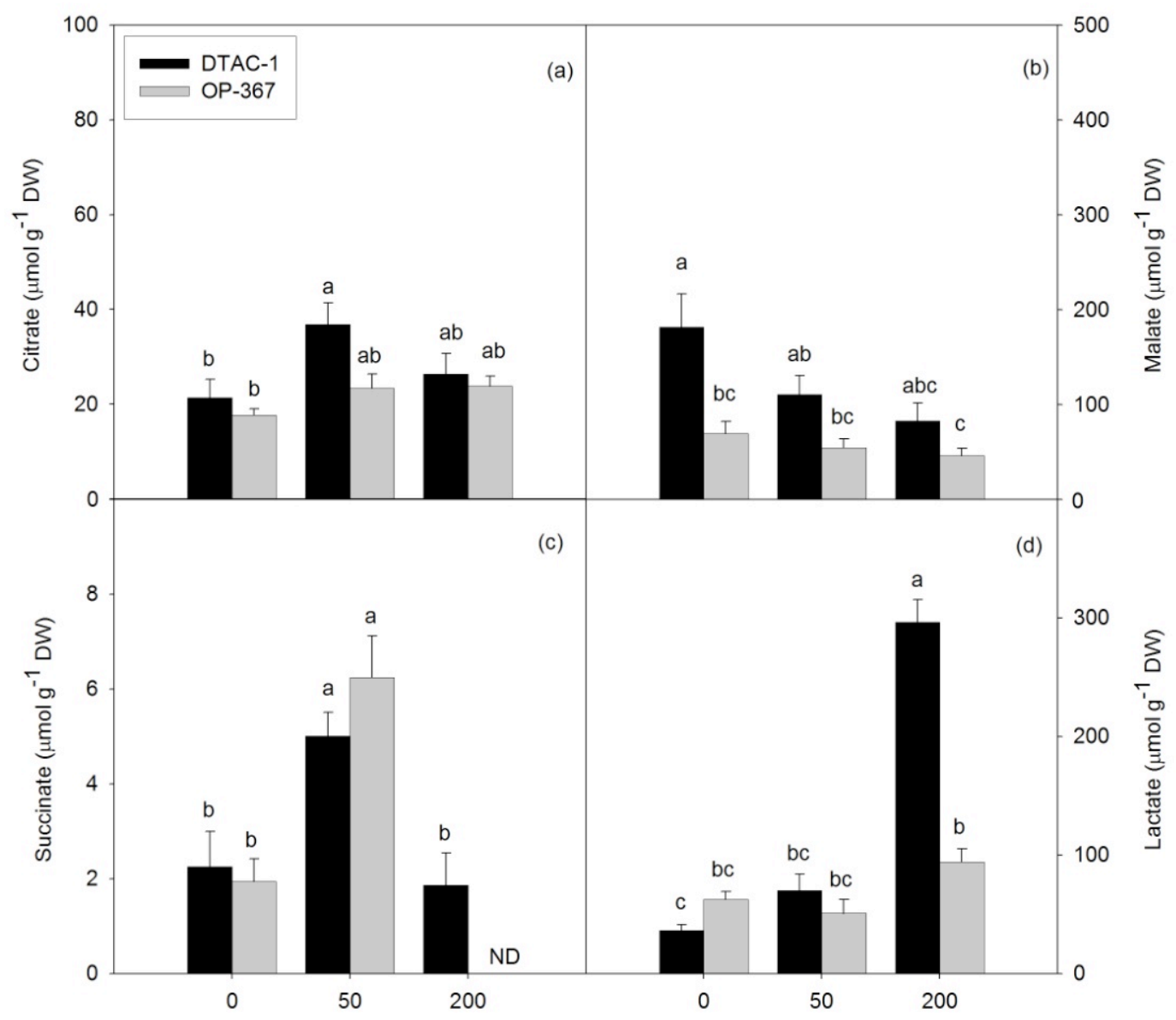

Figure 2-5 Root tip organic acid profiles after one day of Al exposure for (a) citrate, (b) malate, (c) succinate and (d) lactate. Values $(n=6)$ are means \pm SE. Means between genotypes and $\mathrm{Al}$ treatments denoted with different letters are significantly different at $\mathrm{P}<0.05$ (Tukey-Kramer's HSD Test). Note different organic acids are on different scales.

After $7 \mathrm{~d}$ of $\mathrm{Al}$ exposure, root tip organic acid concentrations varied by genotype and $\mathrm{Al}$ treatment as well (Figure 2-6, Table A.4). Citrate concentration in DTAC-7 was elevated at 50 $\mu \mathrm{M} \mathrm{Al}$, but returned to control levels at $200 \mu \mathrm{M} \mathrm{Al}$ (Figure 2-6a). Root tip citrate in OP-367 decreased as $\mathrm{Al}$ concentration increased, decreasing by almost $90 \%$ at $200 \mu \mathrm{M} \mathrm{Al}$ (Figure 2-6a). DTAC-7 had higher root tip malate concentrations across all Al treatments than OP-367 and malate concentrations in root tips of both genotypes decreased as Al increased (Figure 2-6b). Succinate increased in root tips of both genotypes at $50 \mu \mathrm{M} \mathrm{Al}$, but was not detected at $200 \mu \mathrm{M}$ $\mathrm{Al}$ in OP-367 (Figure 2-6c), consistent with patterns at $24 \mathrm{~h}$. At $200 \mu \mathrm{M} \mathrm{Al}$, lactate concentrations in DTAC-7 declined with Al exposure, but were unaffected by $\mathrm{Al}$ in OP-367 (Figure 2-6d). 


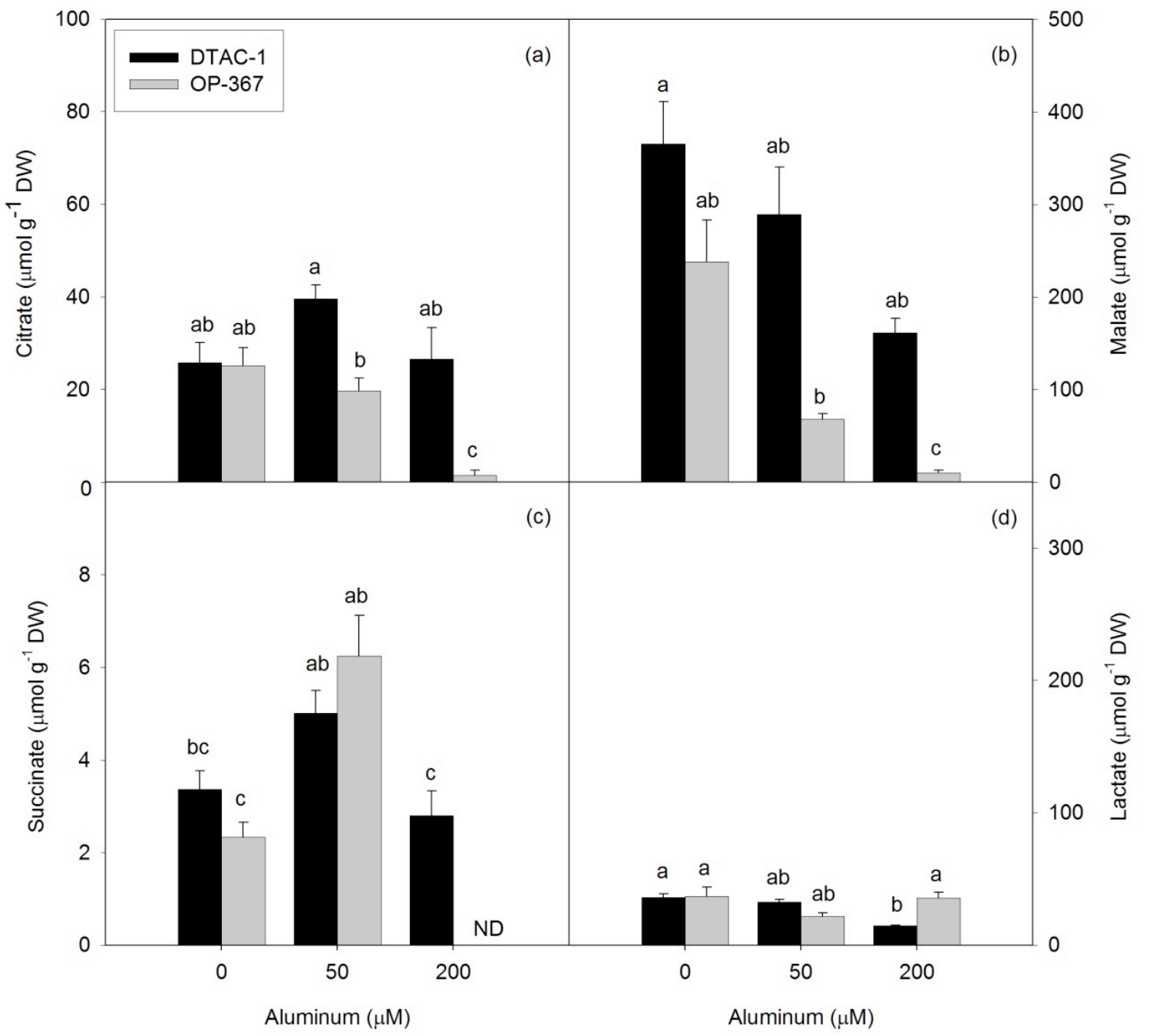

Figure 2-6 Root tip organic acid profiles after seven days of Al exposure for (a) citrate, (b) malate, (c) succinate and (d) lactate. Values $(n=6)$ are means \pm SE. Means between genotypes and Al treatments denoted with different letters are significantly different at $\mathrm{P}<0.05$ (Tukey-Kramer's HSD Test). Note different scales among organic acids.

\subsubsection{Root tip phenol concentration}

The concentration of total phenols in root tips increased by $31 \%$ in DTAC-7 after 1 day of exposure to $50 \mu \mathrm{M} \mathrm{Al}$ (Figure 2-7c). Conversely, root tip phenol concentrations in OP-367 significantly dropped by one-third at $200 \mu \mathrm{M}$ Al during the same timeframe (Figure 2-7a). Following 7d of Al exposure, root tip phenol concentrations were consistently higher in DTAC-7 than OP-367 across all Al treatments without any Al treatment effects (Figure 2-7d). 


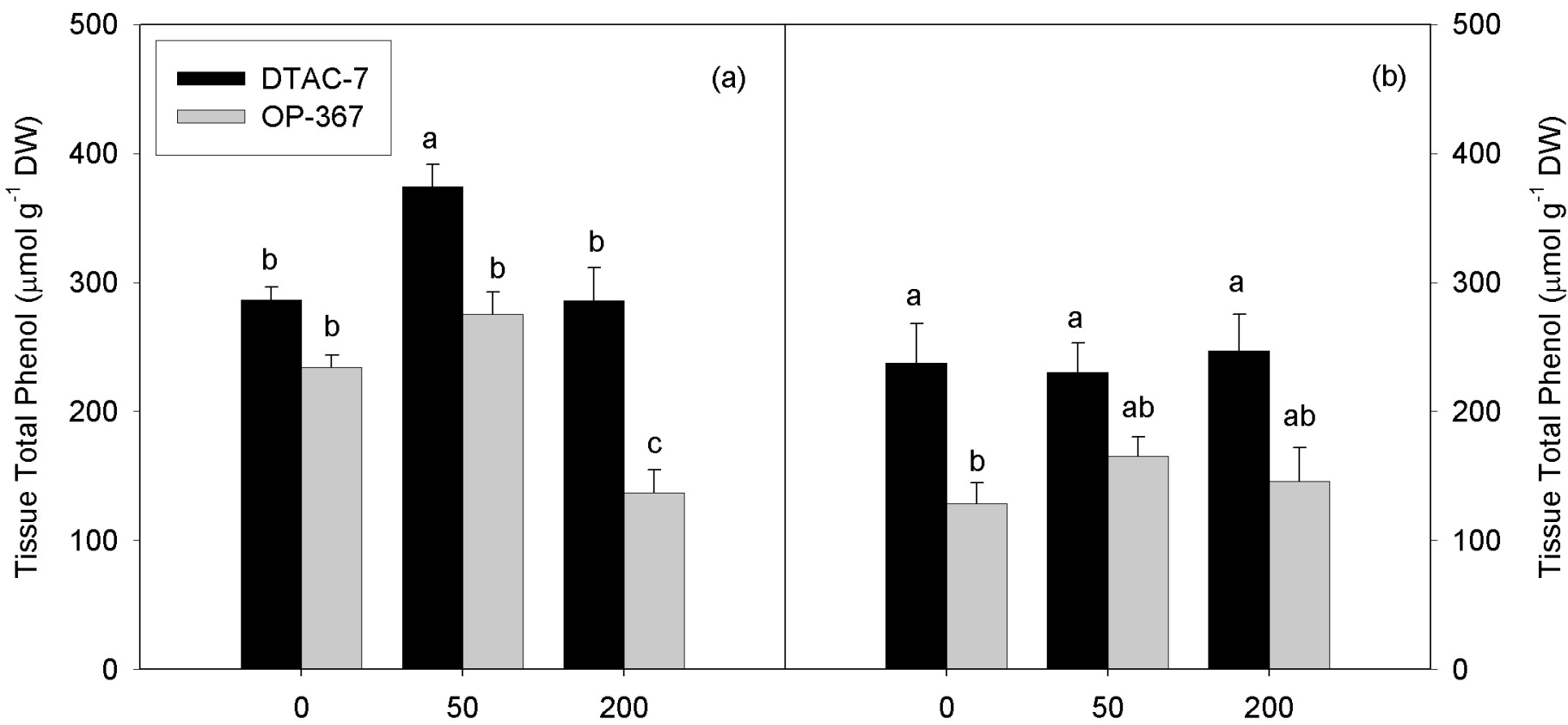

Figure 2-7 Root tip total phenol concentrations after one day (a) and seven days (b) Al exposure. Values ( $\mathrm{n}=6$ ) are means \pm SE. Means between genotypes and Al treatments denoted with different letters are significantly different at $\mathrm{P}<0.05$ (Tukey-Kramer's HSD Test).

\subsubsection{Bound Al in solution}

The analysis of total and cationic $\mathrm{Al}$ in solution indicated that the two Populus genotypes differentially affected $\mathrm{Al}$ speciation in solution (Figure 2-8, Table A.4). Following $24 \mathrm{~h}$ of $\mathrm{Al}$ exposure, the amount of bound $\mathrm{Al}$ in solution was three-times higher in solutions from DTAC-7 compared to OP-367 plants over both $\mathrm{Al}$ treatments, with the concentration of bound $\mathrm{Al}$ tending to increase as $\mathrm{Al}$ increased for both genotypes (Figure 2-8a). After $7 \mathrm{~d}$ of Al exposure, the levels of bound $\mathrm{Al}$ declined compared to $24 \mathrm{~h}$, and the concentrations of bound $\mathrm{Al}$ declined or tended to decline in solutions from both DTAC-7 and OP-367 as Al increased (Figure 2-8b). 


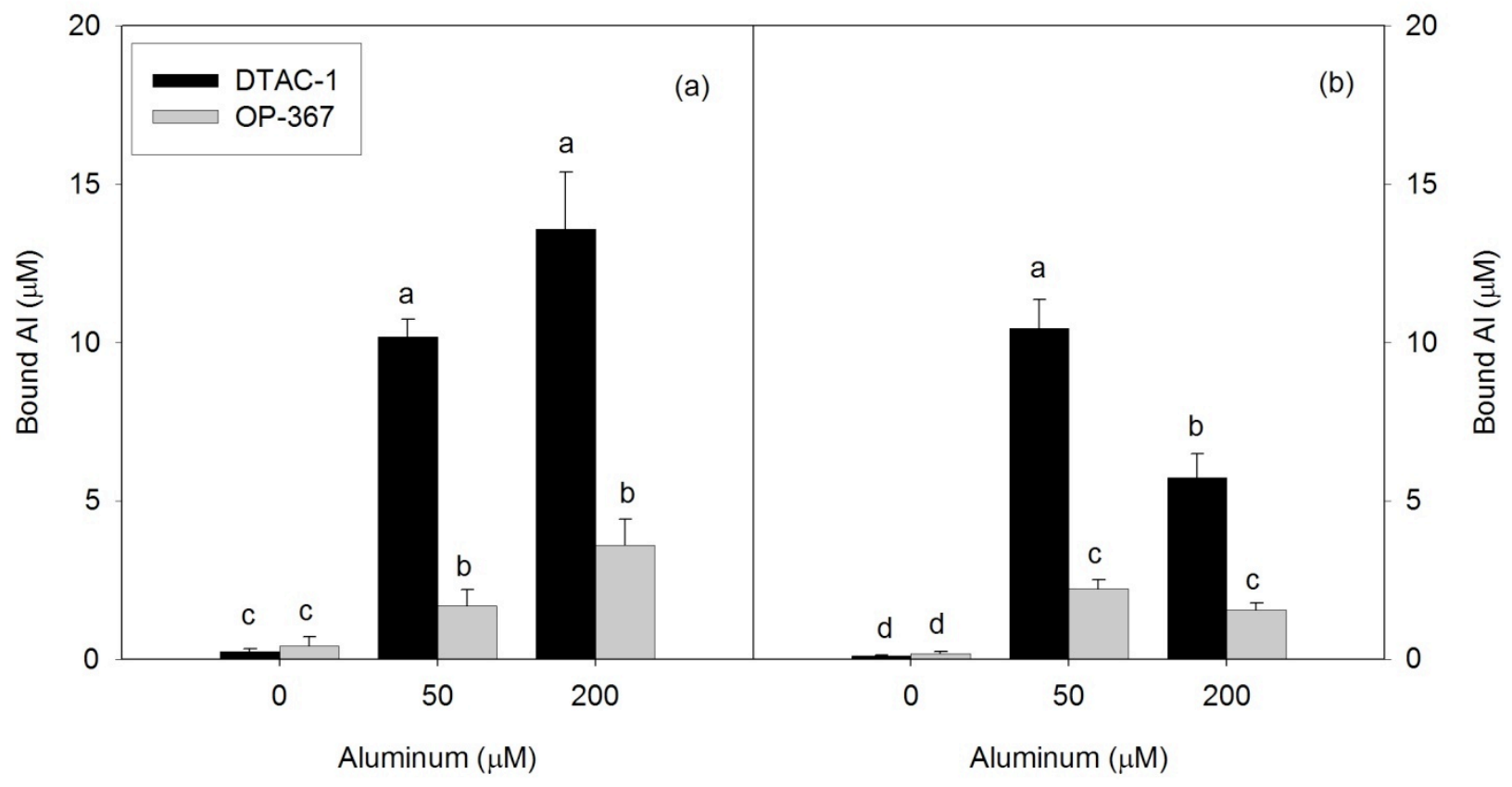

Figure 2-8 Concentration of bound $\mathrm{Al}$ in solution due to poplar genotype exudation after one day (a) and seven days (b) of $\mathrm{Al}$ exposure. Values $(\mathrm{n}=6)$ are means \pm SE. Means between genotypes and Al treatments denoted with different letters are significantly different at $\mathrm{P}<0.05$ (Tukey-Kramer's HSD Test).

\subsubsection{Tissue Al fractionation}

Upon exposure to $\mathrm{Al}$ for $24 \mathrm{~h}$, apoplastic and symplastic root $\mathrm{Al}$ increased with external Al concentrations in DTAC-7 to a greater extent than in OP-367 (Figure 2-9a and c, Table A.4). The symplastic Al fraction in root tips of DTAC-7 was six-times greater in DTAC-7 than OP367 at $200 \mu \mathrm{M} \mathrm{Al}$ (Figure 2-9c). Total root tip Al concentrations of the two Populus genotypes were far greater than the two fractions extracted and were not significantly different from one another and there was a two-fold increase of total $\mathrm{Al}$ from 50 to $200 \mu \mathrm{M} \mathrm{Al}$ (Figure 2-9e).

Following $7 \mathrm{~d}$ of $\mathrm{Al}$ exposure, patterns of $\mathrm{Al}$ fractionation were different than at $24 \mathrm{~h}$ (Figure 2-9, Table A.4, A.5). Apoplastic Al increased with external Al in OP-367, whereas apoplastic Al plateaued in roots of DTAC-7 (Figure 2-9b). No significant differences were noted in symplastic Al fractions between genotypes over the two Al treatments (Figure2-9d). Total root tip $\mathrm{Al}$ concentrations were significantly higher than extracted fractions and were significantly different between genotypes at both Al treatments (Figure 2-9f). DTAC-7 had twice as much $\mathrm{Al}$ in root tips as $\mathrm{OP}-367$ at $50 \mu \mathrm{M} \mathrm{Al}$, whereas $\mathrm{OP}-367$ had $50 \%$ more $\mathrm{Al}$ in root tips than DTAC-7 at $200 \mu \mathrm{M} \mathrm{Al}$ (Figure 2-9f). 


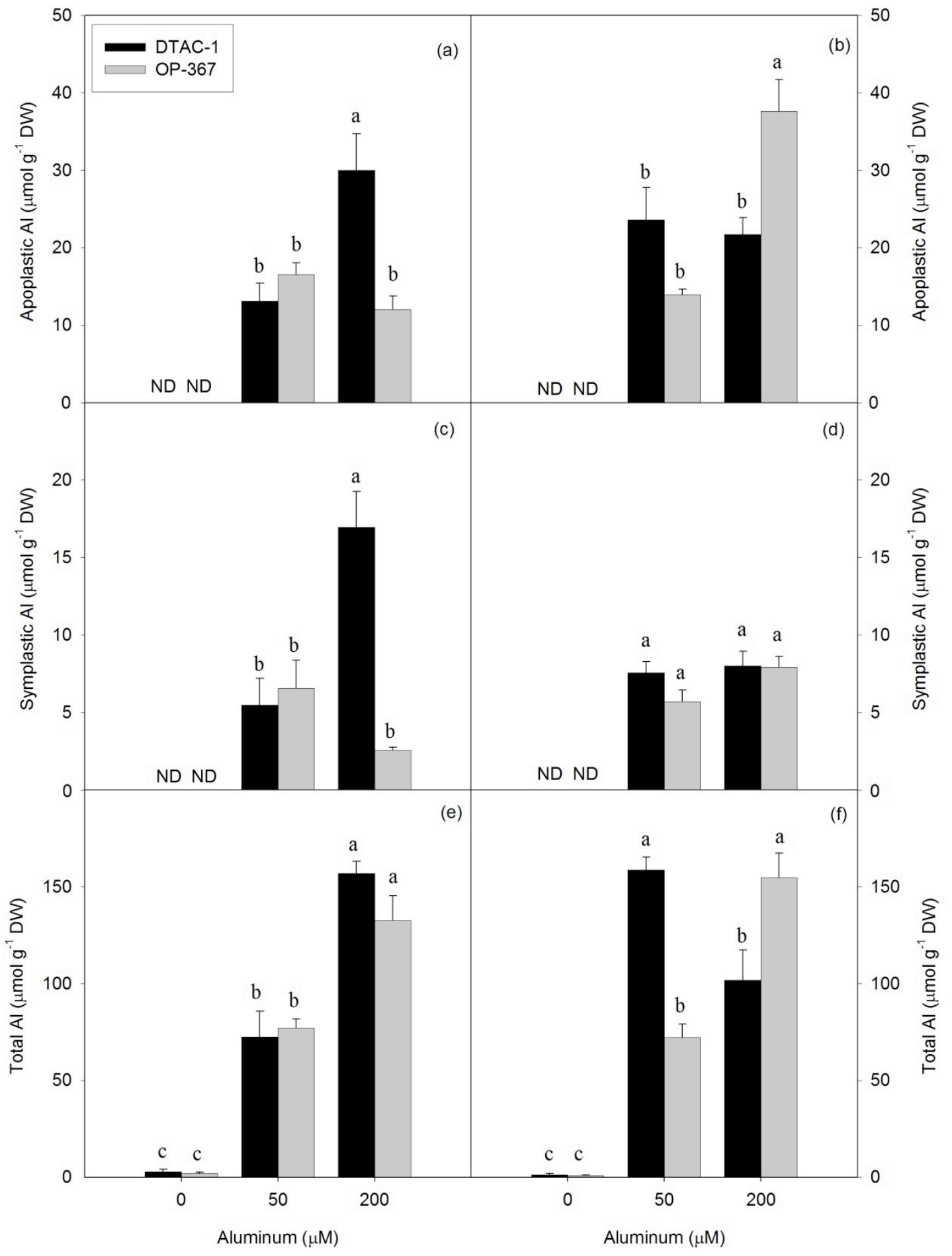

Figure 2-9 Compartmentalization of $\mathrm{Al}$ in poplar genotype root tissue after $\mathrm{Al}$ exposure for one day in the apoplast (a), symplast (c) and total (e). Also the same fractions after seven days Al exposure (b),(d) and (f). Values (n=6) are means $\pm \mathrm{SE}$. Means between genotypes and $\mathrm{Al}$ treatments denoted with different letters are significantly different at $\mathrm{P}<0.05$ (Tukey-Kramer's HSD Test). ND denotes Al not detected. 


\subsubsection{Callose accumulation}

Aluminum-induced callose accumulation in roots differed between the two Populus genotypes (Figure 2-10, Table A.4). Across all Al treatments and exposure times, callose accumulation in roots of OP-367 was significantly greater than that in DTAC-7 (Figure 2-10a, b). After $24 \mathrm{~h} \mathrm{Al}$ exposure, callose accumulation increased with $\mathrm{Al}$ concentration in both genotypes, but to a greater extent in OP-367, and differences were most pronounced at $50 \mu \mathrm{M} \mathrm{Al}$ (Figure 2-10a). Following $7 \mathrm{~d}$ of Al exposure, the accumulation of callose in roots of DTAC-7 was significantly less than that of OP-367 and the difference was pronounced at both 50 and 200 $\mu \mathrm{M}$ Al (Figure 2-10b).

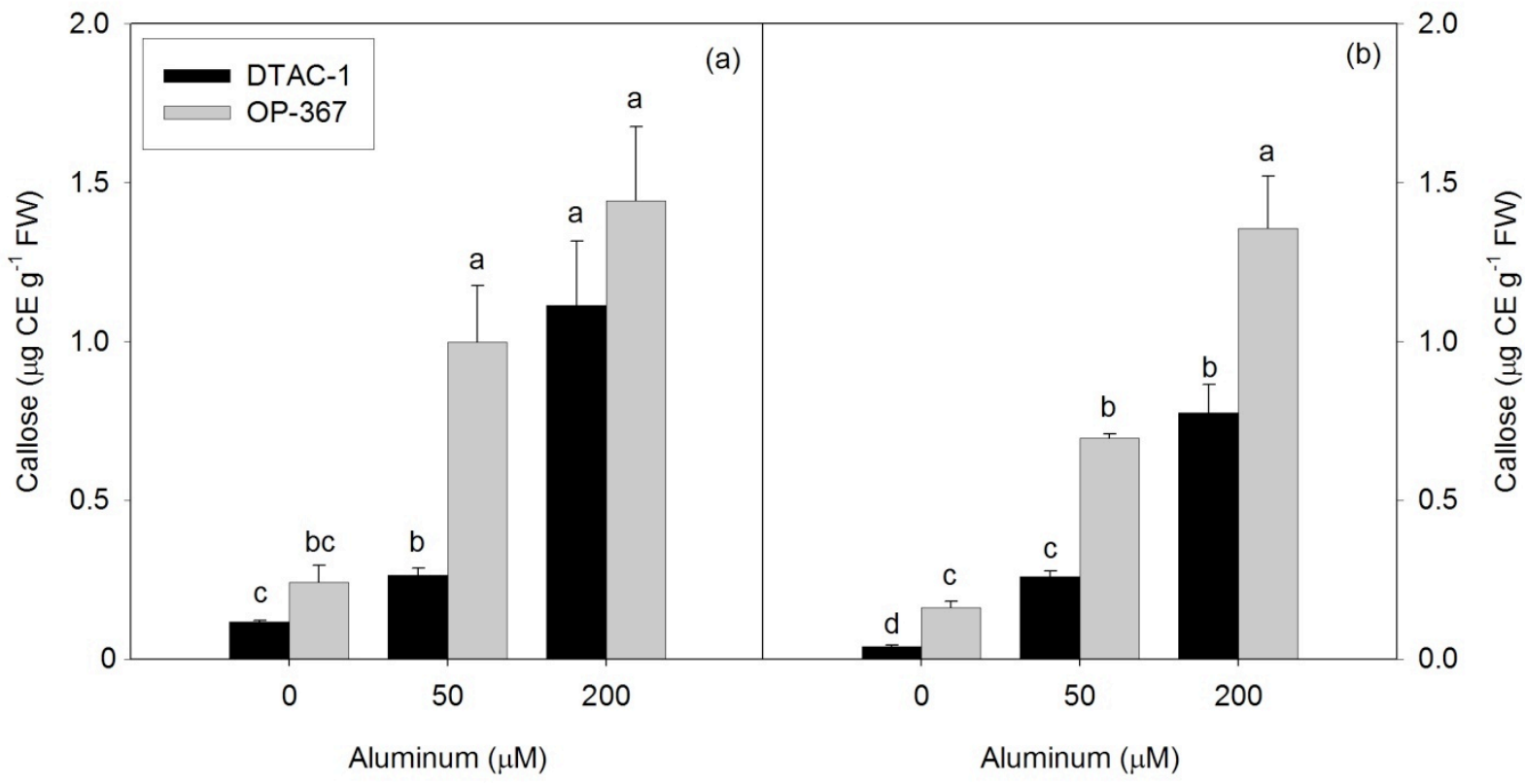

Figure 2-10 Callose accumulation in root tips of poplar genotypes after one day (a) and seven days (b) of $\mathrm{Al}$ exposure. Values $(n=3)$ are means \pm SE. Means between genotypes and $\mathrm{Al}$ treatments denoted with different letters are significantly different at $\mathrm{P}<0.05$ (Tukey-Kramer's HSD Test).

\subsubsection{Biomass}

No significant differences were noted between Populus genotypes in shoot or root biomass following $24 \mathrm{~h}$ of Al exposure (Figure 2-11a, c). Following $7 \mathrm{~d}$ of Al exposure, however, the growth of shoots of OP-367 was reduced by up to $45 \%$ at $200 \mu \mathrm{M} \mathrm{Al}$, whereas shoot growth of DTAC-7 was not significantly affected (Figure 2-11b). Root growth of DTAC-7 
tended to increase at $50 \mu \mathrm{M} \mathrm{Al}$ and declined slightly at $200 \mu \mathrm{M} \mathrm{Al}$ compared to the control (Figure 2-11d), whereas root growth of OP-367 declined as $\mathrm{Al}$ in solution increased, with a $60 \%$ reduction in growth at $200 \mu \mathrm{M} \mathrm{Al}$ (Figure 2-11d).

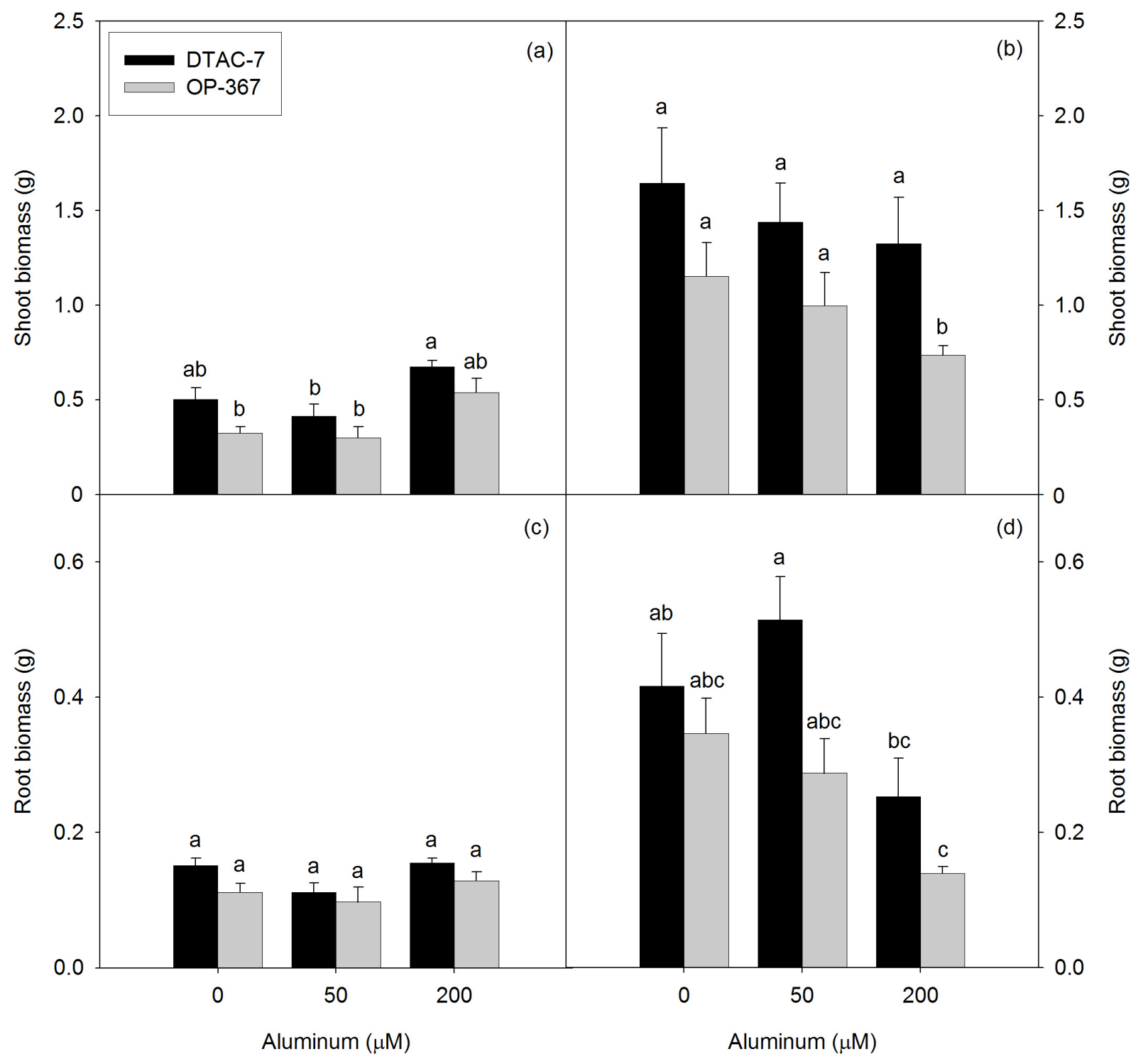

Figure 2-11 Biomass accumulation in poplar genotypes after one day $\mathrm{Al}$ exposure (shoots (a) and roots (c)) and after seven days of Al exposure (shoots $(b)$ and roots $(d)$ ). Values $(n=6)$ are means $\pm S E$. Means between genotypes and $\mathrm{Al}$ treatments denoted with different letters are significantly different at $\mathrm{P}<0.05$ (Tukey-Kramer's HSD Test). 


\subsubsection{Mechanisms of Al resistance}

A positive relationship was found between citrate exudation and the amount of organically bound $\mathrm{Al}$ in solution for both genotypes and all Al concentrations (Figure 2-12). The two poplar genotypes tended to segregate in this association, with DTAC-7 genotypes exhibiting elevated levels of citrate exudation and higher concentrations of bound Al in solution (Figure 212). Root tip callose accumulation was negatively associated with citrate exudation (Figure 213), with DTAC-7 exhibiting higher exudation of citrate and lower callose content in root tips than OP-367 (Figure 2-13).

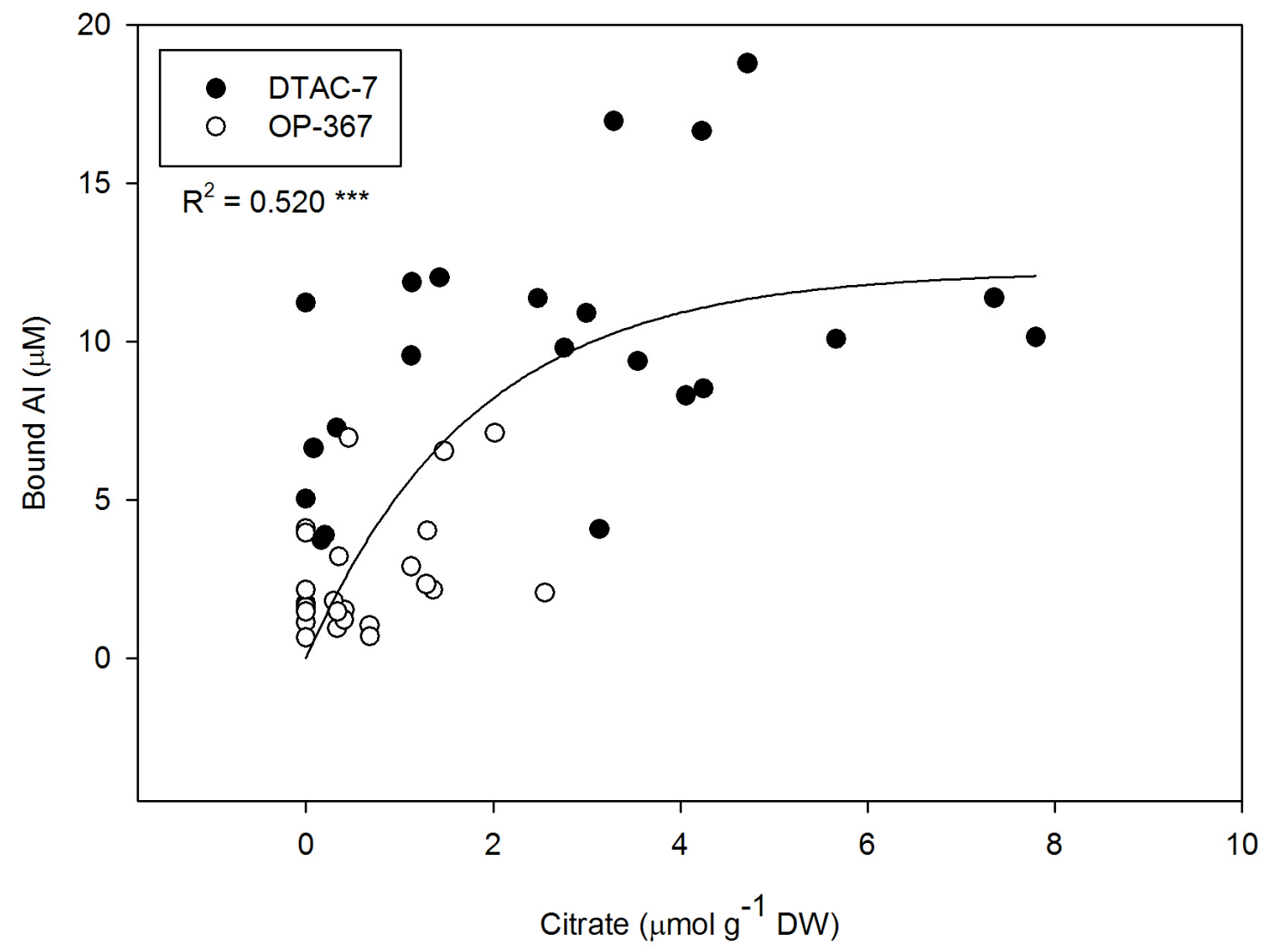

Figure 2-12 Association between bound Al in solution and citrate exudation in two poplar genotypes exposed to Al. Data are across two Al treatments (50 and $200 \mu \mathrm{M} \mathrm{Al})$ and two exposure periods ( 1 and $7 \mathrm{~d})(\mathrm{n}=6)$. Control removed for analysis. 


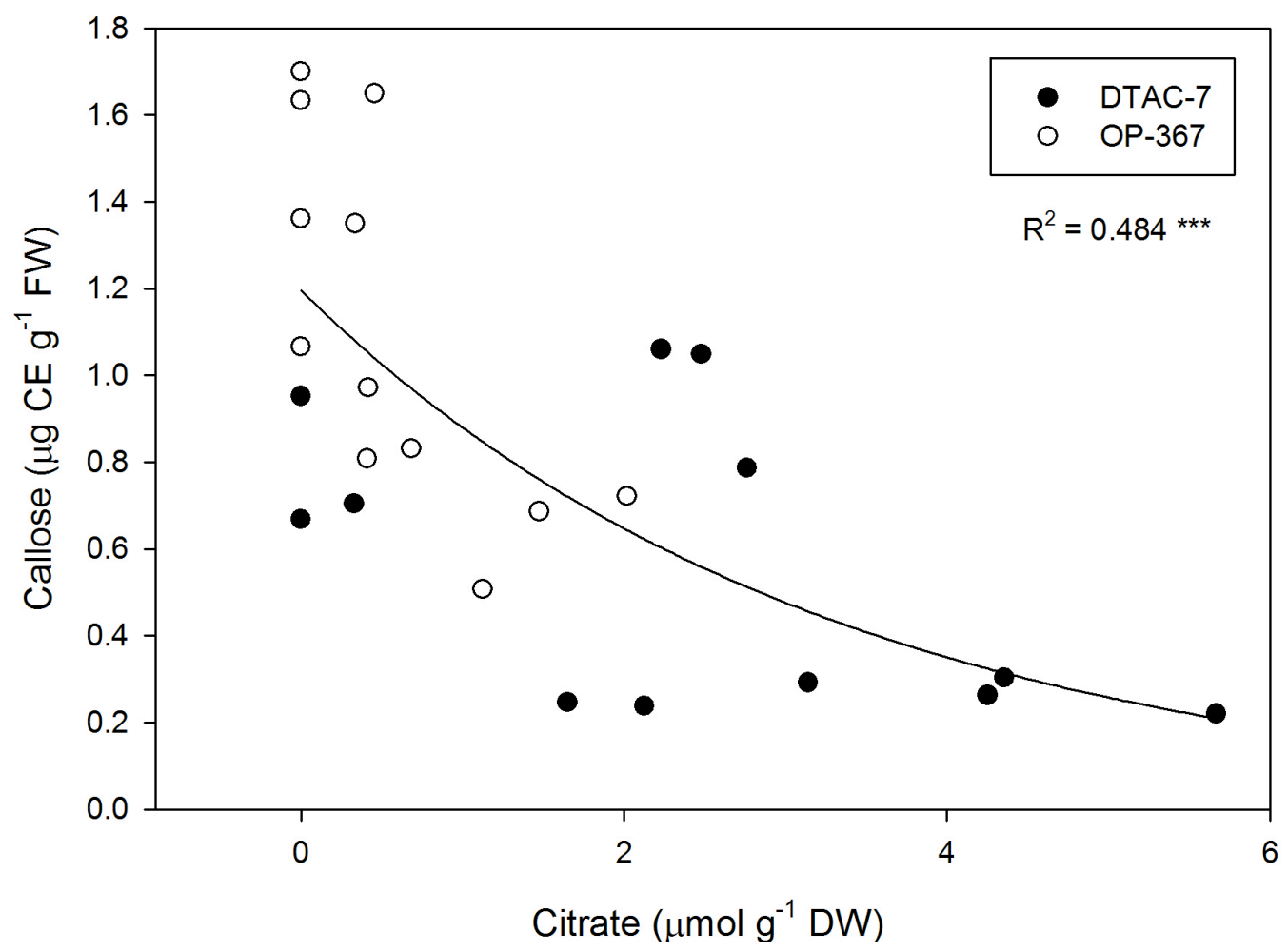

Figure 2-13 Association between root tip callose accumulation and citrate exudation in two poplar genotypes exposed to Al. Data are across two $\mathrm{Al}$ treatments $(50$ and $200 \mu \mathrm{M} \mathrm{Al})$ and two exposure periods $(1$ and $7 \mathrm{~d})(\mathrm{n}=3)$. Control removed for analysis.

\subsubsection{Aluminum induced changes in exudation}

Exudation of OAs increased over ten-fold in both $\mathrm{Al}$ treatments after one day of exposure in DTAC-7. While after one day of Al exposure, OP-367 showed a small increase in OA exudation at $50 \mu \mathrm{M} \mathrm{Al}$ and a decrease at $200 \mu \mathrm{M} \mathrm{Al}$ (Figure 2-14). Both genotypes exhibited a similar decrease in phenol exudation after one day Al exposure (Figure 2-14). DTAC-7 increased TOC exudation slightly after one day at $50 \mu \mathrm{M}$ Al, while all other treatments and genotypes decreased TOC in exudates (Figure 2-14).

DTAC-7 continued to stimulate greater OA exudation than OP-367 after seven days of Al exposure (Figure 2-15). OP-367 decreased OA exudation at $200 \mu \mathrm{M}$ Al after seven days treatment (Figure 2-15). OP-367 had a larger decrease in phenol exudation compared to DTAC-7 after seven days treatment, yet both genotypes decreased in response to Al (Figure 2-15). Despite no large increase in OA and phenol exudation both genotypes showed in increase in TOC 
content of exudates in response to $200 \mu \mathrm{M} \mathrm{Al}$ after seven days treatment (Figure 2-15).

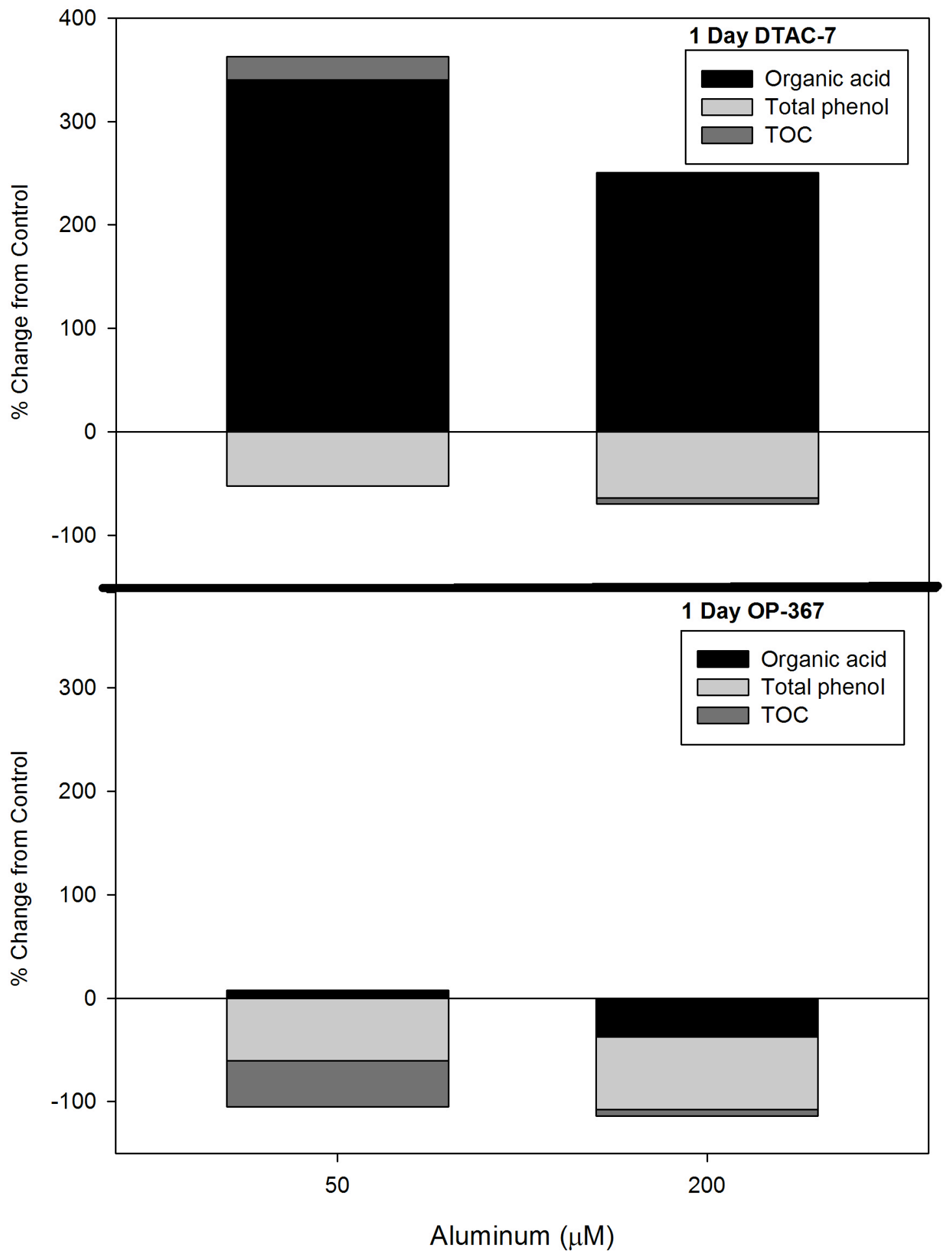

Figure 2-14 Percentage of change in exudation in regard to control plants of Populus genotypes exposed to two levels of $\mathrm{Al}$ (50 and $200 \mu \mathrm{M} \mathrm{Al}$ ) for one day. 


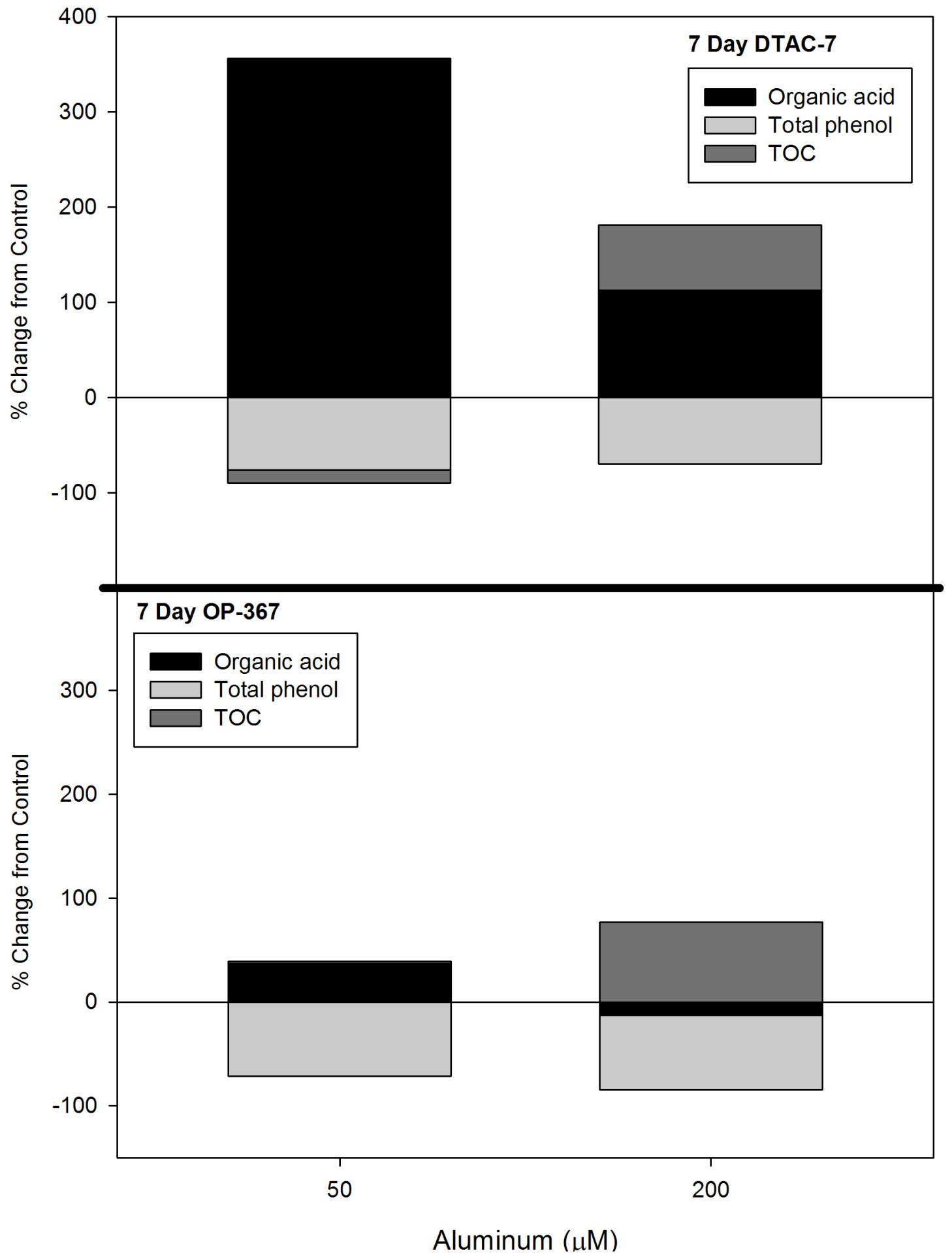

Figure 2-15 Percentage of change in exudation in regard to control plants of Populus genotypes exposed to two levels of Al (50 and $200 \mu \mathrm{M} \mathrm{Al}$ ) for seven days. 


\subsubsection{DISCUSSION}

Over the years, several physiological and biochemical indicators of Al resistance have been identified in both agricultural and arboreal species (Barceló and Poschenrieder, 2002; Hirano et al., 2004; Kochian et al., 2005; Qin et al., 2007). In previous studies, Smith et al. (2011) suggested that $\mathrm{Al}$ sensitivity/resistance in poplar genotypes could be identified using a variety of physiological and biochemical markers. Differences in Al-induced reductions in biomass were associated with differences in root tip organic acid contents, callose and pectin accumulation, and subcellular fractionation of $\mathrm{Al}$ (Smith et al., 2011).

The current study specifically assessed mechanisms underlying these patterns of Al resistance in one $\mathrm{Al}$ tolerant (DTAC-7) and one $\mathrm{Al}$ sensitive (OP-367) poplar genotype. Following seven days of exposure to 50 or $200 \mu \mathrm{M} \mathrm{Al}$, distinct differences in root morphology between genotypes were observed after seven days of exposure to $\mathrm{Al}$ (data not presented). The Al-sensitive genotype OP-367 exhibited darkened and stunted lateral roots that were not present in DTAC-7 and these differences were reflected in root biomass differences between the two genotypes (Figure 2-11). Underlying these differences in sensitivity may lie responses that function to limit the effects of $\mathrm{Al}$ on root homeostasis.

\subsubsection{Organic acid exudation}

After one day of $\mathrm{Al}$ exposure, citrate and malate exudation increased in response to $\mathrm{Al}$ (Figure 2-1). DTAC-7, the more Al tolerant genotype, exuded greater amounts of both citrate and malate in response to Al treatments (Figure 2-1), although the flux of malate was comparatively small. The exudation patterns in this study were markedly different than those found by Qin et al. (2007), where citrate and oxalate were the predominant organic acids produced after 48 hours $\mathrm{Al}$ exposure. In the current study, six organic acids were detected (Figure 2-1) and citrate dominated the exudation profile.

After seven days of $\mathrm{Al}$ exposure, the exudation of organic acids declined compared to that at 24 hours (Figures 2-2). This suggests that, after prolonged exposure to Al, OA exudation may not be a primary mechanism of $\mathrm{Al}$ tolerance. This is also suggested by comparing exudation profiles for these genotypes (Figures 2-14 and 2-15), which highlight the decline in organic acid contribution to exudation after 7 days of $\mathrm{Al}$ exposure. Many published studies of 
organic acid exudation use short Al exposure times of 48 hours or less (Jones, 1998; Heim et al., 2001; Nguyen et al., 2003; Qin et al., 2007) and, from these, it is difficult to conclude that organic acid exudation is a sustainable characteristic of Al-resistant genotypes. Other studies have examined OA exudation on a long-term scale (Silva et al. 2004, Naik et al. 2009), although there is rarely consistent data from which to compare possible acclimation responses in short term $\mathrm{Al}$ exposures to long term adaptive Al resistance mechanisms. Future studies focusing should evaluate how time of Al exposure may be related to OA exudation and the dynamics of root exudation as an $\mathrm{Al}$ resistance mechanism (Heim et al., 2000).

\subsubsection{Total phenol exudation}

The exudation of phenolic compounds may function to chelate $\mathrm{Al}$ in the rhizosphere and may play a role in protecting plants from the perturbations associated with metal exposure (Heim et al. 2000, Nguyen et al. 2003). The current study showed that total phenol exudation was significantly decreased in response to Al treatments at both time points (Figure 2-3a, 2-3b, Table A.4). This suggests that exudation of phenols do not play a role in external detoxification of Al in poplar genotypes. Several other reports suggest that phenol exudation is not associated with Al resistance. Nguyen et al. (2003) noted limited exudation of phenol compounds from the roots of four tropical woody species, with levels significantly below those recorded in the present study (even accounting for mass basis differences). Similarly, in Norway spruce, no change was found in total phenol exudation after Al exposure (Heim et al., 2000; Heim et al., 2001). Together, these data do not support Al-phenol chelation as a potential Al-resistance strategy in woody species.

\subsubsection{Exudate TOC}

In the current study, trends seen in exudation of organic acids and total phenols of poplar genotypes were not reflected in overall solution TOC concentrations (Figures 2-4 and Figure 214 and Figure 2-15). Root exudation in tree species may be quite complex in composition and may account for almost 6\% of a tree's total carbon allocation (Grayston et al., 1996). Common tree roots exudates include organic acid and phenolic compounds and other non-Al binding 
exudates such as sugars, amino acids and other carbohydrates (Heim et al., 2000; Heim et al., 2001; Jones et al., 2003; Nguyen et al., 2003; Walker et al., 2003; Silva et al., 2004; Qin et al., 2007; Naik et al., 2009). In the current study, the exudation of organic acids accounted for between 3 and 15\% of TOC and phenolics between 2 and 10\% of TOC, depending on genotype/treatment. These contributions are significantly less than those reported by Naik et al. (2009) for two Populus species, which may reflect differences in culture systems between these two studies.

\subsubsection{Root tip organic acid concentration}

Internal detoxification of $\mathrm{Al}$ has also been proposed as an $\mathrm{Al}$ tolerance mechanism in several species (Delihaze and Ryan, 1995; Wattanbe and Osaki, 2002; Ma et al., 2001; Naik et al., 2009). In the current study, no clear pattern of root tip OA content in response to Al was observed that would support OA accumulation as an Al-detoxification mechanism. On the contrary, Al exposure reduced root tip citrate, malate, and succinate concentrations in OP-367 and malate in DTAC-7 (Figures 2-5 and 2-6). Increased malate concentration in root tips of Al tolerant (Naik et al., 2009) and sensitive (Smith et al., 2011) poplar genotypes has been previously reported.

As with organic acid exudation, patterns of OA accumulation may vary with duration of exposure and may reflect complex interactions between carbon flux through the TCA cycle, demands for secondary compounds, and exudation of low molecular weight OAs (Piñeros et al., 2002). Smith et al. (2011) noted clear segregation of Al resistance responses in poplar genotypes following 30 days of exposure to Al. In that study, DTAC-7 exhibited low concentrations of citrate in root tips and low symplastic Al concentrations compared to Al sensitive OP-367. However, in the current study, DTAC-7 exhibited sustained root tip citrate concentrations after 1 and 7 days, whereas root citrate concentration declined precipitously in OP-367 after 7 days of exposure (Figures 2-5 and 2-6). DTAC-7 also exhibited elevated symplastic Al compared to PC367 , but only after 1 day of exposure. Changes in tissue OA concentrations could be attributed to exudation demands or related to Al-induced changes in metabolism (Lopez-Bucio et al., 2000; Kochian et al., 2005; Barceló and Poschenrieder, 2002). Such complex patterns are typical in the literature and support the view that $\mathrm{Al}$ resistance is a complex trait (Piñeros et al., 2002, Nian et al., 2004). 


\subsubsection{Root tip total phenol}

The accumulation of phenolic compounds in roots may be a physiological response to oxidative stress resulting from metal exposure (Heim et al., 2001, Naik et al., 2009). The concentration of total phenols in root tips of Al tolerant DTAC-7 was consistently higher than that in OP-367 in response to $\mathrm{Al}$ over all $\mathrm{Al}$ treatments and exposure times (Figure 2-7c, 2-7d). However, while there were genotypic differences in the concentration of total phenol in roots, there were no consistent patterns in the accumulation of phenolics in response to Al that suggested that these played a role in Al resistance (Figure 2-7). This was consistent with the findings of Tolrá et al. (2005) in common sorrell.

\subsubsection{Apoplastic, symplastic and total Al in root tips}

Previous study of the partitioning of $\mathrm{Al}$ in roots of poplar genotypes indicated that $\mathrm{Al}$ sensitivity was associated with elevated compartmentation within the symplast (Smith et al. 2011). The uptake of Al may lead to perturbations of cellular physiology that lead to reductions in growth. In the current study, Al-resistant DTAC-7 had double the amount of apoplastic Al compared to OP-367 at $200 \mu \mathrm{M}$ Al following one day of Al exposure (Figure 2-9a). However, the pattern was reversed after seven days of exposure, with OP-367 accumulating almost double the amount of apoplastic Al (Figure 2-9b). Symplastic Al was also elevated in DTAC-7 after one day, but did not differ between the genotypes after seven days of exposure (Figure 2-9). While these patters differ from those found in the long-tern exposures employed by Smith et al. (2011), the elevated apoplastic Al in OP-367 after seven days is consistent with lesser concentrations of solution bound $\mathrm{Al}$ resulting from the exudation of citrate in these genotypes (Figure 2-12) (Sattelmacher, 2000; Nowak and Friend, 2005).

The elevated symplastic Al in DTAC-7 compared to OP-367 after one day of Al exposure at $200 \mu \mathrm{M} \mathrm{Al}$ (Figure 2-9c) and its subsequent recovery (Figure 2-9d) may reflect some fundamental difference between these genotypes that affects the driving force for $\mathrm{Al}$ accumulation. Differences in root cell membrane electrical potentials, for example, may provide differential driving forces for Al accumulation in the short term (Olivetti et al., 1995). These 
findings may be supported by Vasquez et al. (1999), who showed that Al may enter the symplast well before severe cell damage has occurred. Subsequent recovery at seven days may reflect the operation of exudation processes that bind $\mathrm{Al}$ in solution (Figure 2-12).

Total Al concentration in poplar roots after one day of $\mathrm{Al}$ exposure exhibited no difference between genotypes (Figure 2-9e). However, total Al in root tips showed the same trend as the apoplastic Al fraction after seven days of Al treatment (Figure 2-9f). This suggests that after intermediate time exposures to Al, apoplastic fractions in root tips can govern total $\mathrm{Al}$ concentrations in poplar root tips. The apoplast functions as a cation exchanger and would represent a sizable sink for Al accumulation (Ma et al., 1999; Sattelmacher, 2000). Total root Al concentration values and trends are not comparable to those presented for poplar genotypes by Smith et al. (2011) because those measures were on total toot systems are the current on root tips. Tice et al. (1992) noted differences in cellular fractions after two days of Al exposure in wheat genotypes, with the Al-sensitive variety accumulating greater quantities of apoplastic, symplastic and residual Al.

\subsubsection{Callose}

Previous studies have examined callose production in root tips in tree species in response to Al exposure (Hirano et al., 2004; Hirano and Brunner, 2006), however studies on genotypic differences in callose accumulation in response to Al have only been undertaken in agricultural species (Horst et al., 1997; Wissemeier et al., 1998; Yang et al., 2000). Recently Smith et al. (2011) found that Al tolerance in Populus genotypes could be distinguished based on callose accumulation in root tips, with strong correlations between tolerance indices based on biomass and root tip callose concentration. The current study corroborated those findings with the Al tolerant DTAC-7 accumulating less callose than OP-367 over all treatments (Figure 2-10). These findings suggest callose as a good physiological measure of Al tolerance in Populus and may be used to rapidly and simply discriminate Al-resistant genotypes.

\subsubsection{Biomass}

Despite observed significant physiological differences between the two poplar genotypes induced by Al, no significant differences were observed in root or shoot biomass over all 
treatments after one day of Al exposure (Figure 2-11 a, c). However, after seven days of Al exposure, significant differences in shoot biomass were observed at $200 \mu \mathrm{M} \mathrm{Al}$ with Al-induce reductions being more pronounced in OP-367 that DTAC-7 (Figure 2-11b). DTAC-7 also had consistently higher root biomass over all Al treatments after seven days of exposure (Figure 211d). These differences in growth sensitivity are consistent with other poplar genotypes of the same lineages exposed to Al treatments for seven days (Steiner et al., 1984) and thirty days (Smith et al., 2011).

\subsubsection{Al resistance mechanisms}

Exudation of OA's has been proposed as an effective $\mathrm{Al}$ tolerance mechanism that chelates Al externally in the rhizosphere, rendering it non-phytotoxic (Delihaze and Ryan, 1995; Barcelo and Poschenrieder, 2002; Kochian et al., 2005; Naik et al., 2009). In the current study, the exudation of citrate responded dramatically to $\mathrm{Al}$ exposure, whereas malate and oxalate, while responsive to $\mathrm{Al}$, were produced to much lesser extents in response to $\mathrm{Al}$ treatments (Figure 1,2). The goals of this study were to examine how $\mathrm{Al}$ resistance mechanisms, such as citrate exudation, would be related to the speciation of $\mathrm{Al}$ in the rhizosphere and other plant responses to Al. Citrate exudation should chelate $\mathrm{Al}$ and genotypes with higher levels of citrate exudation should exhibit lower levels of physiological stress, such as callose accumulation in root tips.

To our knowledge, this is the first report analyzing levels of organically bound Al within nutrient solution, plant exudates, and stress physiology markers. Over all time points and $\mathrm{Al}$ treatments, DTAC-7 had significantly higher levels of bound Al in solution compared to OP-367 (Figure 2-8, Table A.4). Citrate exudation was also highest in DTAC-7 over all Al treatments and times of exposure (Figure 2-1a, 2-2a, Table A.5). A positive relationship was found between the level of bound $\mathrm{Al}$ in solution and the level of citrate exudation in these poplar genotypes (Figure 2-12). This finding supports the existence of citrate as an effective chelator of $\mathrm{Al}$ in the rhizosphere of Populus genotypes exposed to Al. Although the concentration of bound $\mathrm{Al}$ was relatively low, these values are for a large volume hydroponic exposure system. In thin layer solutions at the root surface and in the cell walls in a soil system, these differences in $\mathrm{Al}$ speciation between poplar genotypes would be more pronounced.

Callose accumulation in root tips has been widely recognized as an effective 
physiological marker of Al stress in crop (Wissemeier et al., 1992; Horst et al., 1997) and tree species (Hirano et al., 2004; Hirano et al., 2006). In the current study, callose accumulation was induced by $\mathrm{Al}$ exposure after one day (Figure 2-10). The Al tolerant genotype could be distinguished based on callose accumulation, with DTAC-7 accumulating less callose than OP367 over all Al treatments and times (Figure 2-10). The negative relationship between callose accumulation in root tips and citrate exudation (Figure 2-12) further supports citrate as an Al tolerance mechanism in poplar. Other studies have examined citrate exudation and callose accumulation concurrently (Yang et al., 2000; Qin et al., 2007). However, this study is the first to directly correlate callose accumulation and citrate exudation on a genotypic basis.

In the short term, the patterns of $\mathrm{Al}$ speciation, callose accumulation, and citrate exudation are consistent with citrate exudation representing an Al resistance strategy in Populus. The Al-resistant genotype DTAC-7 maintained carbon flux into the rhizosphere under Al exposure (Figures 2-14 and 2-15) and the changes in C flux in comparison to controls were related to changes in OA exudation. Carbon flux from the roots of OP-367 generally declined in response to $\mathrm{Al}$ (Figures 2-14 and 2-15). In the longer term (7 days), however, organic acid exudation and carbon flux in general declined compared to short-term exposures (Figures 2-1 and 2-2). This pattern suggests that Al resistance in poplar may not solely rely on organic acid production and, with the numerous short-term exposure and exudation studies in the literature, points to the need for longer-term studies on Al resistance, exudation, and rhizosphere Al speciation.

\subsubsection{Conclusions}

This work shows that $\mathrm{Al}$ tolerant and susceptible genotypes can be distinguished on a physiological basis over short and long term Al exposure. Although the more Al resistant genotype could be identified by biomass differences after only seven days of Al exposure, physiological responses, such as OA exudation and root tip callose accumulation, divereged after as little as one day of $\mathrm{Al}$ exposure. These distinct differences in physiology between genotypes in response to Al suggest that poplar represents a good model system to further elucidate genetic mechanisms of $\mathrm{Al}$ tolerance in a tree species.

In this study, we hypothesized that OA exudation would be greater in the Al tolerant Populus genotype DTAC-7 and that this exudation functions as an Al tolerance mechanism in 
this genotype. Exudation of citrate and malate was induced by Al exposure and oxalate production was also stimulated by Al. Of these responses, citrate exudation was found to be highest in DTAC-7 and this exudation was coupled with increased bound $\mathrm{Al}$ in the rhizosphere and with decreased callose accumulation in root tips. The fractionation of Al within the root did not provide any clear indication that citrate production altered the fate of $\mathrm{Al}$ within roots in the short term. As time of $\mathrm{Al}$ exposure increased from one to seven days, OA exudation declined. This suggests that $\mathrm{OA}$ exudation may not be the sole mechanism of $\mathrm{Al}$ resistance in poplar.

After seven days of Al exposure, the shoot and root biomass of the Al tolerant DTAC-7 genotype were significantly greater than the shoot and root biomass of OP-367 under Al exposure, indicating that the Al-induced physiological responses were translated into differences in growth between these genotypes. The availability of Al-resistant genotypes and genetic resources for poplar may yield successful genotypes for sustainable reforestation/reclamation and carbon sequestration projects where soil acidity may limit tree growth (Godbold and Brunner, 2007). Furthermore, these physiological response mechanisms of hybrid poplar genotypes can be used to probe the poplar genome for genetic traits conferring acid soil tolerance for future work aimed at developing transgenic $\mathrm{Al}$ resistant poplar genotypes suitable for production on acidic soils. 


\subsection{CONCLUSIONS}

Soil acidity is a global concern for both agriculture and silviculture. Approximately $40 \%$ of arable land has acidic soils where nutrient limitation and soil metal availability, especially Al, may limit plant growth. Soil acidity is exacerbated by various agricultural practices and from the long-term deposition of nitrogen into ecosystems. While the application of lime to offset acidity is practical on agricultural sites, such practice is not feasible for forested ecosystems impacted by nitrogen deposition. In addition, vast areas throughout the Appalachian region that are impacted by coal mining are also plagued by soil acidity due to weathering reactions of the overburden. While such sites are often reclaimed with grasses or other herbaceous plants, such practices may not optimize ecosystem services in comparison to the forested ecosystems that once covered these lands. Reclamation to trees would provide vast benefits in regards to carbon storage and nutrient and water cycling. Therefore utilizing fast growing, Al tolerant tree species in these areas can help restore the productivity in these disrupted areas. With increasing demands for bioenergy, the reclamation of once mined lands with fast growing Populus genotypes may provide a sustainable option for biomass production in the future.

The first study of this thesis aimed to assess the genotypic variation in $\mathrm{Al}$ resistance/sensitivity of Populus genotypes. To assess these differences, we measured growth and callose production of eight genotypes representing crosses of three poplar species as indicators of $\mathrm{Al}$ resistance as well as potential mechanisms of $\mathrm{Al}$ resistance, including $\mathrm{CW}$ pectin content and root tissue OA accumulation. Finally, we assessed the relationships between tolerance indices and resistance mechanisms and the concentrations of symplastic, apoplastic and total $\mathrm{Al}$ in the root to determine the efficacy of these mechanisms in conferring $\mathrm{Al}$ resistance to Populus genotypes. This study showed that Al tolerant Populus genotypes could be distinguished by lower callose accumulation in root tips. Aluminum tolerant genotypes also exhibited significantly lower symplastic Al concentrations in root tips, which fits a model based on $\mathrm{Al}$ exclusion as the basis of $\mathrm{Al}$ resistance. While $\mathrm{Al}$ susceptible genotypes exhibited increased OA accumulation in root tips, which could unction as an internal detoxification system, this accumulation did not convey $\mathrm{Al}$ tolerance. This study illustrated the high degree of genetic variability in Al tolerance of Populus, which could be useful in developing future reforestation projects or in undertaking transgenic research to combine $\mathrm{Al}$ resistance traits with other desirable traits in Populus. 
Observations of limited uptake of $\mathrm{Al}$ into the symplast of $\mathrm{Al}$ resistant genotypes in the first study suggested that Al tolerant Populus genotypes possess an external Al chelation mechanism that promotes tolerance. In other species, Al resistance is associated with the exudation of organic acids (OAs) that chelate and detoxify Al in the root zone. For this reason, the second study in this thesis aimed to assess the role of root exudation in Al tolerance in Populus genotypes. I hypothesized that Al tolerant genotypes would exhibit elevated levels of root exudation of OAs such as citrate, malate, or oxalate that would correlate with $\mathrm{Al}$ resistance. Further, I hypothesized that this increased exudation would result in higher levels of organically bound $\mathrm{Al}$ in solution-bound $\mathrm{Al}$ is not toxic to plants. Results from this study confirmed the hypothesis that the Al tolerant genotypes DTAC-7 exuded more OAs over short- and long-term Al exposure, with citrate being the dominant $\mathrm{OA}$ in the exudation profile. As with the first study, callose accumulation in the Al tolerant genotype was significantly lower than that in the Al sensitive genotype. While OA exudation was stimulated by $\mathrm{Al}$ exposure, the opposite trend was observed for phenol exudation, suggesting no role for this potential Al-binding molecule in Al tolerance in Populus genotypes. While this study suggested that the exudation of citrate plays a role in Al tolerance of Populus genotypes, OA exudation decreased as exposure time to Al increased, suggesting that exudation may be primarily a short-term Al tolerance mechanism. Together, this second study suggests that a long term study of exudation and Al chelation and tolerance should be undertaken to investigate possible long-term Al resistance strategies in Populus. Additionally, the results highlight citrate as a possible Al tolerance mechanism that could be manipulated in transgenic studies to promote Al tolerance in Populus genotypes.

These studies show that Populus is a good candidate for future reforestation projects in areas characterized by high soil acidity. Both studies illustrated distinct delineations in resistance and underlying physiology between Al tolerant/susceptible genotypes. This in-depth understanding of Al stress physiology in Populus coupled with the high degree of genetic variation in tolerance allows for future production of Al tolerant Populus genotypes. These genotypes can promote increased fiber production, carbon sequestration and plant productivity in areas affected by soil acidity.

\section{APPENDIX}

Table A. 1. Significance of treatment effects for growth and biochemical measurements of eight poplar genotypes 
grown at $0,50,100,200$ and $500 \mu \mathrm{M}$ Al. Significance is denoted as follows: ${ }^{*}, P<0.05 ; * *, P<0.01{ }^{* * *}, P<0$ .001 .

\begin{tabular}{|c|c|c|c|c|c|c|}
\hline \multirow[t]{2}{*}{ Measurement } & \multicolumn{2}{|c|}{ Genotype } & \multicolumn{2}{|c|}{ Al } & \multicolumn{2}{|c|}{ Genotype $\times$ Al } \\
\hline & $F$ & $P$ & $F$ & $P$ & $F$ & $P$ \\
\hline Shoot Biomass (g) & 288.7 & $* * *$ & 295.8 & $* * *$ & 13.7 & $* * *$ \\
\hline Root Biomass (g) & 226.5 & $* * *$ & 236.0 & $* * *$ & 17.7 & $* * *$ \\
\hline Root:Shoot (g) & 119.7 & $* * *$ & 12.3 & $* * *$ & 5.9 & $* * *$ \\
\hline Shoot Al $\left(\mu \mathrm{mol} \mathrm{g}{ }^{-1} \mathrm{DW}\right)$ & 22.5 & $* * *$ & 71.8 & $* * *$ & 2.8 & $* * *$ \\
\hline Root Al $\left(\mu \mathrm{mol} \mathrm{g}{ }^{-1} \mathrm{DW}\right)$ & 5.7 & $* * *$ & 206.5 & $* * *$ & 2.0 & $* *$ \\
\hline Apoplastic Al ( $\left.\mathrm{mmol} \mathrm{g}^{-1} \mathrm{DW}\right)$ & 79.4 & $* * *$ & 483.3 & $* * *$ & 19.2 & $* * *$ \\
\hline Symplastic Al ( $\left.\mu \mathrm{mol} \mathrm{g}{ }^{-1} \mathrm{DW}\right)$ & 51.6 & $* * *$ & 387.5 & $* * *$ & 10.2 & $* * *$ \\
\hline Callose $\left(\mu \mathrm{g} \mathrm{CE} \mathrm{g}^{-1} \mathrm{FW}\right)$ & 12.4 & $* * *$ & 150.7 & $* * *$ & 2.3 & $* * *$ \\
\hline Pectin $\left(\mu \mathrm{g} \mathrm{GAE} \mathrm{g}^{-1} \mathrm{FW}\right)$ & 96.9 & $* * *$ & 460.3 & $* * *$ & 20.0 & $* * *$ \\
\hline Citrate $\left(\mu \mathrm{mol} \mathrm{g}{ }^{-1} \mathrm{FW}\right)$ & 88.4 & $* * *$ & 382.2 & $* * *$ & 23.0 & $* * *$ \\
\hline Malate $\left(\mu \mathrm{mol} \mathrm{g}{ }^{-1} \mathrm{FW}\right)$ & 239.9 & $* * *$ & 1222.4 & $* * *$ & 84.5 & $* * *$ \\
\hline Succinate $\left(\mu \mathrm{mol} \mathrm{g} \mathrm{g}^{-1} \mathrm{FW}\right)$ & 192.2 & $* * *$ & 1099.8 & $* * *$ & 26.4 & $* * *$ \\
\hline Formate $\left(\mu \mathrm{mol} \mathrm{g}{ }^{-1} \mathrm{FW}\right)$ & 86.4 & $* * *$ & 229.9 & $* * *$ & 15.7 & $* * *$ \\
\hline
\end{tabular}


Table A.2. Significance of treatment effects for growth and biochemical measurements of three poplar hybrid crosses grown at $0,50,100,200$ and $500 \mu \mathrm{M} \mathrm{Al}$. Significance is denoted as follows: ${ }^{*}, P<0.05$; **, $P<0.01$; ***, $P<0.001$.

\begin{tabular}{|c|c|c|c|c|c|c|}
\hline \multirow[t]{2}{*}{ Measurement } & \multicolumn{2}{|c|}{ Hybrid } & \multicolumn{2}{|c|}{ Al } & \multicolumn{2}{|c|}{ Hybrid $\times$ Al } \\
\hline & $F$ & $P$ & $F$ & $P$ & $F$ & $P$ \\
\hline Shoot Biomass (g) & 0.7 & ns & 67.2 & $* * *$ & 4.3 & $* *$ \\
\hline Root Biomass (g) & 5.6 & $*$ & 62.1 & $* * *$ & 6.0 & $* * *$ \\
\hline Root:Shoot (g) & 0.6 & ns & 2.3 & ns & 1.8 & ns \\
\hline Shoot Al ( $\left.\mu \mathrm{mol} \mathrm{g}{ }^{-1} \mathrm{DW}\right)$ & 3.7 & ns & 44.8 & $* * *$ & 3.6 & $* *$ \\
\hline $\operatorname{Root} \mathrm{Al}\left(\mu \mathrm{mol} \mathrm{g}{ }^{-1} \mathrm{DW}\right)$ & 1.3 & ns & 139.7 & $* * *$ & 0.8 & ns \\
\hline Apoplastic Al ( $\left.\mu \mathrm{mol} \mathrm{g} \mathrm{g}^{-1} \mathrm{DW}\right)$ & 3.9 & ns & 37.6 & $* * *$ & 3.6 & $*$ \\
\hline Symplastic Al ( $\left.\mu \mathrm{mol} \mathrm{g}{ }^{-1} \mathrm{DW}\right)$ & 14.5 & $* *$ & 30.6 & $* * *$ & 3.2 & $*$ \\
\hline Callose $\left(\mu \mathrm{g} \mathrm{CE} \mathrm{g}^{-1} \mathrm{FW}\right)$ & 9.8 & $*$ & 80.9 & $* * *$ & 11.4 & $* * *$ \\
\hline $\operatorname{Pectin}\left(\mu \mathrm{g} \mathrm{GAE} \mathrm{g}^{-1} \mathrm{FW}\right)$ & 35.2 & $* *$ & 132.4 & $* * *$ & 8.6 & $* * *$ \\
\hline Citrate $\left(\mu \mathrm{mol} \mathrm{g}{ }^{-1} \mathrm{FW}\right)$ & 89.8 & $* * *$ & 225.3 & $* * *$ & 31.9 & $* * *$ \\
\hline Malate $\left(\mu \mathrm{mol} \mathrm{g}{ }^{-1} \mathrm{FW}\right)$ & 5.9 & $*$ & 15.7 & $* * *$ & 1.4 & ns \\
\hline Succinate $\left(\mu \mathrm{mol} \mathrm{g}{ }^{-1} \mathrm{FW}\right)$ & 2.5 & ns & 24.5 & $* * *$ & 3.9 & $* *$ \\
\hline Formate $\left(\mu \mathrm{mol} \mathrm{g}{ }^{-1} \mathrm{FW}\right)$ & 19.8 & $* *$ & 74.7 & $* * *$ & 13.9 & $* * *$ \\
\hline
\end{tabular}

Table A.3. Coefficient of determination $\left(\mathrm{R}^{2}\right)$ between poplar root tolerance index (TI) and root Al fractions across 
all poplar genotypes. Significance is denoted as follows: *, $P<0.05$; **, $P<0.01$; ***, $P<0.001$.

\begin{tabular}{|c|c|c|c|}
\hline $\begin{array}{c}\text { Al Treatment } \\
(\mu \mathrm{M})\end{array}$ & $\begin{array}{l}\text { Apoplastic Al } \\
\left(\mu \mathrm{mol} \mathrm{g}^{-1} \mathrm{DW}\right)\end{array}$ & $\begin{array}{l}\text { Symplastic Al } \\
\left(\mu \mathrm{mol} \mathrm{g}^{-1} \mathrm{DW}\right)\end{array}$ & $\begin{array}{c}\text { Total Al } \\
\left(\mu \mathrm{mol} \mathrm{g}{ }^{-1} \mathrm{DW}\right)\end{array}$ \\
\hline 0 & - & - & - \\
\hline 50 & $0.471 * *$ & $-0.558 * * *$ & -0.252 \\
\hline 100 & 0.293 & $-0.704 * * *$ & -0.251 \\
\hline 200 & $0.802 * * *$ & $-0.926 * * *$ & -0.145 \\
\hline 500 & $0.754 * * *$ & $-0.623 * * *$ & $-0.474 * *$ \\
\hline
\end{tabular}

Table A.4 Three way ANOVA on all measured parameters of two Populus genotypes exposed to three levels of Al 
$(0,50,200 \mu \mathrm{M})$ over two time points (1, 7 days).

Al x Genotype x Time

\begin{tabular}{|c|c|c|}
\hline Response variable & $\mathrm{F}$ & $\mathrm{P}$ \\
\hline Exudate Citrate $\left(\mu \mathrm{mol} \mathrm{g}{ }^{-1} \mathrm{DW}\right)$ & 11.826 & $<0.001$ \\
\hline Exudate Malate $\left(\mu \mathrm{mol} \mathrm{g}{ }^{-1} \mathrm{DW}\right)$ & 1.759 & 0.181 \\
\hline Exudate Lactate ( $\left.\mu \mathrm{mol} \mathrm{g}{ }^{-1} \mathrm{DW}\right)$ & 3.708 & 0.031 \\
\hline Exudate Formate $\left(\mu \mathrm{mol} \mathrm{g}{ }^{-1} \mathrm{DW}\right)$ & 6.572 & 0.003 \\
\hline Exudate Acetate $\left(\mu \mathrm{mol} \mathrm{g}{ }^{-1} \mathrm{DW}\right)$ & 0.507 & 0.605 \\
\hline Tissue Citrate ( $\left.\mu \mathrm{mol} \mathrm{g}{ }^{-1} \mathrm{DW}\right)$ & 1.391 & 0.257 \\
\hline Tissue Malate ( $\left.\mu \mathrm{mol} \mathrm{g}{ }^{-1} \mathrm{DW}\right)$ & 4.402 & 0.017 \\
\hline Tissue Succinate $\left(\mu \mathrm{mol} \mathrm{g}{ }^{-1} \mathrm{DW}\right)$ & 1.136 & 0.328 \\
\hline Tissue Lactate $\left(\mu \mathrm{mol} \mathrm{g}{ }^{-1} \mathrm{DW}\right)$ & 2.373 & 0.103 \\
\hline Exudate phenol $\left(\mu \mathrm{mol} \mathrm{g}{ }^{-1} \mathrm{DW}\right)$ & 0.634 & 0.534 \\
\hline Tissue phenol ( $\left.\mu \mathrm{mol} \mathrm{g}^{-1} \mathrm{DW}\right)$ & 0.045 & 0.957 \\
\hline Exudate TOC ( $\mu$ molC g $\left.{ }^{-1} \mathrm{DW}\right)$ & 0.219 & 0.804 \\
\hline Bound $\mathrm{Al}(\mu \mathrm{M})$ & 2.009 & 0.1432 \\
\hline Apoplastic Al ( $\left.\mu \mathrm{mol} \mathrm{g}^{-1} \mathrm{DW}\right)$ & 31.794 & $<0.001$ \\
\hline Symplastic Al ( $\left.\mu \mathrm{mol} \mathrm{g}{ }^{-1} \mathrm{DW}\right)$ & 3.455 & 0.038 \\
\hline Total Al $\left(\mu \mathrm{mol} \mathrm{g}{ }^{-1} \mathrm{DW}\right)$ & 3.334 & 0.042 \\
\hline Callose $\left(\mu \mathrm{g} \mathrm{CE} \mathrm{g}{ }^{-1} \mathrm{FW}\right)$ & 4.101 & 0.029 \\
\hline Shoot biomass (g) & 0.305 & 0.739 \\
\hline Root biomass (g) & 1.361 & 0.264 \\
\hline
\end{tabular}

Table A.5 Two way ANOVAs on all measured parameters of two Populus genotypes exposed to three levels of Al 
$(0,50,200 \mu \mathrm{M})$ over two time points (1, 7 days). Degree of freedom are as follows $\mathrm{Al}_{2}$, genotype ${ }_{1}, \mathrm{Al} \mathrm{x}$ genotype 4

\begin{tabular}{lcccccc} 
1d & \multicolumn{2}{c}{ Al } & \multicolumn{2}{c}{ Genotype } & \multicolumn{2}{c}{ Al x Genotype } \\
\hline & $\mathrm{F}$ & $\mathrm{P}$ & $\mathrm{F}$ & $\mathrm{P}$ & $\mathrm{F}$ & $\mathrm{P}$ \\
\hline Exudate Citrate $\left(\mu \mathrm{mol} \mathrm{g}^{-1} \mathrm{DW}\right)$ & 46.078 & $<0.001$ & 87.449 & $<0.001$ & 23.406 & $<0.001$ \\
Exudate Malate $\left(\mu \mathrm{mol} \mathrm{g}^{-1} \mathrm{DW}\right)$ & 31.946 & $<0.001$ & 5.208 & 0.031 & 1.347 & 0.276 \\
Exudate Lactate $\left(\mu \mathrm{mol} \mathrm{g}^{-1} \mathrm{DW}\right)$ & 2.98 & 0.076 & 12.358 & 0.003 & 20.149 & $<0.001$ \\
Exudate Formate $\left(\mu \mathrm{mol} \mathrm{g}^{-1} \mathrm{DW}\right)$ & 4.779 & 0.018 & 16.284 & $<0.001$ & 10.269 & $<0.001$ \\
Exudate Acetate $\left(\mu \mathrm{mol} \mathrm{g}^{-1} \mathrm{DW}\right)$ & 3.457 & 0.049 & 12.408 & 0.002 & 5.219 & 0.014 \\
Exudate Oxalate $\left(\mu \mathrm{mol} \mathrm{g}^{-1} \mathrm{DW}\right)$ & 25.27 & 0.004 & 9.674 & $<0.001$ & 3.181 & 0.055 \\
Tissue Citrate $\left(\mu \mathrm{mol} \mathrm{g}^{-1} \mathrm{DW}\right)$ & 5.671 & 0.009 & 5.594 & 0.026 & 1.658 & 0.209 \\
Tissue Malate $\left(\mu \mathrm{mol} \mathrm{g}^{-1} \mathrm{DW}\right)$ & 4.62 & 0.033 & 19.098 & $<0.001$ & 0.406 & 0.67 \\
Tissue Succinate $\left(\mu \mathrm{mol} \mathrm{g}^{-1} \mathrm{DW}\right)$ & 27.221 & $<0.001$ & 0.389 & 0.538 & 2.993 & 0.0683 \\
Tissue Lactate $\left(\mu \mathrm{mol} \mathrm{g}^{-1} \mathrm{DW}\right)$ & 72.077 & $<0.001$ & 44.708 & $<0.001$ & 40.849 & $<0.001$ \\
Exudate phenol $\left(\mu \mathrm{mol} \mathrm{g}^{-1} \mathrm{DW}\right)$ & 51.648 & $<0.001$ & 4.881 & 0.036 & 2.267 & 0.123 \\
Tissue phenol $\left(\mu \mathrm{mol} \mathrm{g}{ }^{-1} \mathrm{DW}\right)$ & 23.287 & $<0.001$ & 45.709 & $<0.001$ & 3.599 & 0.042 \\
Exudate TOC $\left(\mu \mathrm{molC} \mathrm{g}^{-1} \mathrm{DW}\right)$ & 7.506 & 0.004 & 1.275 & 0.273 & 9.562 & 0.001 \\
Bound Al $(\mu \mathrm{M})$ & 95.421 & $<0.001$ & 58.592 & $<0.001$ & 18.521 & $<0.001$ \\
Apoplastic Al $\left(\mu \mathrm{mol} \mathrm{g}{ }^{-1} \mathrm{DW}\right)$ & 42.071 & $<0.001$ & 5.598 & 0.021 & 11.495 & $<0.001$ \\
Symplastic $\mathrm{Al}\left(\mu \mathrm{mol} \mathrm{g}^{-1} \mathrm{DW}\right)$ & 98.871 & $<0.001$ & 12.562 & 0.002 & 17.072 & $<0.001$ \\
Total Al $\left(\mu \mathrm{mol} \mathrm{g} \mathrm{gW}^{-1} \mathrm{DW}^{-1}\right.$ & 129.635 & $<0.001$ & 0.872 & 0.359 & 1.501 & 0.2409 \\
Callose $\left(\mu \mathrm{CE} \mathrm{g}^{-1} \mathrm{FW}\right.$ & 83.118 & $<0.001$ & 34.619 & $<0.001$ & 5.747 & 0.018 \\
Shoot biomass $(\mathrm{g})$ & 10.978 & $<0.001$ & 9.799 & 0.004 & 0.159 & 0.854 \\
Root biomass $(\mathrm{g})$ & 4.823 & $<0.001$ & 6.337 & 0.018 & 0.168 & 0.846 \\
\hline
\end{tabular}

\begin{tabular}{lcccccc} 
7d & \multicolumn{2}{c}{ Al } & \multicolumn{2}{c}{ Genotype } & \multicolumn{2}{c}{ Al x Genotype } \\
\hline & $\mathrm{F}$ & $\mathrm{P}$ & $\mathrm{F}$ & $\mathrm{P}$ & $\mathrm{F}$ & $\mathrm{P}$ \\
\hline Exudate Citrate $\left(\mu \mathrm{mol} \mathrm{g}^{-1} \mathrm{DW}\right)$ & 67.925 & $<0.001$ & 2.858 & 0.103 & 1.789 & 0.188 \\
Exudate Malate $\left(\mu \mathrm{mol} \mathrm{g}{ }^{-1} \mathrm{DW}\right)$ & 15.016 & $<0.001$ & 13.177 & 0.002 & 3.451 & 0.05 \\
Exudate Lactate $\left(\mu \mathrm{mol} \mathrm{g} \mathrm{g}^{-1} \mathrm{DW}\right)$ & 5.83 & 0.011 & 0.239 & 0.631 & 0.219 & 0.805 \\
Exudate Formate $\left(\mu \mathrm{mol} \mathrm{g}^{-1} \mathrm{DW}\right)$ & 2.376 & 0.112 & 4.606 & 0.041 & 3.556 & 0.043 \\
Exudate Acetate $\left(\mu \mathrm{mol} \mathrm{g}^{-1} \mathrm{DW}\right)$ & 5.486 & 0.011 & 0.412 & 0.528 & 5.766 & 0.009 \\
Exudate Oxalate $\left(\mu \mathrm{mol} \mathrm{g}^{-1} \mathrm{DW}\right)$ & 5.142 & $<0.001$ & 0.227 & 0.155 & 1.613 & 0.216 \\
Tissue Citrate $\left(\mu \mathrm{mol} \mathrm{g}^{-1} \mathrm{DW}\right)$ & 7.681 & $<0.001$ & 20.183 & 0.003 & 5.293 & 0.013 \\
Tissue Malate $\left(\mu \mathrm{mol} \mathrm{g}^{-1} \mathrm{DW}\right)$ & 37.114 & $<0.001$ & 58.319 & $<0.001$ & 14.869 & $<0.001$ \\
Tissue Succinate $\left(\mu \mathrm{mol} \mathrm{g}^{-1} \mathrm{DW}\right)$ & 47.848 & $<0.001$ & 6.213 & 0.022 & 10.791 & $<0.001$ \\
Tissue Lactate $\left(\mu \mathrm{mol} \mathrm{g}^{-1} \mathrm{DW}\right)$ & 4.249 & 0.029 & 1.108 & 0.305 & 8.137 & 0.003 \\
Exudate phenol $\left(\mu \mathrm{mol} \mathrm{g}^{-1} \mathrm{DW}\right)$ & 31.566 & $<0.001$ & 0.796 & 0.381 & 0.309 & 0.737 \\
Tissue phenol $\left(\mu \mathrm{mol} \mathrm{g}^{-1} \mathrm{DW}\right)$ & 0.601 & 0.556 & 22.958 & $<0.001$ & 0.719 & 0.497 \\
Exudate TOC $\left(\mu \mathrm{molC} \mathrm{g}^{-1} \mathrm{DW}\right)$ & 29.861 & $<0.001$ & 12.399 & 0.002 & 0.478 & 0.626 \\
Bound $\mathrm{Al}(\mu \mathrm{M})$ & 249.048 & $<0.001$ & 118.951 & $<0.001$ & 40.157 & $<0.001$ \\
Apoplastic Al $\left(\mu \mathrm{mol} \mathrm{g}^{-1} \mathrm{DW}\right)$ & 74.537 & $<0.001$ & 1.078 & 0.308 & 13.671 & $<0.001$ \\
Symplastic $\mathrm{Al}\left(\mu \mathrm{mol} \mathrm{g}{ }^{-1} \mathrm{DW}\right)$ & 145.341 & $<0.001$ & 1.801 & 0.193 & 1.619 & 0.221 \\
Total Al $\left(\mu \mathrm{mol} \mathrm{g}{ }^{-1} \mathrm{DW}^{-1}\right.$ & 120.536 & $<0.001$ & 2.171 & 0.153 & 26.094 & $<0.001$ \\
Callose $\left(\mu \mathrm{g} \mathrm{CE} \mathrm{g} \mathrm{FW}^{-1}\right.$ & 395.112 & $<0.001$ & 169.473 & $<0.001$ & 10.197 & 0.003 \\
Shoot biomass $(\mathrm{g})$ & 1.677 & 0.205 & 9.91 & 0.004 & 0.079 & 0.924 \\
Root biomass $(\mathrm{g})$ & 8.149 & 0.002 & 8.922 & 0.006 & 1.042 & 0.365 \\
\hline & & & & & &
\end{tabular}

Figure A.1. Relationships between root tissue organic acid concentrations and root tolerance index (TI). Values 
presented are means \pm S.E. $(\mathrm{n}=4)$ for specific organic acids: (a) citrate; (b) malate; (c) succinate; and (d) formate.

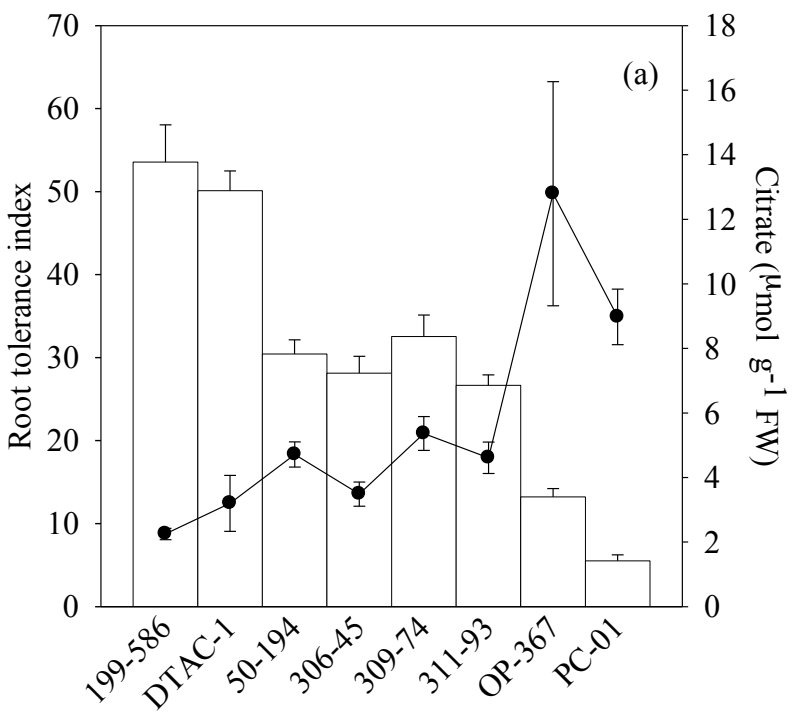

Genotype

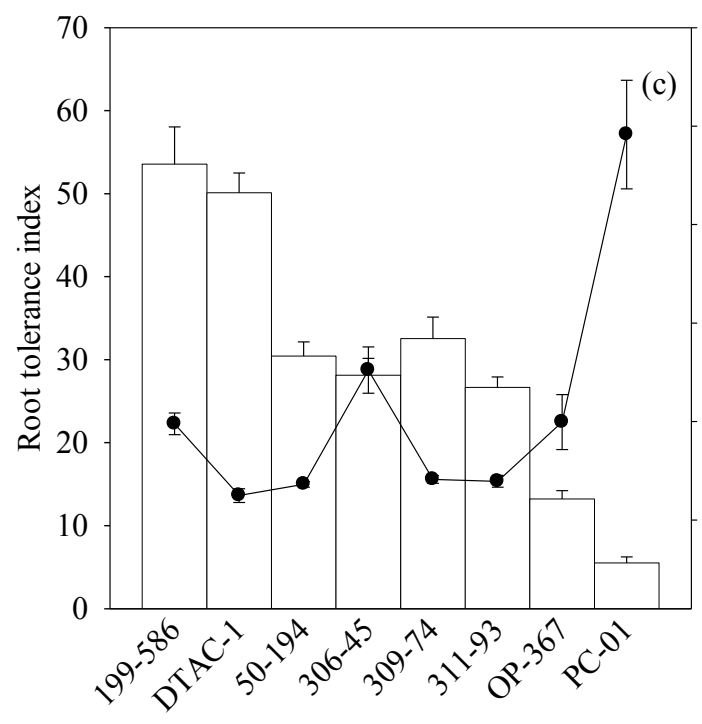

Genotype

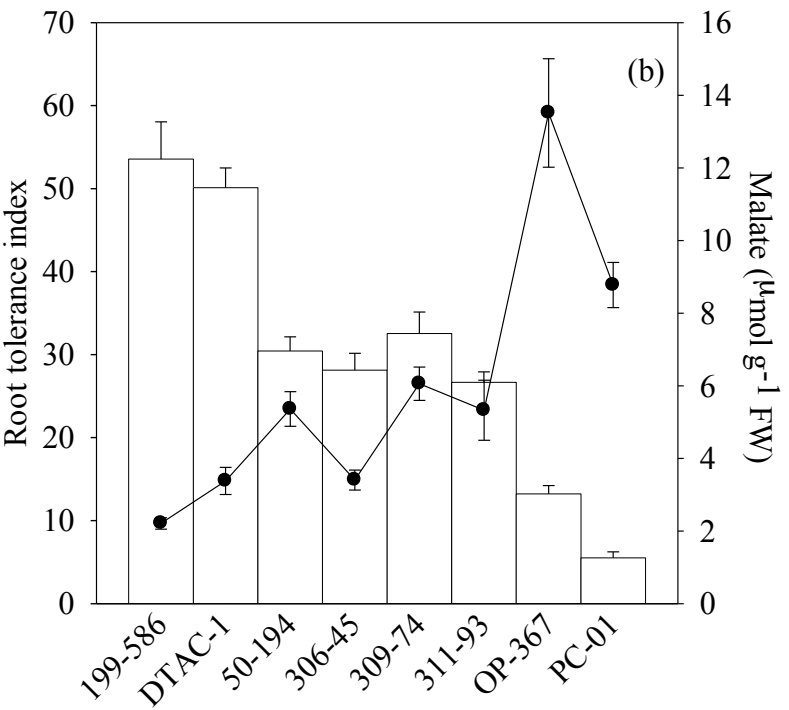

Genotype

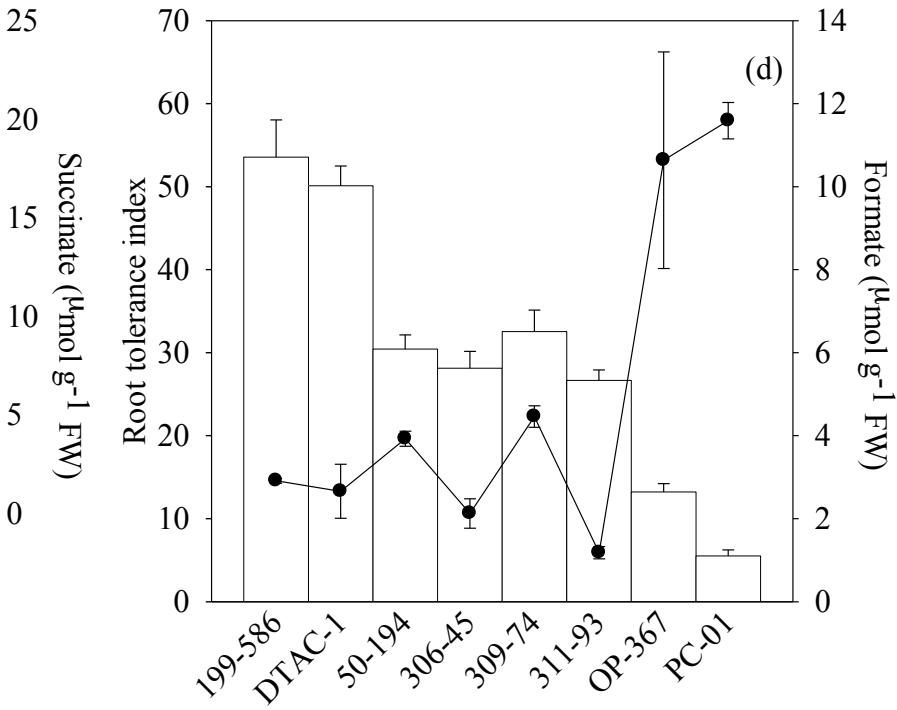

Genotype

$$
\begin{aligned}
& \longleftarrow \text { Root tolerance index } \\
& \longrightarrow \text { Organic acid }\left(\mu \mathrm{mol} \mathrm{g} \mathrm{g}^{-1} \mathrm{FW}\right)
\end{aligned}
$$




\section{REFERENCES CITED}

Aber, J, McDowell W, Nadelhoffer K, Magill A, Berntson G, Kamakea M, McNulty S, Currie W, Rustad L, Fernandez I (1998) Nitrogen saturation in temperate forest ecosystems. BioScience 48:921-934

Barceló J and Poschenrieder C (2002) Fast root growth responses, root exudates, and internal detoxification as clues to the mechanisms of aluminium toxicity and resistance: a review. Environ. Exp. Bot. 48: 75-92

Barinaga M (1997) Plant Science: Making plants aluminum tolerant. Science 276:1497-1502

Blamey FPC, Edmeades DC, Wheeler DM (1990) Role of root cation-exchange capacity in differential aluminum tolerance of lotus species. J. Plant Nutr. 13: 729-744

Blumenkrantz N and Asboe-Hansen G (1973) New method for quantitative determination of uronic acids. Anal. Biochem. 54: 484-489

Brunner I and Godbold DL (2007) Tree roots in a changing world. J. For. Res. 12: 78-82

Chang YC, Yamamoto Y, Matsumoto H (1999) Accumulation of aluminium in the cell wall pectin in cultured tobacco (Nicotiana tabacum L.) cells treated with a combination of aluminium and iron. Plant Cell Envion. 22: 1009-1017

Cuenca G, Herrera R, Medina, E (1990) Aluminium tolerance in trees of a tropical cloud forest. Plant Soil 125: 169-175

Cumming JR, Swiger TD, Kurnik BS, Panaccione DG (2001) Organic acid exudation by Laccaria bicolor and Pisolithus tinctorius exposed to aluminum in vitro. Can. J. For. Res. 31: 703-710

Cumming JR, Cumming AB, Taylor GJ (1992) Patterns of root respiration associated with the induction of aluminum tolerance in Phaseolus vulgaris L. J. Exp. Bot. 43:1075-1081

Cumming JR and Tomsetti AB (1992) Biogeochemistry of Trace Metals, Lewis Publishers, Boca Raton, FL, p.329-364.

de Macêdo CEC, van Sint Jan V, Kinet J-M, Lutts S (2009) Effects of aluminium on root growth and apical root cells in rice (Oryza sativa L.) cultivars. Reliability of screening tests to detect $\mathrm{Al}$ resistance at the seedling stage. Acta Physiol. Planta. 31: 1255-1262

Delhaize E and Ryan, PR (1995) Aluminum toxicity and tolerance in plants. Plant Physiol. 107: $315-321$

Delihaze E, Craig S, Beaton CD, Bennet RJ, Jagadish VC, Randall PJ(1993a) Aluminum 
tolerance in wheat (Triticum aestivum L.): I. Uptake and distribution of aluminum in root apices. Plant Physiol. 103:685-693

Delihaze E, Ryan PR, Randall PJ (1993b) Aluminum tolerance in wheat (Triticum aestivum L.): II. Aluminum stimulated excretion of malic acid from root apices. Plant Physiol. 103:695702

Eticha D, Stass A, Horst WJ (2005) Cell-wall pectin and its degree of methylation in the maize root-apex: significance for genotypic differences in aluminium resistance. Plant Cell Envion. 28: 1410-1420

Geburek TH and Scholz F (1992) Response of Picea abies (L.) Karst. Provenances to sulphur dioxide and aluminum: A pilot study. Water Air Soil Poll. 62: 227-232

Godbold DL and Brunner I (2007) The platform for European root science, COST action E38: An introduction and overview. Plant Biosys. 141: 390-393

Grayston SJ, Vaughn D, Jones D (1996) Rhizosphere carbon flow in trees, in comparison with annual plants: the importance of root exudation and its impact on microbial activity and nutrient availability. Appl. Soil Ecol. 5:29-56

Guglielmino N, Liberman M, Catesson AM, Mareck A, Prat R et al. (1997) Pectin methylesterases from poplar cambium and inner bark: localization, properties and seasonal changes. Planta 202: 70-75

Halvin JL, Beaton JD, Tisdale SL, Nelson WL (1999) Soil Fertility and Fertilizers: An Introduction to Nutrient Management, 6 ed. Prentice Hall, Upper Saddle River, NJ

Hansen EA, Ostrey ME, Johnson WD, Tolstead DN, Netzer DA, Berguson WE, Hall RB (1994) Field performance of Populus in short rotation intensive culture plantations in the northcentral U.S. Res. Pap. NC-320. St. Paul, MN: U.S. Department of Agriculture, Forest Service, North Central Forest Research Station. 13 p.

Heim A, Brunner I, Frey B, Frossard E, Luster J (2001) Root exudation, organic acids, and element distribution in roots of Norway spruce seedlings treated with aluminum in hydroponics. J.Plant Nutr. Soil Sci. 164: 519-526

Heim A, Luster J, Brunner I, Frey B, Frossard E (2000) Effects of aluminum treatment on Norway spruce roots: Aluminum binding forms, element distribution, and release of organic substances. Plant Soil 216: 103-116

Hiradate S, Ma JF, Matsumoto H (2007) Strategies of plants to adapt to mineral stresses in problem soils, in: Donald, L.S. (Ed.), Advances in Agronomy. Academic Press, pp 65-132

Hirano Y and Brunner I (2006) Quantitative determination of callose in tree roots. 163: 1333- 
Hirano Y, Walthert L, Brunner I (2006) Callose in root apices of European chestnut seedlings: a physiological indicator of aluminum stress. Tree Physiol. 26: 431-440

Hirano Y, Pannatier EG, Zimmermann S, Brunner I (2004) Induction of callose in roots of Norway spruce seedlings after short-term exposure to aluminum. Tree Physiol. 24: 12791283

Horst WJ, Püschel AK, Schmohl N (1997) Induction of callose formation is a sensitive marker for genotypic aluminium sensitivity in maize. Plant Soil 192: 23-30

Horst WJ, Wang YX, Eticha D (2010) The role of the root apoplast in aluminium-induced inhibition of root elongation and in aluminium resistance of plants: a review. Ann. Bot., 106: $185-197$

Huang JW, Shaff JE, Grunes DL, Kochian LV (1992) Aluminum effects on calcium fluxes at the root apex of aluminum-tolerant and aluminum-sensitive wheat cultivars. Plant Physiol. 98: $230-237$

Jones DL, Dennis PG, Owen AG, van Hees PAW (2003) Organic acid behaviour in soilsmisconceptions and knowledge gaps. Plant Soil 248: 31-41

Jones DL (1998) Organic acids in the rhizosphere - a critical review. Plant Soil 205: 25-44

Jones JB and Case VW (1990) Sampling, handling and analyzing plant tissue samples, in: Westerman, R.L. (Ed.), Soil Testing and Plant Analysis, 3 ed. Soil Science Society of America, Madison, WI, pp 389-427

Karathanasis AD, Evangelou VP, Thompson YL, (1988) Aluminum and iron equilibria in soil solutions and surface waters of acid mine watersheds. J. Environ. Qual. 17: 534-543

Kinraide TB and Parker DR (1989) Assessing the phytotoxicity of mononuclear hydroxyaluminum. Plant Cell Envion. 12: 479-487

Klugh KR and Cumming JR (2007) Variations in organic acid exudation and aluminum resistance among arbuscular mycorrhizal species colonizing Liriodendron tulipifera. Tree Physiol. 27: 1103-1112

Kochian L, Piñeros, M, Hoekenga, O (2005) The physiology, genetics and molecular biology of plant aluminum resistance and toxicity. Plant Soil 274: 175-195-195

Larsen PB, Kochian LV, Howell SH (1997) Al inhibits both shoot development and root growth in als3, an Al-sensitive arabidopsis mutant. Plant Physiol. 114: 1207-1214 
Llugany M, Massot N, Wissemeier AH, Poschenrieder C, Horst WJ et al. (1994) Aluminium tolerance of maize cultivars as assessed by callose production and root elongation. J. Plant Nutr. Soil. Sci. 157: 447-451

Lopez-Bucio J, Nieto-Jacobo, MF, Ramirez-Rodriguez, VV, Herrera-Estrella L (2000) Organic acid metabolism in plants: from adaptive physiology to transgenic varieties for cultivation in extreme soils. Plant Sci. 160: 1-13

Lu E-Y and Sucoff EI (2003) Responses of quaking aspen seedlings to solution calcium and aluminum. J. Plant Nutr. 26: 97 - 123

Lux HB and Cumming, JR (2001) Mycorrhizae confer aluminum resistance to tulip-poplar seedlings. Can. J. For. Res. 31: 694-702

Ma JF, Ryan, PR, Delhaize, E (2001) Aluminium tolerance in plants and the complexing role of organic acids. Trends Plant Sci. 6: 273-278

Ma JF, Yamamoto R, Nevins DJ, Matsumoto H, Brown PH (1999) Al binding in the epidermis cell wall inhibits cell elongation of okra hypocotyl. Plant Cell Physiol. 40: 549-556

Marschner H (1991) Mechanisms of adaptation of plants to acid soils. Plant Soil 134: 1-20

Matsumoto H (2000) Cell biology of aluminum toxicity and tolerance in higher plants. Int. Rev. Cytol. 200: 1-46

McCormick LH and Steiner KC (1978) Variation in aluminum tolerance among six genera of trees. Forest Sci. 24: 565-568

Miyasaka SC and Hawes MC (2001) Possible role of root border cells in detection and avoidance of aluminum toxicity. Plant Physiol. 125:1978-1987

Miyasaka SC, Kochian LV, Shaff JE, Foy CD (1989) Mechanisms of aluminum resistance in wheat. Plant Physiol. 91: 1188-1196

Naidoo G, Stewart JM, Lewis RJ (1978) Accumulation sites of Al in snapbean and cotton roots. Agron. J. 70: 489-492

Naik D, Smith E, Cumming JR (2009) Rhizosphere carbon deposition, oxidative stress and nutritional changes in two poplar species exposed to aluminum. Tree Physiol. 29: 423-436

Nguyen NT, Nakabayashi K, Thompson J, Fujita K (2003) Role of exudation of organic acids and phosphate in aluminum tolerance of four tropical woody species. Tree Physiol. 23: 1041-1050

Nian H, Yang ZM, Huang H, Yan XL, Matsumoto H (2004) Citrate secretion induced by 
aluminum stress may not be a key mechanism responsible for differential aluminum tolerance of some soybean genotypes. J. Plant Nutr. 27: 2047-2066

Nowak J and Friend AL (2005) Aluminum fractions in root tips of slash pine and loblolly pine families differing in Al resistance. Tree Physiol. 25: 245-250

Olivetti GP, Cumming JR, Etherton B (1995) Membrane potential depolarization of root cap cells precedes aluminum tolerance in snapbean. Plant Physiol. 109: 123-129

Osawa H and Kojima K (2006) Citrate-release-mediated aluminum resistance is coupled to the inducible expression of mitochondrial citrate synthase gene in Paraserianthes falcataria. Tree Physiol. 26: 565-574

Piñeros MA, Magalhaes JV, Carvalho Alves VM, Kochian LV (2002) The physiology and biophysics of an aluminum tolerance mechanism based on root citrate exudation in maize. 129: 1194-1206

Purcino AAC, Alves VMC, Parentoni SN, Belele CL, Loguercio LL (2003) Aluminum effects on nitrogen uptake and nitrogen assimilating enzymes in maize genotypes with contrasting tolerance to aluminum toxicity. J. Plant Nutr. 26: 31-61

Qin R, Hirano Y, Brunner I (2007) Exudation of organic acid anions from poplar roots after exposure to Al, $\mathrm{Cu}$ and $\mathrm{Zn}$. Tree Physiol. 27: 313-320

Qiu J and Jin X (2002) Development and optimization of organic acid analysis in tobacco with ion chromatography and suppressed conductivity detection. J. Chromatgr. A 950: 81-88

Rangel AF, Rao IM, Horst WJ (2009) Intracellular distribution and binding state of aluminum in root apices of two common bean (Phaseolus vulgaris) genotypes in relation to Al toxicity. Physiol. Plant. 135: 162-173

Ruf M and Brunner I (2003) Vitality of tree fine roots: reevaluation of the tetrazolium test. Tree Physiol. 23: 257-263

Sattelmacher B (2000) The apoplast and its significance for plant mineral nutrition. New Phytol. 149: $167-192$

Schaedle M, Thornton FC, Raynal DJ, Tepper HB (1989) Response of tree seedlings to aluminum. Tree Physiol. 5: 337-356

Schmohl N and Horst WJ (2000) Cell wall pectin content modulates aluminium sensitivity of Zea mays (L.) cells grown in suspension culture. Plant Cell Envion. 23: 735-742

Silva IR, Novais, RF, Jham, GN, Barros, NF, Gebrim, FO, et al. (2004) Responses of eucalypt species to aluminum: the possible involvement of low molecular weight organic acids in 
the Al tolerance mechanism. Tree Physiol. 24: 1267-1277

Smith E, Naik D, Cumming JR (2011) Genotypic Variation in Aluminum Resistance, Cellular Aluminum Fractions, Callose and Pectin Formation and Organic Acid Accumulation in Roots of Populus Hybrids. Env. Exp. Bot. (In Press)

Steiner KC, Barbour JR, McCormick LH (1984) Response of Populus hybrids to aluminum toxicity. Forest Sci. 30: 404-410

Strauss SH and Maritn FM (2004) Poplar genomics comes of age. New Phytol. 164: 1-4

Tahara K, Norisada, M, Hogetsu, T, Kojima, K (2005) Aluminum tolerance and aluminuminduced deposition of callose and lignin in the root tips of Melaleuca and Eucalyptus species. J. For. Res. 10: 325-333

Tangen G, Wickstorm T, Lierhagen S, Vogt R, Lund W (2002) Fractionation and determination of aluminum and iron in soil water samples using SPE columns and ICP-AES. Environ. Sci. Technol. 36: 5421-5425

Taylor G, McDonald-Stevens J, Hunter D, Bertsch P, Elmore D, Rengel Z, Reid R (2000) Direct measurement of aluminum uptake and distribution in single cells of Chara coralline. Plant Physiol. 123:987-996

Tice KR, Parker DR, DeMason DA (1992) Operationally defined apoplastic and symplastic aluminum fractions in root tips of aluminum-intoxicated wheat. Plant Physiol. 100: 309318

Tolrà RP, Barceló J, Poschenrieder C (2009) Constitutive and aluminum-induced patterns of phenolic compounds in two maize varieties differing in aluminum tolerance. J. Inorg. Biochem. 103: 1486-1490

Tolrà RP, Poschenrieder C, Luppi B, Barceló J (2005) Aluminium-induced changes in the profiles of both organic acids and phenolic substances underlie Al tolerance in Rumex acetosa L. Environ. Exp. Bot. 54: 231-238

Tuskan GA and Walsh ME (2001) Short-rotation woody crop systems, atmospheric carbon dioxide and carbon management: a U.S. case study. Forest Chron. 77:259-264

Vanguelova EI, Hirano Y, Eldhuset TD, Sas-Paszt L, Bakker MR, Püttsepp Ü, Brunner I, Lõhmus K, Godbold, D (2007) Tree fine root Ca/Al molar ratio - Indicator of Al and acidity stress. Plant Biosys. 141: 460-480

Vázquez MD, Poschenrieder C, Corrales I, Barceló J (1999) Change in aluminum during the initial growth response to aluminum by roots of a tolerant maize variety. Plant Physiol 119: 
435-444

von Uexküll HR and Mutert E (1995) Global extent, development and economic impact of acid soils. Plant Soil 171: 1-15

Walker TS, Bais HP, Grotewold E, Vivanco JM (2003) Root exudation and rhizosphere biology. Plant Physiol. 132: 44-51

Wang Y, Stass A, Horst WJ (2004) Apoplastic binding of aluminum is involved in siliconinduced amelioration of aluminum toxicity in maize. Plant Physiol. 136: 3762-3770

Watanabe T and Osaki M (2002) Role of organic acids in aluminum accumulation and plant growth in Melastoma malabathricum. Tree Physiol. 22: 785-792

Wissemeier AH, Hahn G, Marschner H (1998) Callose in roots of Norway spruce (Picea abies (L.) Karst.) is a sensitive parameter for aluminium supply at a forest site (Höglwald). Plant Soil 199: 53-57

Wissemeier AH, Diening A, Hergenroder A, Horst WJ, Mix-Wagner G (1992) Callose formation as a parameter for assessing genotypical plant tolerance of aluminum and manganese. 146: 67-75

Wojciechowski CL and Fall R (1996) A continuous fluorometric assay for pectin methylesterase. Anal. Biochem. 237: 103-108

Yamamoto Y, Hachiya A, Matsumoto H (1997) Oxidative damage to membranes by a combination of aluminum and iron in suspension-cultured tobacco cells. Plant Cell Physiol. 38:1333-1339

Yang JL, Zhu XF, Zheng C, Zhang YJ, Zheng SJ (2011) Genotypic differences in Al resistance and the role of cell-wall pectin in Al exclusion from the root apex in Fagopyrum tataricum. Ann. Bot. 107: 371-378

Yang X, Römheld V, Marschner H (1994) Effect of bicarbonate on root growth and accumulation of organic acids in $\mathrm{Zn}$-inefficient and $\mathrm{Zn}$-efficient rice cultivars (Oryza sativa L.). Plant Soil 164: 1-7

Yang Z-B, Eticha D, Rao IM, Horst WJ (2010) Alteration of cell-wall porosity is involved in osmotic stress-induced enhancement of aluminium resistance in common bean (Phaseolus vulgaris L.). 61: 3245-3248

Yang ZM, Sivaguru M, Horst WJ, Matsumoto H (2000) Aluminium tolerance is achieved by exudation of citric acid from roots of soybean (Glycine max). Physiol. Plant. 110: 72-77

Zhang G, Hoddinott J, Taylor GJ (1994) Characterization of 1, 3-ß-D-glucan (callose) synthesis 
in roots of Triticum aestivum in response to aluminum toxicity. J. Plant Physiol. 144: 229234

Zhang G and Taylor GJ (1989) Kinetics of aluminum uptake by excised roots of aluminumtolerant and aluminum-sensitive cultivars of Triticum aestivum L. Plant Physiol. 91: 10941099

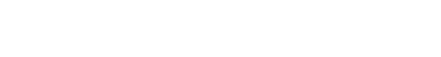

